Universidade de São Paulo

Curso de Pós-Graduação em Física

\title{
POLÍMERO COM MONÔMEROS E LIGAÇÕES INTERAGENTES NA REDE QUADRADA
}

\author{
Tese \\ para obtenção do grau de \\ DOUTOR EM FÍSICA
}

Submetida ao Curso de Pós-Graduação em Física da Universidade de São Paulo

Orientando: Kleber Daum Machado

Orientador: Mário José de Oliveira - USP

Co-orientador: Jürgen Fritz Stilck - UFF

Banca examinadora:

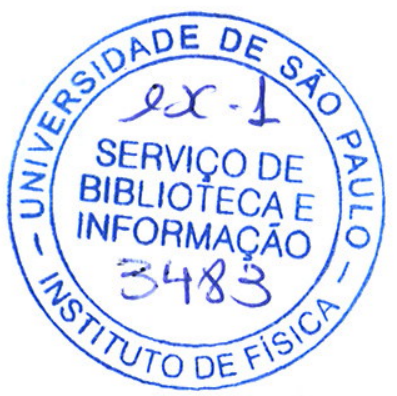

Mário José de Oliveira - USP

Dora Izzo - USP

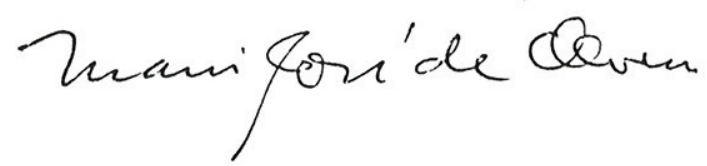

Roberto Nicolau Onody - USP - São Carlos

Vera Bohomoletz Henriques - UFRJ

Wagner Figueiredo - UFSC

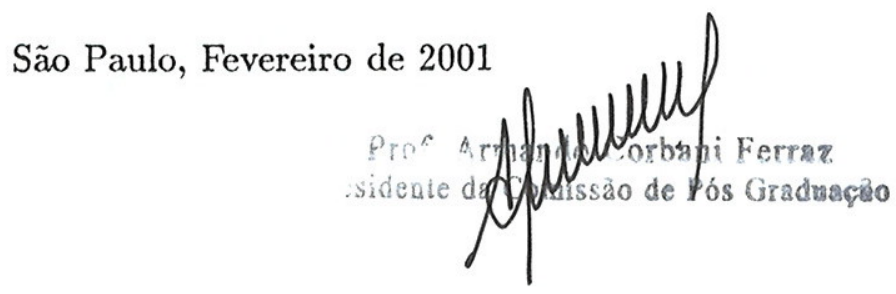

SBI-IFUSP 
FICHA CATALOGRÁFICA

Preparada pelo Serviço de Biblioteca e Informação do Instituto de Física da Universidade de São Paulo

Machado, Kleber Daum

Polímero com monômeros e ligações interagentes na rede quadrada. São Paulo, 2001.

Tese (Doutoramento) - Universidade de São Paulo. Instituto de Física - Departamento de Física Geral

Orientador: Prof. Dr. Mario José de Oliveira

Área de Concentração: Física da Matéria Condensada.

Unitermos: 1. Polímeros interagentes;

2. Rede quadrada; 3. Matriz de Transferência;

4. Renormalização Fenomenológica; 5.Finite-size scaling; 6 . Transições de fases. 


\section{Sumário}

Agradecimentos iv

Resumo $\quad$ v

$\begin{array}{lll}\text { Abstract } & \text { vii }\end{array}$

Lista de Figuras $\quad$ ix

Lista de Tabelas $\quad$ xii

1 INTRODUÇÃ O

1.1 Matriz de Transferência . . . . . . . . . . . . . . . 3

1.2 Finite-Size Scaling . . . . . . . . . . . . . . 14

1.2.1 Fundamentação Teórica . . . . . . . . . . . . . . . . . 14

1.2.2 O Método de Finite-Size Scaling . . . . . . . . . . . . 15

1.3 Renormalização Fenomenológica . . . . . . . . . . . . . 18

1.4 Invariância Conforme $\ldots \ldots \ldots \ldots \ldots \ldots$

2 OS MODELOS $\quad 29$

2.1 Modelo de Ligaços Interagentes . . . . . . . . . . . . . . 32

2.2 Modelo de Monomeros Interagentes . . . . . . . . . . . . . . . 33 
2.3 Resolução dos Modelos . . . . . . . . . . . . . . . . . 35

2.3.1 Construção da Matriz de Transferência . . . . . . . . . . . . . 37

2.3.2 Cálculo das Fronteiras de Fase . . . . . . . . . . . . . . 41

2.3 .3 Cálculo do Expoente Crítico $\nu \ldots \ldots \ldots \ldots$. . . . . . . . 42

2.3 .4 Cálculo do Expoente Crítico $\eta \ldots \ldots \ldots$. . . . . . . . . 42

2.3.5 Cálculo da Densidade de Sítios Ocupados e da Densidade de Interaşoses . . . . . . . . . . . . . . . . . . . . 43

3 RESULTADOS E DISCUSSÕES

3.1 Resultados para o Modelo de Ligações Interagentes . . . . . . . . . . . . . . 49

3.2 Resultados para o Modelo de Monòmeros Interagentes . . . . . . . . . . 72

4 CONCLUSÕES $\quad 98$

4.1 Modelo de Ligações Interagentes . . . . . . . . . . . . . . . . 98

4.2 Modelo de Monômeros Interagentes . . . . . . . . . . . . . . . . . . . 102

4.3 Considerações Gerais a Respeito dos Dois Modelos . . . . . . . . . . . . 106

4.4 Consiclerações Finais sobre as Técnicas Empregadas . . . . . . . . . . . . . 109

A ESTADOS DA MATRIZ DE TRANFERENCIA PARA $L=3 \quad 110$

$\begin{array}{ll}\text { Referências Bibliográficas } & \mathbf{1 1 7}\end{array}$ 


\section{Agradecimentos}

Ao Mário, pela orientação, pelas discussões e pela amizade.

Ao Jïrgen, pela co-orientação, pelo apoio, pelas discussóes e pela amizade.

Ao Centro Nacional de Supercomputaç̃o - CESUP (UFRGS), e ao Núcleo de Atendimento à Computação de Alto Desempenho - NACAD/COPPE (UFRJ), pelo uso dos recursos computacionais.

A FAPESP, pelo indispensável apoio financeiro. 


\section{Resumo}

Utilizando a técnica da matriz de transferencia e as idéias de finite-size scaling, de renormalização fenomenológica e de invariância conforme estudamos dois modelos de polímeros interagentes na rede quadrada. Em ambos, a atividade de un monomero pertencente ao polímero vale $x=e^{\beta \mu}$. Quando as interações são entre as ligações primeiras-vizinhas que pertencem ao polímero definimos um fator de Boltzmann y associado à interação como sendo $y=e^{-\beta \epsilon_{\ell}}$, onde $\epsilon_{\ell}$ é a energia de interação entre ligações. Se as interaçóes são entre os monómeros que pertencem a sítios primeiros-vizinhos mas não-consecutivos ofator de Boltzmann associado à interação é $z=e^{-\beta \epsilon_{m}}$, sendo $\epsilon_{m}$ a energia de interação entre os monômeros. Através do estudo de pares de tiras de larguras $L-L^{\prime}$ obtivemos estimativas para os diagramas de fases dos dois modelos. Ambos apresentam três fases: uma fase não-polimerizada, uma fase polimerizada usual e uma fase polimerizada densa, na qual o polímero se encontra colapsado. Nessa fase, o polímero assume uma configuração que maximiza o número de interaçoes, de modo que a densidade de sítios ocupados pelo polímero tende a 1 e a densidade de interaçóes assume valores muito próximos de 1 .

Os diagramas de fases dos dois modelos são qualitativamente semelhantes, havendo diferenças quantitativas, já esperadas. A transição entre a fase não-polimerizada e a fase polimerizada densa é de primeira ordem. A transição entre a fase não-polimerizada e a fase polimerizada usual é de segunda ordem, e um ponto dessa fronteira, que corresponde 
ao modelo sem interaçóes ( $y=1$ ou $z=1$, dependendo do modelo), é bem conhecido $[1-3]$ e vale $x_{c}=0,37905227 \pm 0,00000012$. A transição entre as fases polimerizadas é de primeira ordem para valores pequemos de $x$, mas muda para uma transição de segunda ordem quando $x$ aumenta. Nessa fronteira existe um ponto tricrítico, que foi estimado em $\left(x \mathrm{prC}=1,5 \pm 0,1, y_{\mathrm{P}} \mathrm{TC}=1,1 \pm 0,1\right)$, para o modelo de ligaçóes interagentes. No caso do modelo de monômeros interagentes, não foi possivel obter uma estimativa conclusiva a respeito da localização do ponto tricrítico. No encontro das três fronteiras existe um ponto crítico terminal, no qual terminam a linha de transições de segunda ordem entre a fase não-polimerizada e a fase polimerizada usual, a linha de transiçoes descontínuas entre as duas fases polimerizadas e a linha de transiçôes de primeira ordem entre as fases não-polimerizada e polimerizada densa. Os valores estimados por nós são $\left(x \mathrm{PCT}=0,244 \pm 0,002, y_{\mathrm{PCT}}=3,86 \pm 0,03\right)$ para o modelo de ligaçóes interagentes e $(x \mathrm{PCT}=0,345 \pm 0,001, z \mathrm{pCT}=1,52 \pm 0,01)$ para monômeros interagentes. $O$ ponto $\theta$, no qual texmina a fronteira de segunda ordem entre a fase não-polimerizada e a fase polimerizada usual e onde ocorre pela primeira vez a transição de colapso é um ponto crítico terminal em ambos os modelos.

Os expoentes críticos $\nu$ e $\eta$ associados à fronteira entre a fase não-polimerizada e polimerizada usual também foram calculados, e encontramos os valores $\nu=0,7507 \pm 0,0008 \mathrm{e}$ $\eta=0,2082 \pm 0,0004$, para $y=1, \mathrm{e} \nu=0,7498 \pm 0,0004 \mathrm{e} \eta=0,205 \pm 0,003$, para $y=1,2$ para o modelo de ligações interagentes. Para o modelo de monômeros interagentes, os dados foram $\nu=0,7507 \pm 0,0007$ e $\eta=0,2089 \pm 0,0009$, para $z=1$, e $\nu=0,7500 \pm 0,0004$ e $\eta=0,205 \pm 0,008$, para $z=1,2$. Observando os valores dos expoentes, vemos que eles ficam constantes dentro das barras de erros, de modo que a transição é uma transição de segunda ordem usual. Os valores concordam muito ben com os valores esperados, que são (exatamente) $\nu=\frac{3}{4}$ e $\eta=\frac{5}{24}[4]$. 


\section{Abstract}

Using the transfer matrix technique, finite-size scaling, phenomenological renormalization group, and conformal invariance ideas, we studied the thermodynamic behavior of two interacting models of polymers on the square lattice. In both models one monomer that belongs to the polymer has an activity $x=e^{\beta \mu}$. When the interactions are between first-

neighbor bonds that belong to the polymer, we define a Boltzmann factor $y=e^{-\beta \epsilon_{\ell}}$, where $\epsilon_{\ell}$ is the interaction energy between two bonds. If the interactions are between monomers located at first-neighbor but non-consecutive sites, the associated Boltzmann factor is $z=e^{-\beta \epsilon_{m}}$, where $\epsilon_{m}$ is the interaction energy between two monomers. We consider pairs of strips of widths $L-L^{\prime}$ and found estimates for the phase diagrams of both models. They have three phases: a non-polymerized phase, an usual polymerized phase and a dense phase, in which the polymer is colapsed. In this phase, the configuration of the polymer is that maximizes the number of interactions, and the density of sites occupied by the polymer goes to 1 , while the density of interactions is very close to 1 .

The phase diagrams of two models are qualitatively similar, but there are quantitative differences between them, as we already expected. The transition between non-polymerized phase and dense phase is of first order. The transition between non-polymerized phase and usual polymerized phase is of second order, and one point of this frontiex, which corresponds to the non-interacting model ( $y=1$ ou $z=1$, depending on the specific model), is well 
known $[1-3]$ and has the value $x_{c}=0,37905227 \pm 0,00000012$. The transition between the two polymerized phases is of first order for small values of $x$, and it changes to a second order transition when $x$ increases. At this frontier there is a tricritical point, and we found ( $x_{\mathrm{TCP}}=$ $1,5 \pm 0,1, y \mathrm{TCP}=1,1 \pm 0,1)$ for the interacting bond model. It was not possible to obtain a conclusive estimation of the location of the tricritical point for the model of interacting monomers. At the point that all transition lines meet there is a critical endpoint, in which the second order transition line between non-polymerized phase and usual polymerized phase, the first order transition line between polymerized phases and the first order transition line between non-polymerized and dense polymerized phases finish. We found ( $x_{\text {CEP }}=0,244 \pm$ $\left.0,002, y_{\mathrm{CEP}}=3,86 \pm 0,03\right)$ for the interacting bond model and $\left(x_{\mathrm{CEP}}=0,345 \pm 0,001, z_{\mathrm{CEP}}=\right.$ $1,52 \pm 0,01)$ for the interacting monomer model. The $\theta$ point is where ends the second order transition between non-polymerized phase and usual polymerized phase and at this point the collapse transition happens at the first time. Then, in our models, the $\theta$ point is a critical endpoint.

We also found the critical exponents $\nu$ and $\eta$ of the second order transition line between non-polymerized phase and usual polymerized phase. The values we obtained are $\nu=0,7507 \pm$ 0,0008 and $\eta=0,2082 \pm 0,0004$, for $y=1$, and $\nu=0,7498 \pm 0,0004$ and $\eta=0,205 \pm 0,003$, for $y=1,2$, to the model of interacting bonds. The interacting monomers model has $\nu=$ $0,7507 \pm 0,0007$ and $\eta=0,2089 \pm 0,0009$, for $z=1$, and $\nu=0,7500 \pm 0,0004$ and $\eta=$ $0,205 \pm 0,008$, for $z=1,2$. Looking at these results we can see that the exponents remain constant within error bars, thus the transition is a usual second order transition. Furthermore, these values are in a very good agreement with the expected values, which are $\nu=\frac{3}{4}$ and $\eta=\frac{5}{24}($ exactly) $[4]$. 


\section{Lista de Figuras}

$1 . t$ Um anel de spins de $I$ sing $\ldots \ldots \ldots \ldots \ldots \ldots \ldots$

1.2 Calor específico para o modelo de Ising bidimensional para $L=8,32$ e $\infty \ldots 15$

1.3 Mapeamento conforme de um plano infinito numa tira de largura $L \ldots \ldots$. . 23

2.1 Uma configuração possível para um polímero numa interface bidimensional . 30

2.2 Configuração de um polímero numa rede quadrada . . . . . . . . . . . 31

2.3 Configuração de molímero com ligaçôes interagentes $\ldots \ldots \ldots$. . . . . 33

2.4 Configuração de um polímero com monôneros interagentes . . . . . . . 34

2.5 Configuração de um polímero numa tira de largura $L=4 \ldots \ldots \ldots$

2.6 Dois exemplos de configuraçôes para $L=4 \ldots \ldots \ldots \ldots \ldots$

2.7 Configuração de um elemento da matriz de transferencia . . . . . . . . . . . 39

2.8 Elemento da matriz de transferência para o caso de ligações interagentes . . . 39

2.9 Elemento da matriz de transferencia para o caso de monômeros interagentes . $\quad 40$

3.1 Diagramas de fases para o modelo de ligações interagentes . . . . . . . . 50

3.2 Densidade $\rho_{x}$ de sítios ocupados para $x=0,2 \ldots \ldots \ldots \ldots$

3.3 Densidarle $\rho_{y j}$ de interaçóes entre as ligações para $x=0,2 \ldots \ldots \ldots$

3.4 Derivada da densidade $\rho_{x}$ de sítios ocuparlos para $x=0,2 \ldots \ldots \ldots$

3.5 Derivada da densidade $\rho_{y}$ de interações entre as ligaçóes para $x=0,2 \ldots \ldots 7$

3.6 Densidade $\rho_{x}$ de sítios ocupados para $x=0,4 \ldots \ldots \ldots \ldots$ 
3.7 Densidade $\rho_{y}$ de interargoes entre ligações para $x=0,4 \ldots \ldots \ldots \ldots$

3.8 Derivada da densidade $\rho_{2}$ de sítios ocupados para $x=0,4 \ldots \ldots \ldots$

3.9 Derivarla da densidade $\rho_{y}$ de interações entre ligaçóes para $x=0,4 \ldots \ldots 1$

3.10 Densidade $\rho_{x}$ de sítios ocupados para $x=2,4 \ldots \ldots \ldots 2$

3.11 Densidade $\rho_{y}$ de interações entre ligações para $x=2,4 \ldots \ldots \ldots$

3.12 Derivarla da densidade $\rho_{x}$ de sítios ocupados para $x=2,4 \ldots \ldots \ldots$

3.13 Derivada da densidade $\rho_{y}$ de interaçôes entre ligaçóes para $x=2,4 \ldots \ldots 5$

3.14 Derivada da densidade $\rho_{x}$ de sítios ocupados para alguns valores de $x$, para estimar o ponto tricrítico . . . . . . . . . . . . . 67

3.15 Derivada da densidade $\rho_{y}$ de interaçòes entre ligaçóes para alguns valores de $x$, para estimar o ponto tricrítico $\ldots \ldots \ldots 68 \ldots \ldots \ldots$

3.16 Esboço do diagrama de fases para o modelo de interações entre ligações para a rede quadrada ...................... 70

3.17 Diagramas de fases para o modelo de monômeros interagentes . . . . . . . 73

3.18 Densidade $\rho_{x}$ de sítios ocupados para $x=0,2 \ldots \ldots \ldots \ldots$

3.19 Densidade $\rho_{z}$ de interações entre os monômeros para $x=0,2 \ldots \ldots \ldots$

3.20 Derivarda da densidade $\rho_{x}$ de sítios ocupados para $x=0,2 \ldots \ldots \ldots$

3.21 Derivada da densidade $\rho_{z}$ de interações entre os monômeros para $x=0,2 \quad \ldots \quad 77$

3.22 Densidade $\rho_{x}$ de sítios ocupados para $x=0,4 \ldots \ldots \ldots \ldots$

3.23 Densidade $\rho_{z}$ de interações entre os monômeros para $x=0,4 \ldots \ldots \ldots$

3.24 Derivada da densidade $\rho_{2}$ de sítios ocupados para $x=0,4 \ldots \ldots 80$

3.25 Derivada da densidade $\rho_{z}$ de interaçóes entre os monomeros para $x=0,4 \quad \ldots \quad 81$

3.26 Densiclade $\rho_{:}$de sítios ocupados para $x=1,4 \ldots \ldots \ldots 2$

3.27 Densidade $\rho_{z}$ de interacões entre os monômeros para $x=1,4 \ldots \ldots 3$

3.28 Derivada da densidade $\rho_{x}$ de sítios ocupados para $x=1,4 \ldots \ldots \ldots 4$

3.29 Derivada da densidade $\rho_{z}$ de interações entre os monomeros para $x=1,4 \quad \ldots \quad 85$ 
3.30 Derivada da densidade $\rho_{2}$ de sítios ocupados para $x=0,7 \ldots \ldots 8$

3.31 Derivada da densidade $\rho_{z}$ de interaçóes entre os monomeros para $x=0,7 \ldots 89$

3.32 Derivada da densidade $\rho_{x}$ de sítios ocupados para $x=0,9 \ldots \ldots \ldots$

3.33 Derivada da densidade $\rho_{z}$ de interaçóes entre os monômeros para $x=0,9 \quad$. 91

3.34 Derivada da densidade $\rho_{x}$ de sítios ocupados para $x=1,2 \ldots \ldots 2$

3.35 Derivada da densidade $\rho_{z}$ de interações entre os monômeros para $x=1,2 \ldots 93$

3.36 Esboço do diagrama de fases para o modelo de interações entre monômeros para a rede quadrada . . . . . . . . . . . . . 97

A.1 Estarlos-base da matriz de tranferencia para $L=3 \ldots \ldots \ldots \ldots 112$

A.2 Alguns elementos da matriz de transferência para $L=3$ para o thodelo de ligaçóes interagentes $\ldots \ldots \ldots \ldots \ldots \ldots \ldots$

A.3 Alguns elementos da matriz de transferencia para $L=3$ para o modelo de monomeros interagentes $\ldots \ldots \ldots \ldots \ldots \ldots$ 


\section{Lista de Tabelas}

3.1 Valores de $x_{c}$ para $y=1$, para o modelo de ligaçoos interagentes, juntamente com o valor extrapolado . . . . . . . . . . . . . . 69

3.2 Valores de $\nu$ para $y=1$, para o modelo de ligaçóes interagentes, juntamente com o valor extrapolado . . . . . . . . . . . 71

3.3 Valores de $\eta$ para $y=1$, para o modelo de ligaçôes interagentes, juntamente com o valor extrapolado . . . . . . . . . . . . 71

3.4 Valores extrapolados de $x_{c}, \nu$ e $\eta$ para $y=1,0$ e $y=1,2$, para $o$ modelo de ligaçòes interagentes . . . . . . . . . . . . . . 72

3.5 Resultados para $x_{c}, \nu$ e $\eta$ para o modelo de monômeros interagentes . . . . 96

A.t Número de estados da matriz de transferencia . . . . . . . . . . . . 111 


\section{Capítulo 1}

\section{INTRODUÇÃO}

Polímeros são estruturas químicas formadas pela repetição, em alguns casos milhares de vezes, de uma unidade básica relativamente simples, chamada monômero. Esse fato pode ser exemplificado pela reação química de formação do polietileno, dada por

$$
n\left(-C H_{2}-\right) \rightleftharpoons \cdots-C H_{2}-C H_{2}-C H_{2}-\cdots=\left(-C H_{2}-\right)_{n}
$$

na qual o monômero que se repete é a estrutura química

$$
\left(-\mathrm{CH}_{2}-\right)
$$

Os polímeros, em geral, formam estruturas em forma de cadeias longas, semelhantes a um pedaço de fio ou cordão. Estes materiais têm grande aplicação prática nos dias de hoje, pois apresentam propriedades físicas importantes. Muitos têm grande resistência mecânica, outros são usados como condutores elétricos e também na fabricação de fibras ópticas. Por causa disso, o estudo das propriedades termodinâmicas desses materiais é bastante relevante. Além disso, alguns modelos de polímeros podem ser mapeados em modelos magnéticos de spins [5-7], o que faz com que estudar e resolver um modelo polimérico pode ser um meio de 
resolver ou verificar soluções de modelos magnéticos.

Uma forma de estudar modelos de polímeros é considerar que eles constituem caminhadas auto-excludentes, ou selfavoiding walks (SAW) em redes regulares. Em particular, em duas dimensões, as propriedades críticas desses modelos foram estudadas através do uso de várias técnicas, como expansões em séries [1,2] e estudos envolvendo grupo de renormalização fenomenológico e finite-size scaling exn polímeros lineares não-interagentes [3], polímeros ramificados [8], polímeros com cruzamentos [9] e polímeros interagentes [10, 11]. Este último, por sinal, tem despertado muito interesse por causa da competição que existe entre a interação de volume exclúdo, que impede que o polímero passe duas vezes pelo mesmo ponto, e as interações atrativas entre os seus constituintes. Essa competição pode levar a unna situação em que o polímero apresenta-se colapsado, a qual é normalmente associada com o ponto $\theta$, que pode ser definido como o ponto no qual termina a linha de transiçoes entre a fase não-polimerizada e a fase polimerizada usual.

No modelo de polímeros interagentes, as interações podem ser, por exemplo, entre os monômeros que estejam localizados em sítios primeiros-vizinhos mas não-consecutivos ao longo da cadeia, ou entre as ligações primeiras-vizinhas paralelas entre si, que façam parte do polímero. Entretanto, esses detalhes dos modelos não devem influir nos seus comportamentos qualitativos, e os diagramas de fases devem ser qualitativamente similares. Cálculos baseados em extrapolações envolvendo finite-size scaling e matrizes de transferência [10, 11] conclúram que o ponto $\theta$ da transiģão de colapso deve ser um ponto tricrítico, concordando com resultados anteriores [12, 13]. Por: outro lado, o estudo de um modelo magnético de interaçôes envolvendo quatro spins numa rede do tipo tabuleiro de damas através de cálculos exatos baseados no ansatz de Bethe [7] mostrou que o ponto $\theta$ deste modelo, o qual, no limite $n \rightarrow 0$, corresponde a uma caminhada auto-excludente com interaçoes atrativas entre quadrados alternados, não é um ponto tricrítico. Outros cálculos recentes, realizados numa 
rede de Husimi [14], tiveram como resultado o fato de que, quando a coordenação da rede é igual a 4, duas fases polimerizadas aparecem no diagrama de fases e, se o modelo supõe que as interações são entre as ligaçoes, o ponto $\theta$ é um ponto crítico terminal, ao passo que, se as interações são entre os monômeros localizados em sítios primeiros-vizinhos, ele é um ponto tricrítico. Na rede de Husimi, quando o número de coordenação é 4 temos uma aproximação para uma rede quadrada. Desse modo, esses resultados sugerem que o modelo de polímeros interagentes na rede quadrada deve apresentar um diagrama de fases bastante interessante e, por causa disso, decidimos estudar dois modelos interagentes nessa rede, um considerando as ligações primeiras-vizinhas como sendo interagentes e outro considerando que os sítios primeiros-vizinhos mas não-consecutivos são interagentes. Estes modelos estão definidos no capítulo 2. No capítulo 3 aparecem os resultados obtidos para os dois modelos, enquanto o capítulo 4 apresenta as conclusões finais. $O$ apêndice $A$ traz o número de estados da matriz de transferencia para cada largura $L$ e os estados para $L=3$, além de alguns exemplos de elementos da matriz para essa largura.

Para o estudo dos dois modelos interagentes propostos empregamos alguns métodos e técnicas importantes. Cada um deles é descrito em detalhes a seguir.

\subsection{Matriz de Transferência}

A técnica da matriz de transferência é antiga e conhecida. Vamos introduzi-la aqui utilizando um exemplo simples que facilita o entendimento das idéias por trás dela $[15,16]$. Consideremos um anel com $N$ spins de Ising, de forma que os spins $s_{i}$ só podem assumir os valores $s_{i}= \pm 1$. Além disso, como o sistema é um anel, temos a condição de contorno periódica $s_{i+N} \equiv s_{i}$. Este sistema unidimensional é apresentado na figura 1.1. Sua hamiltoniana é dada 
por

$$
\mathcal{H}_{N}=-J \sum_{i=0}^{N-1} s_{i} s_{i+1}-H \sum_{i=0}^{N-1} s_{i},
$$

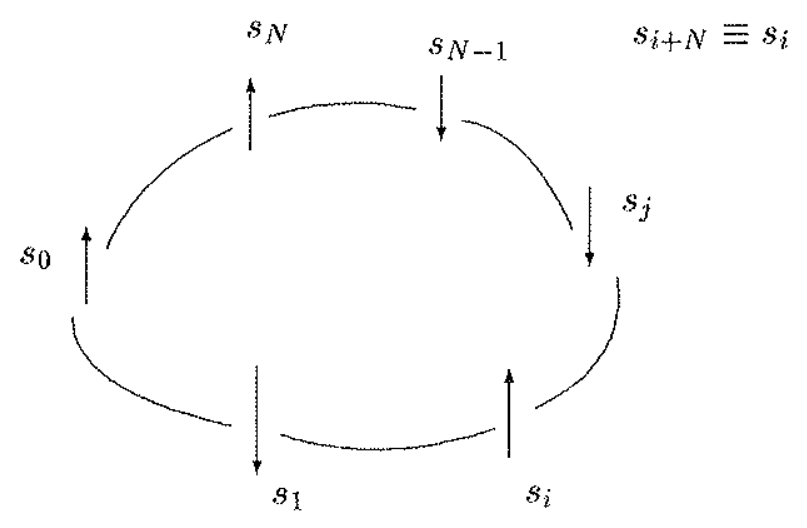

Figura 1.1: Um anel de spins de Ising.

onde $J$ representa a interação entre dois spins e $H$ é o campo magnético externo aplicado. Dessa hamiltoniana obtemos a função de partição como sendo

$$
\mathcal{Z}_{N}=\sum_{\{s\}} e^{-\beta \mathcal{H}_{N}}
$$

Nessa equação, $\beta=1 / k_{B} T$, sendo $k_{B}$ a constante de Boltzmann $\left(k_{B}=1,38 \times 10^{-23} \mathrm{~J} / \mathrm{K}\right), T$ é a temperatura absoluta e $\{s\}$ indica que a soma se dá sobre todas as configurações possíveis para os spins. Podemos reescrever a equação acima expandindo os termos da exponencial, como segue

$$
\mathcal{Z}_{N}=\sum_{\{s\}} e^{\beta J\left(s_{0} s_{1}+s_{1} s_{2}+\cdots+s_{N-1} s_{0}\right)+\beta H\left(s_{0}+s_{1}+\cdots+s_{N-1}\right)}
$$

onde foi usada a condição de contorno periódica $s_{N} \equiv s_{0}$. Essa expressão pode ser escrita de 
uma forma mais simétrica, ou seja,

$$
\mathcal{Z}_{N}=\sum_{\{s\}} e^{\beta J s_{0} s_{1}+\frac{\beta H}{2}\left(s_{0}+s_{1}\right)} e^{\beta J s_{1} s_{2}+\frac{\beta H}{2}\left(s_{1}+s_{2}\right)} \cdots e^{\beta J s_{N-1} s_{0}+\frac{\beta H}{2}\left(s_{N-1}+s_{0}\right)} .
$$

Podemos agora definir a variável

$$
T_{i, i+1}=e^{\beta J s_{i} s_{i+1}+\frac{\beta H}{2}\left(s_{i}+s_{i+1}\right)}
$$

de forma que a equação 1.1 fica sendo, explicitando as somatórias,

$$
Z_{N}=\sum_{\left\{s_{0}\right\}} \sum_{\left\{s_{1}\right\}} \cdots \sum_{\left\{s_{N-1}\right\}} T_{0,1} T_{1,2} \cdots T_{N \cdots 1,0}
$$

na qual $\left\{s_{j}\right\}$ representa as configuraçoes de spin com $s_{j}= \pm 1$. Comparando esta expressão com a do produto de duas matrizes

$$
c_{i j}=\sum_{k} a_{i k} b_{k j},
$$

notamos que os $T_{i, i+1}$ podem ser entendidos como sendo elementos de uma matriz $T$, cujas linhas são referidas pelos $s_{i}$ e colunas são rotuladas pelos $s_{i+1}$. Escrevendo a matriz $T$ explicitamente para esse caso, temos

$$
T=\left(\begin{array}{cc}
e^{\beta(J+H)} & e^{-\beta J} \\
e^{-\beta J} & e^{\beta(J-H)}
\end{array}\right)
$$

Essa matriz $T$ é a matriz de transferencia para este probletna. Ela age acrescentando um spin ao anel, "transferindo" nossa posição no anel de um passo. Um anel com $N$ spins de Ising com as características definidas anteriormente é obtido aplicando-se a matriz de transferência acima $N$ vezes. Voltando à equação 1.2 e realizando as somas sobre as configurações de todos 
os spins, exceto o spin $s_{0}$, obtemos

$$
\mathcal{Z}_{N}=\sum_{s_{0}= \pm t} T_{0,0}^{N}
$$

Nessa expressão, $\mathcal{Z}_{N}$ é a função de partição de um anel $\operatorname{com} N$ spins (ou sítios, se pensarmos numa rede unidimensional) e $T_{0,0}^{N}$ é o elemento da diagonal principal da matriz de transferência após ser multiplicada $N$ vezes. A equação acima pode ser simplificada se escrevermos a matriz $T$ na base em que ela é diagonal. Além disso, a somatória no lado direito é o traço (soma dos elementos da diagonal principal) da matriz, de forma que a função de partição pode ser expressa de um modo simples, como sendo

$$
\mathcal{Z}_{N}=\sum_{i} \lambda_{i}^{N}
$$

onde os $\lambda_{i}$ são os autovalores da matriz de transferência. A função de partição deste sistema de spins pode ser obtida de uma forma relativamente fácil, dependendo apenas dos dois autovalores de uma matriz $2 \times 2$. Entretanto, à medida que as interações consideradas aumentam, como por exemplo, interações entre spins segundos-vizinhos, o tamanho da matriz de transferência também aumenta, de forma que pode não ser mais possível o cálculo analítico dos autovalores. Devemos então calculá-los numericamente. Para esse modelo de anel de spins em particular, os autovalores são

$$
\lambda_{0,1}=e^{\beta J} \cosh \beta H \pm \sqrt{e^{-2 \beta J}+e^{2 \beta J} \operatorname{senh}^{2} \beta H}
$$


e a função de partição fica sendo

$$
\begin{aligned}
\mathcal{Z}_{N}=\left\{e^{\beta J} \cosh \beta H+\sqrt{e^{-2 \beta J}+e^{2 \beta J} \operatorname{senh}^{2} \beta H}\right\}^{N}+ & \\
& \left\{e^{\beta J} \cosh \beta H-\sqrt{e^{-2 \beta J}+e^{2 \beta J} \operatorname{senh}^{2} \beta H}\right\}^{N} .
\end{aligned}
$$

Devemos ressaltar que a técnica da matriz de transferência pode ser utilizada mesmo em sistemas que inicialmente não têm uma hamiltoniana definida, como é o caso dos modelos de polímeros que vamos estudar, e que são definidos no capítulo 2. É preciso apenas que o sistema possa ser "construído" por partes, de maneira iterativa, partindo de uma configuração e obtendo a próxima através da aplicação da matriz de transferência.

Partindo da expressão 1.3, podemos escrevê-la na forma

$$
\not{B}_{N}=\lambda_{1}^{N}\left[1+\sum_{i \neq 1}\left(\frac{\lambda_{i}}{\lambda_{1}}\right)^{N}\right],
$$

em que $\lambda_{1}$ é o maior autovalor da matriz de transferência e a fração é sempre menor do que 1 (no caso de haver uma degenerescência $d$ em $\lambda_{1}$, devemos substituir o 1 que aparece sendo adicionado à somatória por $d$ ). Aplicando o logaritmo na equação acima, temos

$$
\begin{aligned}
& \ln \mathcal{Z}_{N}=\ln \left\{\lambda_{1}^{N}\left[1+\sum_{i \neq 1}\left(\frac{\lambda_{i}}{\lambda_{1}}\right)^{N}\right]\right\} \\
& \ln \mathcal{Z}_{N}=N \ln \lambda_{1}+\ln \left[1+\sum_{i \neq 1}\left(\frac{\lambda_{i}}{\lambda_{1}}\right)^{N}\right] .
\end{aligned}
$$

A expressão acima é muito útil já que, tomando o limite termodinâmico, ficamos com a função 
de partição (na verdade o seu logarítmo) para o sistema infinito, ou seja

$$
\begin{aligned}
\ln \mathcal{Z} & =\lim _{N \rightarrow \infty} \frac{1}{N} \ln \mathcal{Z}_{N} \\
& =\lim _{N \rightarrow \infty} \frac{1}{N}\left\{N \ln \lambda_{1}+\ln \left[1+\sum_{i \neq 1}\left(\frac{\lambda_{i}}{\lambda_{1}}\right)^{N}\right]\right\} \\
& =\ln \lambda_{1}+\lim _{N \rightarrow \infty} \frac{1}{N} \ln \left[1+\sum_{i \neq 1}\left(\frac{\lambda_{i}}{\lambda_{l}}\right)^{N}\right] \\
\ln \mathcal{Z} & =\ln \lambda_{1} .
\end{aligned}
$$

Agora, a energia livre de Helmholtz por spin pode ser obtida através de

$$
f=-k_{B} T \ln \mathcal{Z}
$$

resultando em

$$
f=-k_{B} T \ln \lambda_{1}
$$

Dessa forma, a energia livre de Helmholtz é obtida de uma forma bem simples, dependendo apenas do maior atutovalor da matriz de transferencia. É importante notar que todas as outras propriedades termodinâmicas do sistema podem ser extraídas através de combinações dessa função e de suas derivadas. Para o caso específico do anel, temos

$$
\ln \mathcal{Z}=\ln \left\{e^{\beta J} \cosh \beta H+\sqrt{e^{-2 \beta J}+e^{2 \beta J} \operatorname{senh}^{2} \beta H}\right\}
$$

e

$$
f=-k_{B} T \ln \left\{e^{\beta J} \cosh \beta H+\sqrt{e^{-2 \beta J}+e^{2 \beta J} \operatorname{senh}^{2} \beta H}\right\}
$$

Uma outra grandeza de interesse relevante é chamada função de correlação. Consideremos, como exemplo, uma rede quadrada $L \times L$. Nos sítios desta rede quadrada existem 
spins, os quais só podem assumir valores $s_{i}= \pm 1$. Podemos perguntar o que acontece com a magnetização de um spin situado num sitio $j$ da rede quando ocorre uma flutuação na magnetização de um spin localizado num sítio $i$ desta rede, ou seja, qual é a correlação que existe entre estes spins? Para responder a esta questão, definimos a função de correlação de pares de spins $\Gamma(i, j)[15]$. Essa grandeza dá uma idéia das interações que ocorren entre os spins, e matematicamente pode ser expressa por

$$
\Gamma(i, j)=\left\langle s_{i} s_{j}\right\rangle-\left\langle s_{i}\right\rangle\left\langle s_{j}\right\rangle
$$

onde já fizemos uso do fato da rede ser translacionalmente invariante, sendo que $\langle x\rangle$ denota uma média térmica definida por

$$
\begin{aligned}
\langle x\rangle & =\frac{\sum_{\{s\}} x e^{-\beta \mathcal{H}}}{\sum_{\{s\}} e^{-\beta \mathcal{H}}} \\
\langle x\rangle & =\frac{\sum_{\{s\}} x e^{-\beta \mathcal{H}}}{\mathcal{Z}} .
\end{aligned}
$$

Na prática, observa-se que a função de correlação decresce com o aumento da distância entre os sítios, o que também é esperado teoricamente. Perto do ponto crítico, a função de correlação segue um comportamento do tipo

$$
\Gamma(i, j) \sim \frac{e^{-R / \xi}}{R^{\zeta}}, \quad R \text { grande }
$$

onde $R$ é a distância entre os sítios $i$ e $j, \zeta$ está relacionado a um expoente crítico (veja a seção 1.4) e $\xi$ é um parâmetro, com dimensões de comprimento, chamado comprimento de correlação. Esta grandeza está associada ao alcance das correlações que ocorrem no sistema. Quanto mais perto o sistema estiver da região crítica, maior será o comprimento de correlação. Exatamente na região crítica, o comprimento de correlação diverge, se o sistema for infinito, 
ou torna-se comparável ao tamanho do sistema, se este for finito. Esta grandeza é fundamental para o nosso estudo, pois podemos relacioná-la aos autovalores da matriz de transferencia definida anterioriormente. Para mostrar isso, primeiro reescrevemos a equação 1.7 isolando o comprimento de correlação, ou seja,

$$
\xi^{-1}=\lim _{R \rightarrow \infty}\left\{-\frac{1}{R} \ln \left[\left\langle s_{i} s_{j}\right\rangle-\left\langle s_{i}\right\rangle\left\langle s_{j}\right\rangle\right]\right\}
$$

na qual utilizamos a expressão 1.6. Vamos transladar a origem para o sítio $i$ e calcular, para o nosso anel de $N$ sítios, a grandeza

$$
\begin{aligned}
\left\langle s_{0} s_{R}\right\rangle_{N} & =\frac{\sum_{\{s\}} s_{0} s_{R} e^{-\beta \mathcal{H}_{N}}}{\sum_{\{s\}} e^{-\beta \mathcal{H}_{N}}} \\
\left\langle s_{0} s_{R}\right\rangle_{N} & =\frac{1}{\mathcal{Z}_{N}} \sum_{\{s\}} s_{0} s_{R} e^{-\beta \mathcal{H}_{N}} .
\end{aligned}
$$

Devemos ressaltar que todas as expressões que foram e as que serão obtidas são válidas para qualquer modelo. Apenas é mais simples exemplificar para o caso do anel. Nós conhecemos $\mathcal{Z}_{N}\left(\mathcal{Z}_{N}=\sum_{i} \lambda_{i}^{N}\right)$, e o numerador pode ser escrito como

$$
\begin{aligned}
& \sum_{\{s\}} s_{0} s_{R} e^{-\beta \mathcal{H}_{N}}=\sum_{\{s\}} s_{0} T_{0,1} T_{1,2} \cdots T_{R-1, R} s_{R} T_{R, R+1} \cdots T_{N-1,0} \\
& \sum_{\{s\}} s_{0} s_{R} e^{-\beta \mathcal{H}_{N}}=\sum_{s_{0} s_{R}} s_{0} T_{0, R}^{R} s_{R} T_{R, 0}^{N-R-1}
\end{aligned}
$$

Nessa equação, $T$ refere-se à matriz de transferência da seção 1.1. Esta matriz tem autovetores $\left|u_{i}\right\rangle$ associados aos autovalores $\lambda_{i}, i=1,2, \ldots, n$. Podemos definir uma matriz diagonal $S_{j}$ com os valores dos spins no sítio $j$ na diagonal. Seus autovalores $s_{j}$ são os valores possíveis destes spins, e os autovetores podem ser escritos como sendo $\left\langle S_{j}\right|=(00 \ldots 10 \ldots 0)$ (a dimensão exata depende dos possiveis valores do spin. No caso do anel, só há duas possibilidades, \pm 1 , e o autovetor tem duas componentes, ou seja, $\left\langle S_{j}\right|=(10)$ ou $\left.\left\langle S_{j}\right|=(01)\right)$. Dessa forma, 
escrevemos

$$
\begin{gathered}
S_{j}=\sum_{S_{j}}\left|S_{j}\right\rangle s_{j}\left\langle S_{j}\right| \\
T=\sum_{i}\left|u_{i}\right\rangle \lambda_{i}\left\langle u_{i}\right|
\end{gathered}
$$

e também

$$
T_{0, R}^{R}=\sum_{i}\left\langle S_{0} \mid u_{i}\right\rangle \lambda_{i}^{R}\left\langle u_{i} \mid S_{R}\right\rangle
$$

Utilizando estas relações na equação 1.10 , temosi

$$
\sum_{\{s\}} s_{0} s_{R} e^{-\beta \mathcal{H}_{N}}=\sum_{s_{0} s_{R}} \sum_{i, j} s_{0}\left\langle S_{0} \mid u_{i}\right\rangle \lambda_{i}^{R}\left\langle u_{i} \mid S_{R}\right\rangle s_{R}\left\langle S_{R} \mid u_{j}\right\rangle \lambda_{j}^{N-R-1}\left\langle u_{j} \mid S_{0}\right\rangle
$$

Rearranjando os termos e aplicando a equação 1.11 , obtemos

$$
\sum_{\{s\}} s_{0} s_{R} e^{-\beta \mathcal{H}_{N}}=\sum_{i, j}\left\langle u_{j}\left|S_{0}\right| u_{i}\right\rangle \lambda_{i}^{R}\left\langle u_{i}\left|S_{R}\right| u_{j}\right\rangle \lambda_{j}^{N-R-1}
$$

Utilizamos essa equação juntamente com a expressão 1.3 na equação 1.9 e dividimos tudo por $\lambda_{1}$, que é o maior autovalor, de modo que ficamos com

$$
\left\langle s_{0} s R\right\rangle_{N}=\frac{\sum_{i, j}\left\langle u_{j}\left|S_{0}\right| u_{i}\right\rangle\left(\frac{\lambda_{i}}{\lambda_{1}}\right)^{R}\left\langle u_{i}\left|S_{R}\right| u_{j}\right\rangle\left(\frac{\lambda_{j}}{\lambda_{1}}\right)^{N-R-1}}{\sum_{k}\left(\frac{\lambda_{k}}{\lambda_{1}}\right)^{N}} .
$$


No limite termodinâmico, sobram apenas os termos em que $j=1$ e $k=1$, ou seja,

$$
\begin{aligned}
\left\langle s_{0} s_{R}\right\rangle & =\lim _{N \rightarrow \infty}\left\langle s_{0} s_{R}\right\rangle_{N} \\
& =\sum_{i}\left(\frac{\lambda_{i}}{\lambda_{i}}\right)^{R}\left\langle u_{1}\left|S_{0}\right| u_{i}\right\rangle\left\langle u_{i}\left|S_{R}\right| u_{1}\right\rangle \\
& =\left\langle u_{1}\left|S_{0}\right| u_{1}\right\rangle\left\langle u_{1}\left|S_{R}\right| u_{1}\right\rangle+\sum_{i \neq 1}\left(\frac{\lambda_{i}}{\lambda_{1}}\right)^{R}\left\langle u_{1}\left|S_{0}\right| u_{i}\right\rangle\left\langle u_{i}\left|S_{R}\right| u_{1}\right\rangle \\
\left\langle s_{0} s_{R}\right\rangle & =\left\langle s_{0}\right\rangle\left\langle s_{R}\right\rangle+\sum_{i \neq 1}\left(\frac{\lambda_{i}}{\lambda_{1}}\right)^{R}\left\langle u_{1}\left|S_{0}\right| u_{i}\right\rangle\left\langle u_{i}\left|S_{R}\right| u_{1}\right\rangle,
\end{aligned}
$$

onde foi usado que

$$
\left\langle s_{R}\right\rangle=\left\langle u_{1}\left|S_{R}\right| u_{1}\right\rangle \text {. }
$$

Finalmente, a função de correlação (equação 1.6) fica sendo

$$
\begin{aligned}
& \Gamma_{R}=\left\langle s_{0} s_{R}\right\rangle-\left\langle s_{0}\right\rangle\left\langle s_{R}\right\rangle \\
& \Gamma_{R}=\sum_{i \neq 1}\left(\frac{\lambda_{i}}{\lambda_{1}}\right)^{R}\left\langle u_{1}\left|S_{0}\right| u_{i}\right\rangle\left\langle u_{i}\left|S_{R}\right| u_{1}\right\rangle .
\end{aligned}
$$

O comprimento de correlação (equação 1.8) fica, então,

$$
\xi^{-1}=\lim _{R \rightarrow \infty}\left\{-\frac{1}{R} \ln \left[\sum_{i \neq 1}\left(\frac{\lambda_{i}}{\lambda_{1}}\right)^{R}\left\langle u_{1}\left|S_{0}\right| u_{i}\right\rangle\left\langle u_{i}\left|S_{R}\right| u_{1}\right\rangle\right]\right\}
$$

ou

$$
\begin{aligned}
& \xi^{-1}=-\lim _{R \rightarrow \infty} \frac{1}{R} \ln \left[\left(\frac{\lambda_{2}}{\lambda_{1}}\right)^{R}\left\langle u_{1}\left|S_{0}\right| u_{2}\right\rangle\left\langle u_{2}\left|S_{R}\right| u_{1}\right\rangle+\sum_{i \neq 1,2}\left(\frac{\lambda_{i}}{\lambda_{1}}\right)^{R}\left\langle u_{1}\left|S_{0}\right| u_{i}\right\rangle\left\langle u_{i}\left|S_{R}\right| u_{1}\right\rangle\right] \\
& \xi^{-1}=-\lim _{R \rightarrow \infty} \frac{1}{R} \ln \left\{( \frac { \lambda _ { 2 } } { \lambda _ { 1 } } ) ^ { R } \langle u _ { 1 } | S _ { 0 } | u _ { 2 } \rangle \langle u _ { 2 } | S _ { R } | u _ { 1 } \rangle \left[1+\sum_{i \neq 1,2}\left(\frac{\lambda_{i}}{\lambda_{2}}\right)^{R} \frac{\left\langle u_{1}\left|S_{0}\right| u_{i}\right\rangle\left\langle u_{i}\left|S_{R}\right| u_{1}\right\rangle}{\left.\left.\left\langle u_{1}\left|S_{0}\right| u_{2}\right\rangle\left\langle u_{2}\left|S_{R}\right| u_{1}\right\rangle\right]\right\}}\right.\right.
\end{aligned}
$$


ou ainda,

$$
\begin{aligned}
\xi^{-1}=-\lim _{R \rightarrow \infty} \frac{1}{R} \ln \left[\left(\frac{\lambda_{2}}{\lambda_{1}}\right)^{R}\left\langle u_{1}\left|S_{0}^{\prime}\right| u_{2}\right\rangle\right. & \left.\left\langle u_{2}\left|S_{R}\right| u_{1}\right\rangle\right] \\
& -\lim _{R \rightarrow \infty} \frac{1}{R} \ln \left[1+\sum_{i \neq 1,2}\left(\frac{\lambda_{i}}{\lambda_{2}}\right)^{R} \frac{\left\langle u_{1}\left|S_{0}\right| u_{i}\right\rangle\left\langle u_{i}\left|S_{R}\right| u_{1}\right\rangle}{\left\langle u_{1}\left|S_{0}\right| u_{2}\right\rangle\left\langle u_{2}\left|S_{R}\right| u_{1}\right\rangle}\right] .
\end{aligned}
$$

O segundo termo da equação acima vai a zero no limite. Resta, portanto,

$$
\xi^{-1}=-\lim _{R \rightarrow \infty} \frac{1}{R} \ln \left(\frac{\lambda_{2}}{\lambda_{1}}\right)^{R}-\lim _{R \rightarrow \infty} \frac{1}{R} \ln \left\langle u_{1}\left|S_{0}\right| u_{2}\right\rangle\left\langle u_{2}\left|S_{R}\right| u_{1}\right\rangle
$$

que, no limite, nos fornece

$$
\xi^{-1}=-\ln \left(\frac{\lambda_{2}}{\lambda_{1}}\right)
$$

Nas equaçôes acima, $\lambda_{1}$ é o maior autovalor e $\lambda_{2}$ é o segundo maior autovalor da matriz de transferência. Assim, para obter $\xi$ é necessário apenas conhecer os dois maiores autovalores da matriz de transferência, mesmo que no caso de matrizes grandes isso só possa ser feito numericamente. Como já foi dito, as expressões 1.12 e 1.13 valem para qualquer modelo que possua uma matriz de transferência e não necessariamente apenas para modelos magnéticos. Portanto, elas valem também para modelos de polímeros, percolação, etc. Deve-se apenas relacionar as grandezas magnéticas com as variáveis específicas de cada sistema, como atividades químicas, densidades, probabilidades, etc. A única condição para que essas equações sejam válidas para um dado modelo é que ele possua uma matriz de transferência associada, de forma que seus antovalores possam ser calculados. Como para o sistema que vamos estudar podemos escrever uma matriz de transferencia, nós utilizaremos estas relaçóes para obter suas propriedades. 


\section{$1.2 \quad$ Finite-Size Scaling}

Nesta seção, introduzimos o conceito de finitersize scaling, sua fundamentação teórica e o método propriamente dito. Seguimos as apresentações feitas por Derrida e De Seze [17] e M. N. Barber [18].

\subsubsection{Fundamentação Teórica}

Como fizemos no caso anterior, iniciamos com um exemplo. Tomemos o calor específico para o modelo de Ising bidimensional numa rede quadrada $L \times L$, com condições periódicas de contorno. No caso do sistema infinito $(L \rightarrow \infty)$, essa grandeza diverge em $T_{c}$, como mostra a figura 1.2 .

Entretanto, no caso de $L$ finito, o calor específico não diverge, mas o gráfico apresenta um pico próximo à região em que, no caso infinito, ocorre a divergência. Além disso, o pico fica mais pronunciado à medida que $L$ aumenta. O que se conclui disso é que o sistema finito apresenta um comportamento semelhante ao do sistema infinito. Se uma grandeza termodinâmica apresenta alguma singularidade no sistema infinito (uma divergência ou uma descontinuidade, por exemplo), essa grandeza apresentará um comportamento "semelhante" no caso do sistema finito. Isso é muito útil e vale para qualquer grandeza termodinàmica de qualquer sistema. Essa propriedade é chamada de finite-size scaling, e ela nos fornece um meio de obter estimativas de grandezas perto ou na própria região crítica do sistema infinito. Vejarmos então o método de finite-size scaling. 


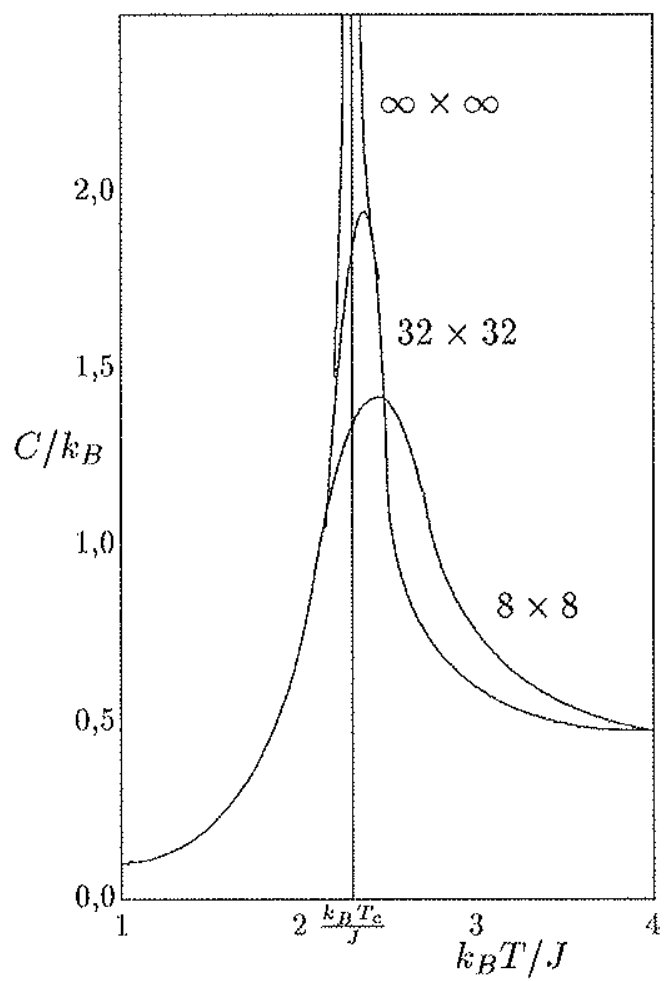

Figura 1.2: Calor específico para o nuodelo de Ising bidimensional para $L=8$, 32 e $\infty[18]$.

\subsubsection{O Método de Finite-Size Scaling}

Vinos anteriormente que o alcance das correlaçoes (representado pelo comprimento de correlação $\xi$ ) num sistema infinito torna-se cada vez maior à medida que nos aproximamos do ponto crítico, sendo que, exatamente nesse ponto, ele diverge. Já num sistema finito, $\xi$ é limitado pelo tamanho do sistema, de forma que ele não pode divergir. Ele vai aumentando enquanto nos aproximarmos da região crítica do sistema infinito e, nesse ponto, fica comparável ao tamanho da rede. Dessa forma, podemos definir um parâmetro a como sendo

$$
a=\frac{L}{\xi_{\infty}(\epsilon)}
$$


onde $L$ é um comprimento característico do sistema finito, $\epsilon$ é a grandeza em função da qual queremos estudar o comportamento crítico (temperatura, probabilidade, etc.) e $\xi_{\infty}(\epsilon)$ é o comprimento de correlação do sistema infinito calculado en $\epsilon$. Por simplicidade, vamos tomar $\epsilon$ como sendo a temperatura $T$ e vamos analisar a transição que ocorre em $T_{c}$, a temperatura crítica. Além disso, consideraremos, por proximidade com os nossos modelos (veja o capítulo 2), sistemas infinitos bidimensionais e sistemas infinitos unidimensionais de largura $L$, isto é, infinitos numa direşão e finitos na outra, a qual tem uma largura $L$. Como sempre, as equações finais valem para qualquer grandeza de qualquer modelo, sendo a nossa escolha apenas uma questão de praticidade.

Quando $a \gg 1$, o sistema finito comporta-se como se fosse infinito. Ele não "sabe" que é finito, já que seu tamanho $L$ é muito maior do que $\xi_{\infty}(T)$, o comprimento de correlação do sistema infinito correspondente. Por outro lado, quando $a \ll 1$, o sistema "sente" fortemente que não é infinito, pois o alcance das correlações no sistema infinito é muito maior do que o tamanho do sistema finito. A transição de um comportamento para outro ocorre quando $a \sim 1$, ou seja, o comprimento de correlação fica da ordem do tamanho do sistema finito.

Vamos supor que estamos numa região próxima ao ponto crítico. Nesta região, uma grandeza termodinânica $Q$ do sistema infinito pode ter um comportamento singular em $T_{c}$. Para representar este comportamento, escolhemos uma forma funcional simples, a saber, uma lei de potências do tipo

$$
Q_{\infty}(T) \sim\left|T-T_{c}\right|^{-\theta},
$$

na qual $Q_{\infty}$ é a grandeza no sistema infinito e $\theta$ é um expoente que depende de qual é a grandeza $Q$ em particular. Esta forma de escala é a mais simples e a mais comum, mas em alguns casos a forma correta é outra.

No sistema finito, como já vimos, não ocorrem singularidades, mas somente uma 
tendência a apresentar esse comportamento. Deve haver então uma função de escala $P_{Q}$ de modo que os sistemas finito e infinito possam ser relacionados por

$$
Q_{L}(T) \simeq Q_{\infty}(T) P_{Q}\left(L / \xi_{\infty}(T)\right)=Q_{\infty}(T) P_{Q}(a)
$$

na qual a foi definido acima $\left(a=L / \xi_{\infty}(T)\right)$. Esta é a idéia básica de finitemsize scaling [19]. Essa função $P_{Q}$ deve ser válida para $L$ grande e $T$ próximo de $T_{c}$. Além disso, $Q_{L}$ é uma função regular em $T_{c}$, de forma que a função de escala $P_{Q}(a)$ deve compensar as singularidades de $Q_{\infty}$, pois elas não poctem ocorrer no sistema finito. Como o comprimento de correlação do sistema infinito diverge em $T_{c}$ seguindo uma lei do tipo

$$
\xi_{\infty}(T) \sim\left|T-T_{c}\right|^{-\nu}
$$

onde $\nu$ é urn expoente crítico, $P_{Q}(a)$ deve ter a forma (veja a equação 1.14)

$$
P_{Q}(a) \sim a^{\theta / \nu}, \quad a \rightarrow 0 .
$$

Desse fato segue que $Q_{L}\left(T_{c}\right)$ deve se comportar em função de $L$ com uma lei do tipo

$$
Q_{L}\left(T_{c}\right) \sim L^{\theta / \nu}, \quad L \text { grande } .
$$

Tomando $Q^{(n)}(T)$ como sendo a n-ésima derivada de $Q(T)$, notamos que essa derivada também é singular em $T_{c}$ para o sistema infinito, e segue uma lei de potências do tipo

$$
\frac{d^{n} Q_{\infty}(T)}{d T^{n}}=Q_{\infty}^{(n)}(T) \sim\left|T-T_{c}\right|^{-\theta-n}
$$

e então,

$$
Q_{L}^{(n)}\left(T_{c}\right) \sim L^{(\theta+n) / \nu}
$$


Expandindo $Q_{L}(T)$ numa série de Taylor exn torno de $T_{c}$, ou seja,

$$
Q_{L}(T)=\sum_{i=0}^{\infty} Q_{L}^{(i)}\left(T_{c}\right) \frac{\left(T-T_{c}\right)^{i}}{i !}
$$

e usando a equação 1.15 , temos

$$
Q_{L}(T) \sim L^{\theta / \nu} R_{Q}\left(L^{1 / \nu}\left(T-T_{c}\right)\right)
$$

onde $R_{Q}$ é outra função regular em $T_{C}$. Podemos sempre expandir $Q_{L}$ pois é uma função sem singularidades. Além disso, a forma explícita de $R_{Q}$ e $P_{Q}$ depende das condiçoes de contorno e da geometria do problema em questão.

Chegamos a expressões que dependem do tamanho $L$ do sistema e da temperatura crítica $T_{c}$. Entretanto, ainda não sabemos como obter, ou pelo menos estimar, a própria temperatura crítica, pois a princípio ela é desconhecida. Um método que pode ser utilizado é apresentado a seguir e chama-se renormalização fenomenológica.

\subsection{Renormalização Fenomenológica}

Na seção anterior, vimos que qualquer grandeza termodinâmica $Q_{L}$ de um sistema finito cujo sistema infinito correspondente tenha uma singularidade em $Q_{\infty}$ pode ser representada por uma lei de escala do tipo mostrado na equação 1.16, ou seja,

$$
Q_{L}(T) \sim L^{\theta / \nu} R_{Q}\left(L^{1 / \nu}\left(T-T_{\sigma}\right)\right)
$$


Vamos escrever a equação acima para o comprimento de correlação. Ficamos com

$$
\xi_{L}(T) \sim L R_{\xi}\left(L^{l / \nu}\left(T-T_{c}\right)\right)
$$

pois o expoente $\theta$ no caso do comprimento de correlação vale $\nu$. Aplicando essa equação em $T_{e}$, temos

$$
\xi_{L}\left(T_{c}\right) \sim L R_{\xi}(0)
$$

Considerando um outro sistema de tamanho $L^{\prime}$ ao invés de $L$ obtemos

$$
\xi_{J^{\prime}}\left(T_{C}\right) \sim L^{\prime} R_{\xi}(0)
$$

As equacões ?? e 1.18 podem ser transformadas numa igualdade acrescentando-se um fator multiplicativo $K$. Fazendo a razão entre estas expressões obtemos

$$
\frac{\xi_{L}\left(T_{c}\right)}{\xi_{L^{\prime}}\left(T_{c}\right)}=\frac{L}{L^{\prime}}
$$

ou, de outra forma,

$$
\frac{\xi_{L}\left(T_{c}\right)}{L}=\frac{\xi_{L^{\prime}}\left(T_{c}\right)}{L^{\prime}}
$$

A equação acima fornece uma estimativa para a temperatura crítica $T_{c}\left(L, L^{\prime}\right)$. Se $L, L^{\prime} \rightarrow \infty$, temos a temperatura crítica do sistema infinito. Essa expressão pode também ser obtida de uma mais geral, a equação de renormalização fenomenológica, que é [20]

$$
\frac{\xi_{L}(T)}{\xi_{L^{\prime}}\left(T^{\prime}\right)}=\frac{L}{L^{\prime}}
$$

que pode ser entendida como sendo uma mudança de escala de um sistema $L$ a uma temperatura $T$ para outro sistema $L^{\prime}$ a uma temperatura $T^{\prime}$. O ponto fixo da transformação é 
a estimativa da temperatura crítica $T_{c}\left(L, L^{\prime}\right)$. A hipótese básica do grupo de renormalização fenomenológica é que a razão entre os comprimentos de correlação depende apenas da razão entre os tamanhos dos sistemas envolvidos, e isto é verificado experimentalnente em um grande número de sistemas.

Podemos calcular também o expoente crítico $\nu$. Para isso, derivamos a equação 1.17 em relação a $T$, ou seja,

$$
\frac{d \xi_{L}(T)}{d T}=L \dot{R}_{\xi}\left(L^{1 / \nu}\left(T-T_{c}\right)\right) L^{1 / \nu}
$$

onde $\dot{R}_{\xi}$ é a derivada de $R_{\xi}$ em relação ao seu argumento. Aplicando esta equação em $T_{c}\left(L, L^{\prime}\right)$, temos

$$
\frac{d \xi_{L}\left(T_{\mathcal{c}}\right)}{d T}=L^{\left(1+\frac{k}{\nu}\right)} \dot{R}_{\xi}(0)
$$

Tomando esta expressão para duas larguras $L$ e $L^{\prime}$ diferentes e fazendo a razão entre elas, ficamos com

$$
\frac{d \xi_{L}\left(T_{c}\right)}{d T} / \frac{d \xi_{L^{\prime}}\left(T_{c}\right)}{d T}=\left(\frac{L}{L^{\prime}}\right)^{1+\frac{1}{\nu}}
$$

Aplicando o logaritmo e rearranjando os termos encontramos a estimativa do expoente $\nu\left(L, L^{\prime}\right)$, ou seja,

$$
1+\frac{1}{\nu}=\frac{\ln \left[\frac{d \xi_{L}\left(T_{c}\right)}{d T} / \frac{d \xi_{Z^{\prime}}\left(T_{c}\right)}{d T^{\prime}}\right]}{\ln \left(L / L^{\prime}\right)}
$$

Assim, tendo o comprimento de correlação para várias larguras $L$, podemos obter várias estimativas para a temperatura crítica $T_{c}$ e para o expoente crítico $\nu$ e depois realizar algum tipo de extrapolação desses resultados para o sistema infinito. O comprimento de correlação pode ser calculado através da matriz de transferência, pois ele depende dos dois maiores 
autovalores desta matriz, como mostra a equação 1.13. O maior problema está, em princípio, no cálculo dos autovalores da matriz, pois ela pode se tornar muito grande, dependendo do modelo considerado. Além do cálculo do expoente $\nu$, também estamos interessados em outro expoente crítico, o expoente $\eta$. No entanto, é necessário primeiro comentar brevemente alguns conceitos de invariância conforme.

\subsection{Invariância Conforme}

Vamos relembrar a equação 1.7, que dá a forma fenomenológica para o decaimento da função de correlação, quando estamos perto do ponto crítico, isto é,

$$
\Gamma(i, j) \sim \frac{e^{-R / \xi}}{R^{\zeta}}, \quad \quad R \text { grande }
$$

Como foi visto, $R$ é a distância entre os sítios $i$ e $j, \xi$ é o comprimento de correlação e $\zeta$ é um expoente. Este expoente relaciona-se com a dimensionalidade espacial em que o modelo está definido através de

$$
\zeta=d-2+\eta
$$

Nesta equação, $d$ é a dimensionalidade espacial e $\eta$ é um novo expoente crítico. A aproximanção de campo médio [15] prevê, para este expoente, um valor $\eta=0$, ou seja, $\zeta=d-2$. Isto é correto apenas quando a dimensionalidade do sistema é igual, ou maior, que uma dimensão crítica superior, $d_{c s}$, que depende de cada tipo de sistema. Por exemplo, para o modelo de Ising, $d_{c s}=4$ [15], e, para polímeros ramificados, $d_{c s}=8$ [8]. Quando $d<d_{c s}$ ocorrem diferenças entre a teoria de campo médio e a experiência. Dessa forma, acrescenta-se $\eta$ a $\zeta$ e constatarse que isso é suficiente para corrigir as discrepâncias que existem. 
Como os modelos que vamos estudar são em duas dimensões, $\zeta=\eta$, pois $\zeta=d-2+\eta$ e $d=2$. Para obter $\eta$ usamos o fato de que a função de correlação deve ser invariante frente a uma transformação conforme quando estamos no ponto crítico [21, 22]. Isto decorre do fato de que a hamiltoniana também deve ser invariante frente transformações conformes no ponto crítico (uma transformação conforme é um tipo de transformação de escala em que o parâmetro de escala não é constante, mas varia suavemente com a posição) [22].

Consideremos a função de correlação no ponto crítico. Nesse caso ela tem um decaimento algébrico da forma

$$
\Gamma\left(\vec{r}_{1}, \vec{r}_{2}\right) \sim\left|\vec{r}_{1}-\vec{r}_{2}\right|^{-2 x}
$$

em que $\vec{r}_{1}$ e $\vec{r}_{2}$ são as posições dos sítios 1 e 2 e $x$ é um expoente. Vamos assumir uma transformação conforme bem simples

$$
\omega=\frac{L}{2 \pi} \ln z
$$

Nesta equação, w e z são números complexos. Esta transformação transforma o plano complexo num cilindro (ou tira) de largura $L$, com condiçóes periódicas de contorno, como mostra a figura 1.3 .

Para que a função de correlação seja invariante, ela deve satisfazer a equação abaixo [21, 22]

$$
\Gamma_{\text {plano }}\left(z_{1}, z_{2}\right)=\left|\dot{\omega}\left(z_{1}\right)\right|^{x}\left|\dot{\omega}\left(z_{2}\right)\right|^{x} \Gamma_{\text {tira }}\left(\omega_{1}, \omega_{2}\right)
$$

onde $\Gamma_{\text {plano }}$ e $\Gamma_{\text {tira }}$ são as funções de correlação no plano e na tira, respectivamente, e $\dot{\omega} e ́$ a derivada de $\omega$ em relação a $z$. Invertendo a transformação conforme 1.22 para $z=e^{\frac{2 \pi}{L} \omega} \mathrm{e}$ supondo que $\omega=a+b i$, obtemos 

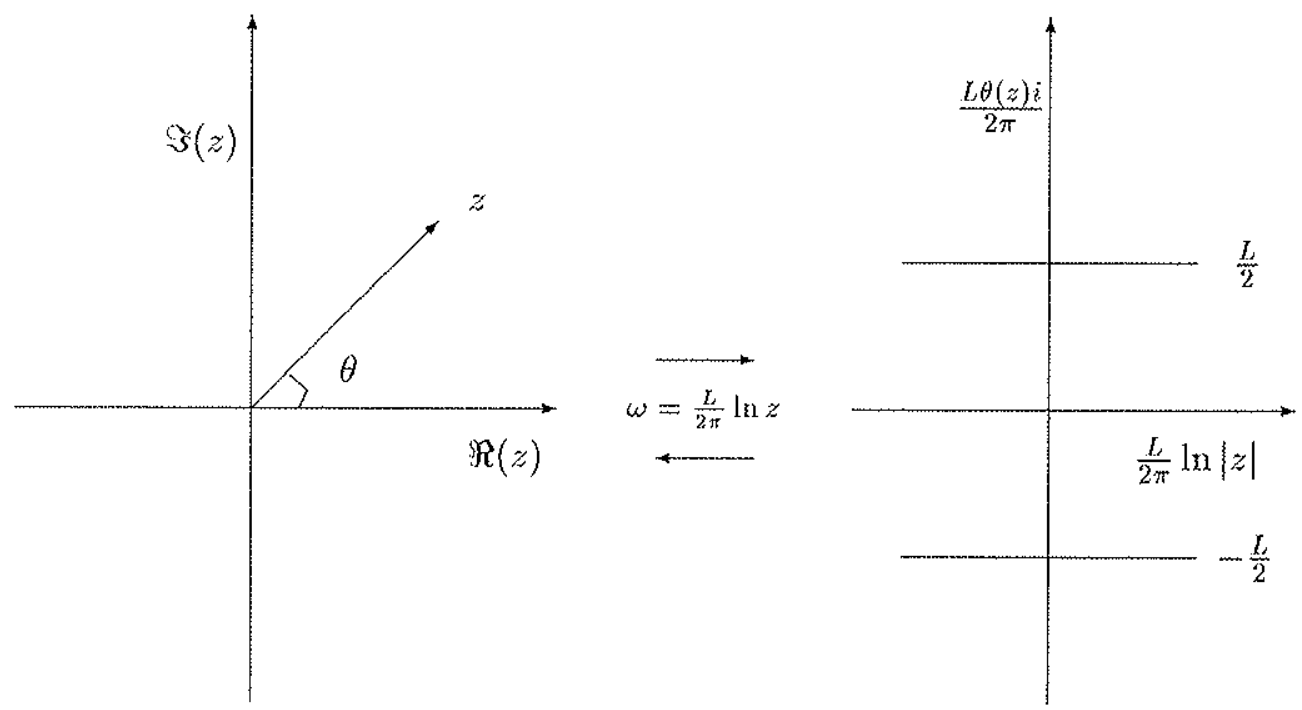

Figura 1.3: Mapeamento conforme de um plano infinito numa tira de largura $L$.

$$
\begin{aligned}
& z_{1}=\exp \left[\frac{2 \pi}{L}\left(a_{1}+b_{1} i\right)\right] \\
& z_{2}=\exp \left[\frac{2 \pi}{L}\left(a_{2}+b_{2} i\right)\right]
\end{aligned}
$$

ou

$$
\begin{aligned}
& z_{1}=e^{\frac{2 \pi}{L} a_{1}}\left[\cos \left(\frac{2 \pi}{L} b_{1}\right)+i \operatorname{sen}\left(\frac{2 \pi}{L} b_{1}\right)\right] \\
& z_{2}=e^{\frac{2 \pi}{L} a_{2}}\left[\cos \left(\frac{2 \pi}{L} b_{2}\right)+i \operatorname{sen}\left(\frac{2 \pi}{L} b_{2}\right)\right] .
\end{aligned}
$$

Calculando $\Gamma_{\text {plano usando a equação } 1.21 \text {, temos }}$

$$
\begin{aligned}
& \Gamma_{\text {plano }}\left(z_{1}, z_{2}\right)=\left|z_{1}-z_{2}\right|^{-2 x} \\
& \Gamma_{\text {plano }}\left(z_{1}, z_{2}\right)=\left|e^{\frac{2 \pi}{L} a_{1}}\left[\cos \left(\frac{2 \pi}{L} b_{1}\right)+i \operatorname{sen}\left(\frac{2 \pi}{L} b_{1}\right)\right]-e^{\frac{2 \pi}{L} a_{2}}\left[\cos \left(\frac{2 \pi}{L} b_{2}\right)+i \operatorname{sen}\left(\frac{2 \pi}{L} b_{2}\right)\right]\right|^{-2 x}
\end{aligned}
$$


ou

$$
\begin{aligned}
& \Gamma_{\text {plano }}\left(z_{1}, z_{2}\right)= \\
& \qquad\left|\left[e^{\frac{2 \pi}{L} a_{1}} \cos \left(\frac{2 \pi}{L} b_{1}\right)-e^{\frac{2 \pi}{L} a_{2}} \cos \left(\frac{2 \pi}{L} b_{2}\right)\right]+i\left[e^{\frac{2 \pi}{L} a_{1}} \operatorname{sen}\left(\frac{2 \pi}{L} b_{1}\right)-e^{\frac{2 \pi}{L} a_{2}} \operatorname{sen}\left(\frac{2 \pi}{L} b_{2}\right)\right]\right|^{-2 x}
\end{aligned}
$$

Se $z=a+b i$, então

$$
\begin{aligned}
|z|^{2} & =z z^{*} \\
& =(a+b i)(a-b i) \\
|z|^{2} & =a^{2}+b^{2}
\end{aligned}
$$

Desse modo, obtemos

$$
\begin{aligned}
\Gamma_{\text {plano }}\left(z_{1}, z_{2}\right)=\left\{\left[e^{\frac{2 \pi}{L} a_{1}} \cos \left(\frac{2 \pi}{L} b_{1}\right)-e^{\frac{2 \pi}{L} a_{2}} \cos \left(\frac{2 \pi}{L} b_{2}\right)\right]^{2}\right. \\
\left.+\left[e^{\frac{2 \pi}{L} a_{1}} \operatorname{sen}\left(\frac{2 \pi}{L} b_{1}\right)-e^{\frac{2 \pi}{L} a_{2}} \operatorname{sen}\left(\frac{2 \pi}{L} b_{2}\right)\right]^{2}\right\}^{-2}
\end{aligned}
$$

ou

$$
\begin{aligned}
& \Gamma_{\text {plano }}\left(z_{1}, z_{2}\right)= \\
& \qquad e^{\frac{2 \pi}{L}\left(2 a_{1}\right)} \cos ^{2}\left(\frac{2 \pi}{L} b_{1}\right)-2 e^{\frac{2 \pi}{L}\left(a_{1}+a_{2}\right)} \cos \left(\frac{2 \pi}{L} b_{1}\right) \cos \left(\frac{2 \pi}{L} b_{2}\right)+e^{\frac{2 \pi}{L}\left(2 a_{2}\right)} \cos ^{2}\left(\frac{2 \pi}{L} b_{2}\right) \\
& \left.+e^{\frac{2 \pi}{L}\left(2 a_{1}\right)} \operatorname{sen}^{2}\left(\frac{2 \pi}{L} b_{1}\right)-2 e^{\frac{2 \pi}{L}\left(a_{1}+a_{2}\right)} \operatorname{sen}\left(\frac{2 \pi}{L} b_{1}\right) \operatorname{sen}\left(\frac{2 \pi}{L} b_{2}\right)+e^{\frac{2 \pi}{L}\left(2 a_{2}\right)} \operatorname{sen}^{2}\left(\frac{2 \pi}{L} b_{2}\right)\right\}^{-x}
\end{aligned}
$$

ou ainda,

$$
\Gamma_{\text {plano }}\left(z_{1}, z_{2}\right)=\left\{e^{\frac{2 \pi}{L}\left(2 a_{1}\right)}+e^{\frac{2 \pi}{L}\left(2 a_{2}\right)}-2 e^{\frac{2 \pi}{L}\left(a_{1}+a_{2}\right)} \cos \left[\frac{2 \pi}{L}\left(b_{1}-b_{2}\right)\right]\right\}^{-x}
$$


ou então,

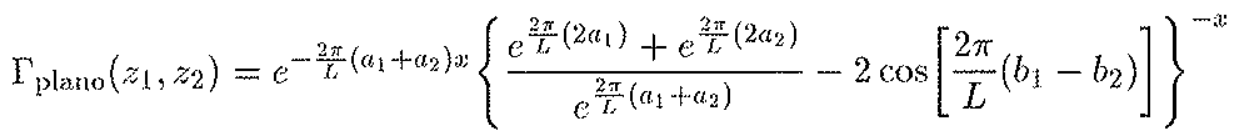

ou, finalmente,

$$
\Gamma_{\text {piano }}\left(z_{1}, z_{2}\right)=e^{-\frac{2 \pi}{L}\left(a_{1}+a_{2}\right) x}\left\{e^{\frac{2 \pi}{L}\left(a_{1}-a_{2}\right)}+e^{\frac{2 \pi}{L}\left(a_{2}-a_{1}\right)}-2 \cos \left[\frac{2 \pi}{L}\left(b_{1}-b_{2}\right)\right]\right\}^{-x}
$$

que pode ser reescrito como

$$
\Gamma_{\text {plano }}\left(z_{1}, z_{2}\right)=e^{-\frac{2 \pi}{L}\left(a_{1}+a_{2}\right) x}\left\{e^{\frac{2 \pi}{L}\left(a_{1} \cdots a_{2}\right)}+e^{-\frac{2 \pi}{L}\left(a_{1}-a_{2}\right)}-2 \cos \left[\frac{2 \pi}{L}\left(b_{1}-b_{2}\right)\right]\right\}^{-i x}
$$

$e$, lembrando que $\cosh \theta=\frac{1}{2}\left(e^{\theta}+e^{-\theta}\right)$, conseguimos

$$
\Gamma_{\text {plano }}\left(z_{1}, z_{2}\right)=e^{-\frac{2 \pi}{L} x\left(a_{1}+a_{2}\right)}\left\{2 \cosh \left[\frac{2 \pi}{L}\left(a_{1}-a_{2}\right)\right]-2 \cos \left[\frac{2 \pi}{L}\left(b_{1}-b_{2}\right)\right]\right\}^{-x} .
$$

Nós queremos a função de correlação na tira, que é relacionada à função de correlação no plano pela equação 1.23 ,

$$
\Gamma_{\text {plano }}\left(z_{1}, z_{2}\right)=\left|\dot{\omega}\left(z_{1}\right)\right|^{2}\left|\dot{\omega}\left(z_{2}\right)\right|^{2} \Gamma_{\text {tira }}\left(\omega_{1}, \omega_{2}\right)
$$

Sendo assim, precisamos calcular a derivada de $\omega=\frac{L}{2 \pi} \ln z$, ou seja,

$$
\dot{\omega}=\frac{L}{2 \pi} \frac{1}{z}
$$

Para os valores de $z$ dados pelas expressões 1.24 temos

$$
\begin{aligned}
& \dot{\omega}\left(z_{1}\right)=\frac{L}{2 \pi} \exp \left[-\frac{2 \pi}{L}\left(a_{1}+b_{1} i\right)\right] \\
& \dot{\omega}\left(z_{2}\right)=\frac{L}{2 \pi} \exp \left[-\frac{2 \pi}{L}\left(a_{2}+b_{2} i\right)\right] .
\end{aligned}
$$


Reescrevendo a equação 1.23 , obtemos

$$
\Gamma_{\text {tira }}\left(\omega_{1}, \omega_{2}\right)=\Gamma_{\text {plano }}\left(z_{1}, z_{2}\right)\left|\dot{\omega}\left(z_{1}\right)\right|^{-i x}\left|\dot{\omega}\left(z_{2}\right)\right|^{-\cdots}
$$

Consequientemente, achamos

$$
\begin{aligned}
& \Gamma_{\text {tira }}\left(\omega_{1}, \omega_{2}\right)=e^{-\frac{2 \pi}{L} x\left(a_{1}+a_{2}\right)}\left\{2 \cosh \left[\frac{2 \pi}{L}\left(a_{1}-a_{2}\right)\right]-2 \cos \left[\frac{2 \pi}{L}\left(b_{1}-b_{2}\right)\right]\right\}^{-i x} \\
&\left|\frac{L}{2 \pi} \exp \left[-\frac{2 \pi}{L}\left(a_{1}+b_{1} i\right)\right]\right|^{-i x}\left|\frac{L}{2 \pi} \exp \left[-\frac{2 \pi}{L}\left(a_{2}+b_{2} i\right)\right]\right|^{-i}
\end{aligned}
$$

ou

$$
\begin{aligned}
&\left.\Gamma_{\text {tira }}\left(\omega_{1}, \omega_{2}\right)=\left(\frac{2 \pi}{L}\right)\right)^{2 \pi} e^{-\frac{2 \pi}{L} x\left(a_{1}+a_{2}\right)}\left\{2 \cosh \left[\frac{2 \pi}{L}\left(a_{1}-a_{2}\right)\right]-2 \cos \left[\frac{2 \pi}{L}\left(b_{1}-b_{2}\right)\right]\right\}^{-x} \\
&\left|\exp \left[-\frac{2 \pi}{L} a_{1}\right] \exp \left[-\frac{2 \pi}{L} b_{1} i\right] \exp \left[-\frac{2 \pi}{L} a_{2}\right] \exp \left[-\frac{2 \pi}{L} b_{2} i\right]\right|^{-x}
\end{aligned}
$$

ou ainda,

$$
\begin{aligned}
\Gamma_{\text {tira }}\left(\omega_{1}, \omega_{2}\right)=\left(\frac{2 \pi}{L}\right)^{2 x} e^{-\frac{2 \pi}{L} r\left(a_{1}+a_{2}\right)}\{2 \cosh & {\left.\left[\frac{2 \pi}{L}\left(a_{1}-a_{2}\right)\right]-2 \cos \left[\frac{2 \pi}{L}\left(b_{1}-b_{2}\right)\right]\right\}^{-i x} } \\
& \left|\exp \left[-\frac{2 \pi}{L}\left(a_{1}+a_{2}\right)\right] \exp \left[-\frac{2 \pi}{L}\left(b_{1}+b_{2}\right) i\right]\right|^{-x}
\end{aligned}
$$

e então,

$$
\begin{array}{r}
\Gamma_{\text {tira }}\left(\omega_{1}, \omega_{2}\right)=\left(\frac{2 \pi}{L}\right)^{2 x} e^{-\frac{2 \pi}{L} x\left(a_{1}+a_{2}\right)}\left\{2 \cosh \left[\frac{2 \pi}{L}\left(a_{1}-a_{2}\right)\right]-2 \cos \left[\frac{2 \pi}{L}\left(b_{1}-b_{2}\right)\right]\right\}^{-x} \\
e^{\left[\frac{2 \pi}{L}\left(a_{1}+a_{2}\right) x\right]}\left|\exp \left[-\frac{2 \pi}{L}\left(b_{1}+b_{2}\right) i\right]\right|^{-x} .
\end{array}
$$


O módulo de uma exponencial complexa vale um, e assim,

$$
\Gamma_{\text {tira }}\left(\omega_{1}, \omega_{2}\right)=\left(\frac{2 \pi}{L}\right)^{2 x}\left\{2 \cosh \left[\frac{2 \pi}{L}\left(a_{1}-a_{2}\right)\right]-2 \cos \left[\frac{2 \pi}{L}\left(b_{1}-b_{2}\right)\right]\right\}^{-\infty} .
$$

Considerando o limite $a_{1} \rightarrow a_{2} \gg L$, apenas o termo que envolve o cosseno hiperbólico contribui para a expressão, e ficamos com

$$
\Gamma_{\text {tira }}\left(\omega_{1}, \omega_{2}\right)=\left(\frac{2 \pi}{L}\right)^{2 x} e^{-\frac{2 \pi}{L} x\left(a_{1}-a_{2}\right)}, \quad\left(\frac{a_{1}-a_{2}}{L}\right) \rightarrow \infty
$$

que decai exponencialmente com a distância. Considexando a função de correlação dada pela equação 1.7, quando $R \rightarrow \infty$ vemos que a exponencial domina sobre o denominador e podemos admitir que

$$
\Gamma(i, j) \sim e^{-R / \xi}, \quad R \rightarrow \infty
$$

Comparando esta equação com a anterior, notamos que os expoentes das duas exponenciais estão relacionados por

$$
\frac{2 \pi x}{L} \cong \frac{1}{\xi}
$$

on seja, o comprimento de correlação é obtido através de

$$
\xi_{L} \cong \frac{L}{2 \pi x}
$$

Podemos relacionar $x$ com $\eta$ através da equação 1.7 aplicada no ponto crítico, isto é,

$$
\Gamma(i, j) \sim|R|^{-\eta}, \quad\left(T=T_{c}\right)
$$

Da equação 1.21 , vemos que $2 x=\eta$ ou $x=\frac{\eta}{2}$. Assim, o comprimento de correlação no ponto 
crítico fica

$$
\xi_{L}\left(T_{c}\right) \cong \frac{L}{\pi \eta}
$$

ot

$$
\frac{\xi_{L}\left(T_{c}\right)}{L} \cong \frac{1}{\pi \eta} .
$$

Devemos lembrar que o comprimento de correlação acima deve ser calculado na temperatura crítica do sistema infinito. Dessa equação notamos que a razão entre o comprimento de correlação e o tamanho da tira é uma constante, reafirmando a renormalização fenomenológica discutida na seção 1.3. Ela vale também para o sistema infinito, pois nesse caso tanto $L$ como $\xi_{L}\left(T_{C}\right)$ divergem, de modo que a razão fica determinada. Com essa expressão podemos obter uma estimativa de $\eta$ para un sistema de tamanho $L$ desde que se calcule o comprimento de correlação de alguma forma. Isto será feito utilizando-se a matriz de transferência para várias tiras de largura $L$. Temos então uma série de estimativas e efetuamos uma extrapolação, como no caso do expoente $\nu$. Convém relembrar que todas as equações relevantes obtidas aplicam-se a qualquer sistema, devendo-se apenas definir as grandezas em termos das variáveis adequadas de cada problema.

Corn isto encerramos a cliscussão sobre as técnicas empregadas. No próximo capítulo definimos os modelos que foram estudados. 


\section{Capítulo 2}

\section{OS MODELOS}

O objetivo deste capítulo é definir os modelos que foram estudados pelas técnicas comentadas no capítulo anterior. Como já foi dito no capítulo 1, nosso interesse está voltado para o estudo de modelos de polímeros em duas dimensões. Nesse caso, uma configuração possível para o polímero é mostrada na figura 2.1.

O estudo de modelos definidos dessa forma genérica é um tanto complicado, e podemos simplificá-lo se considerarmos que o polímero esteja inscrito numa rede e, no nosso caso, essa rede é uma rede quadrada. Um modelo simples consiste em supor que os monômeros situamse nos sítios da rede, enquanto as ligações estão ao longo das linhas que unem os sítios, como exemplifica a figura 2.2. Os monomeros ativos são aqueles que estão incorporados ao polímero (representados por $\triangle$ na figura), ao passo que os inativos não fazem parte dele (são os $\diamond$ ). Nesse modelo podemos associar aos monômeros que fazem parte do polímero uma atividade $x=e^{\beta \mu}$, onde $\beta=\frac{1}{k_{B} T}\left(k_{B}\right.$ é a constante de Boltzmann e $T$ é a temperatura absoluta $)$ e $\mu$ é o potencial químico. Além disso, impomos a condição de que o polímero não pode passar por um mesmo sítio duas vezes (condição de auto-exclusão). A função de partição para esse sistema pode ser escrita como 


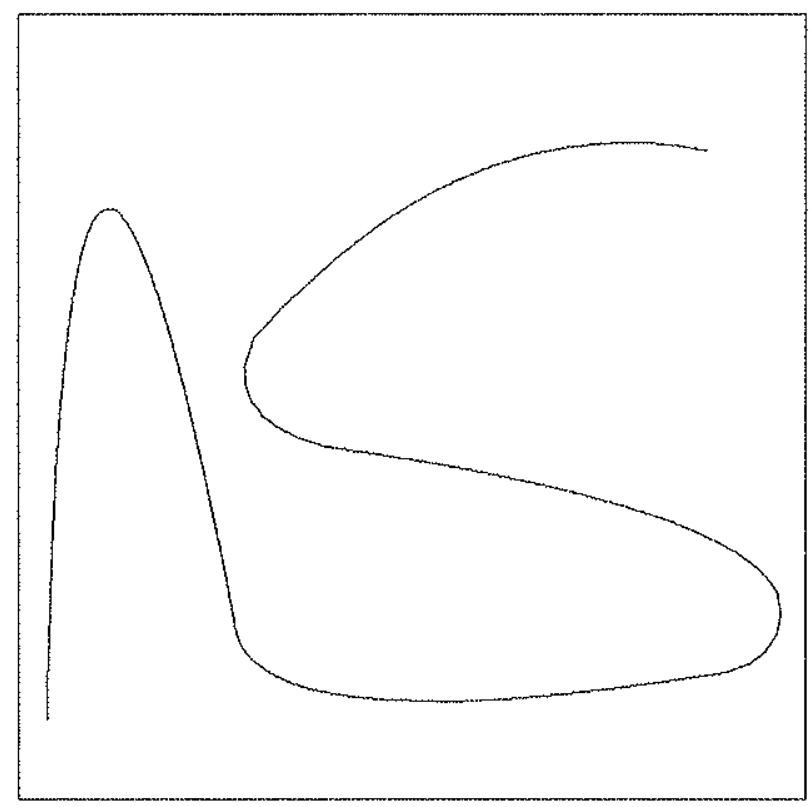

Figura 2.1: Uma configuração possível para um polímero numa interface bidimensional.

$$
\mathcal{Z}_{N}=\sum_{N_{y}=0}^{N} x^{N_{x}} \Gamma\left(N_{x} ; N\right)
$$

na qual $N_{x}$ é o número de monômeros que pertencem ao polímero, $N$ é o número total de monôtreros, ou sítios, da rede quadrada, e $\Gamma\left(N_{x} ; N\right)$ é o número de modos de colocar unx polímero $\operatorname{com} N_{x}$ monômeros numa rede com $N$ sítios. Este problema é semelhante ao de se ter, numa rede quadrada, uma caminhada aleatória anto-excludente, ou SAW (Self-Avoiding Walk), no qual o caminhante não pode passar duas vezes pelo mesmo ponto.

Para que se possa efetivar a resolução desse modelo é necessário "contar" configurações de forma a obter $\Gamma\left(N_{x} ; N\right)$. Entretanto, a função de partição acima é um polinômio finito em $x$, de modo que a função de partição possui derivadas em todas as ordens. Assim, o 


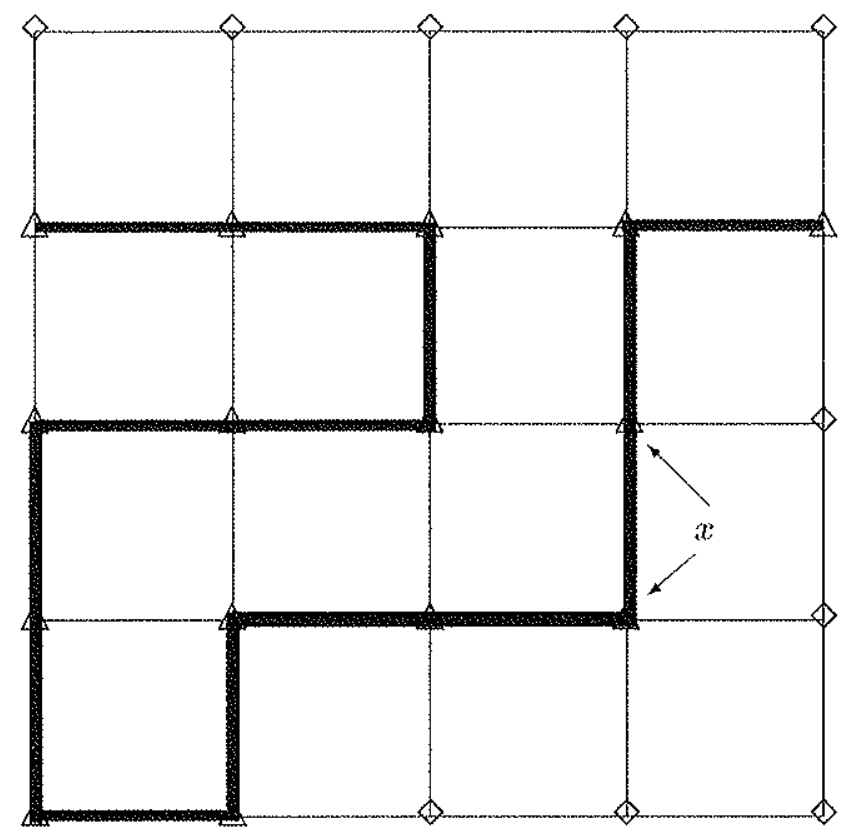

Figura 2.2: Configuração de um polímero numa rede quadrada. Os monồxaeros ativos são representados por $\Delta \mathrm{e}$ os inativos por $\diamond$. Essa configuraçăo tem urn peso estatístico $x^{15}$.

sistema acima não deve apresentar transições de fases, pois é necessário que haja alguma singularidade função de partição para que o sistema possa sofrer algum tipo de transição. Então, se $N_{x}$ e $N$ são finitos o sistema não apresenta transições de fases. Entretanto, se tomarmos o limite em que $N_{x}$ e $N$ vão ao infinito, mantendo $x$ fixo, ou seja, se tomarmos o limite termodinâmico no formalismo grande-canônico, a função de partição poderá exibir alguma singularidade e então poderá ocorrer uma transição de fases. Isto complica ainda mais o processo de contagem das configurações permitidlas, o que faz com que tenhamos que encontrar algum outro modo de tentar estudar esse tipo de sistema. De fato, o modelo acima já foi estudado por algumas técnicas [1-3], e a atividade crítica $x_{c}$ em que ocorre a transição da fase não-polimerizada, quando $x<x_{c}$, para uma fase polimerizada, quando $x>x_{c}$, é conhecida, e vale $x_{c}=0,37905227 \pm 0,00000012$ [1]. Além disso, essa transição é contínua e seus expoentes críticos são conhecidos, sendo que $\nu=\frac{3}{4}$ e $\eta=\frac{5}{24}$ (exatamente) [4], todos 
para o sistema bidimensional infinito. Assim, por enquanto, vamos apenas definir os modelos com os quais desenvolvemos o nosso trabalho.

\subsection{Modelo de Ligações Interagentes}

Tomando por base o modelo simples definido acima, podemos acrescentar mais uma interação, além daquela de volume excluído. Assumimos que, quando duas ligações são primeiras-vizinhas, ocorre uma interação entre elas, sendo que essa interação é representada por um fator de Boltzmann $y=e^{-\beta \epsilon \ell}$, onde $\epsilon_{\ell}$ é a energia de interaşão entre as ligações. Se $\epsilon_{\ell}<0$ temos o caso de ligações atrativas, enquanto que, para $\epsilon_{\ell}>0$, as ligações são repulsivas. $O$ caso $\epsilon_{\ell}=0$, ou seja, $y=1$, corresponde ao modelo sem interações atrativas, o qual foi apresentado acima. Então, para este valor específico de $y$, o nosso modelo deve reproduzir os resultados acima, o que pode ser usado a título de verificação. A figura 2.3 mostra uma das possíveis configurações para um polímero, no caso deste modelo de ligaçoes interagentes.

Para este modelo, a função de partição pode ser escrita como

$$
\mathcal{Z}_{N}^{\ell}=\sum_{N_{x}, N_{y}=0}^{N} x^{N_{*}} y^{N_{y}} \Gamma_{\ell}\left(N_{x}, N_{y} ; N\right)
$$

onde $\mathcal{Z}_{N}^{\ell}$ refere-se à função de partição do modelo de ligações interagentes, $N_{x}$ é o número de monômeros pertencentes ao polímero, $N_{y}$ é o número de interações entre as ligações interagentes (também pode ser entendido como sendo o número de pares de ligações primeirasvizinhas), $N$ é o número total de sítios e $\Gamma_{\ell}\left(N_{x}, N_{y} ; N\right)$ representa o número de maneiras de colocar, numa rede quadrada de $N$ sítios, um polímero com $N_{x}$ monômeros, sendo que $N_{y}$ pares das ligações entre os monôneros devem ser primeiras-vizinhas, ou interagentes. Novamente a função de partição acima é um polinômio e transições de fases só podem ocorrer 


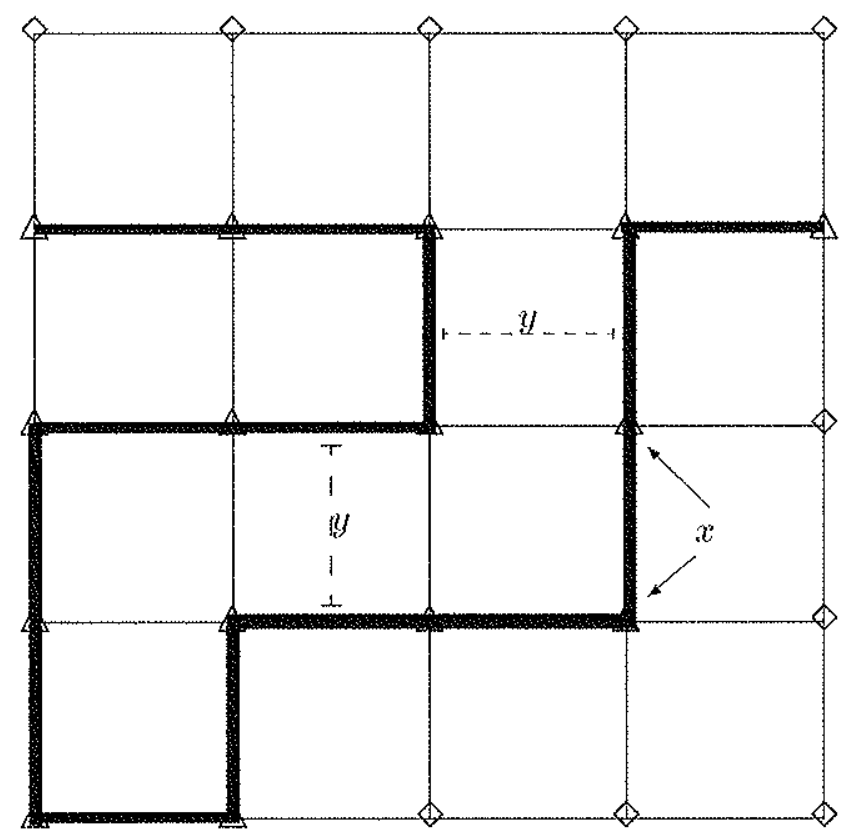

Figura 2.3: Configuração de un polínero com ligaçóes interagentes. Os monômeros ativos săo representados por $\triangle$ e os inativos por $\diamond$. O peso estatístico clessa configuração vale $x^{15} y^{5}$.

se tomarmos o limite termodinâmico, mantendo $x$ e $y$ fixos. O procedimento de estudo do modelo é mostrado na seção 2.3 .

\subsection{Modelo de Monômeros Interagentes}

Considerando novamente o modelo simples não-interagente descrito no início desse capítulo podemos admitir, ao invés de uma interação entre as ligações primeiras-vizinhas, uma interação entre os monômeros primeiros-vizinhos mas não consecutivos (se eles forem consecutivos, eles estão unidos por uma ligação, e toda a energia envolvida nisto está incorporada na atividade $x$ ). Definimos então um fator de Boltzmann $z$, com $z=e^{-\beta \epsilon_{m}}$. Acui, $\epsilon_{m}$ desempenha um papel análogo ao de $\epsilon_{\ell}$ no modelo de ligações interagentes $e$, no caso de 
$\epsilon_{m}=0$, ou seja, $z=1$, recaímos novamente no modelo não-interagente. A figura 2.4 mostra uma configuração possível para o polímero nesse caso.

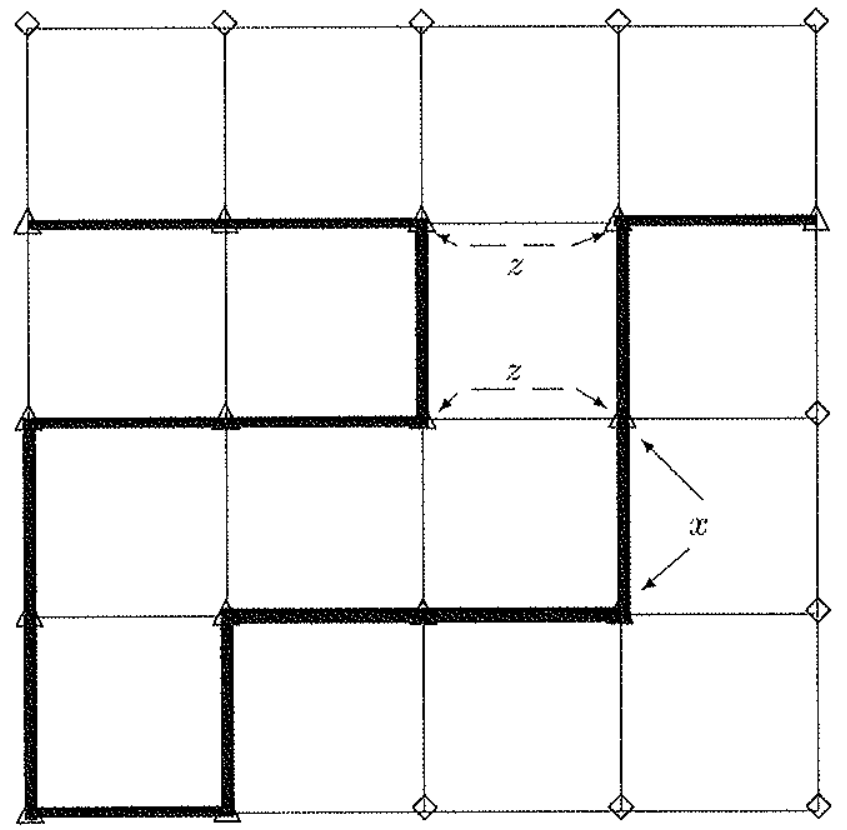

Figura 2.4: Configuração de um polímero com monômeros interagentes. Os monômeros ativos săo representados por $\Delta$ e os inativos por $\diamond$. O peso estatístico dessa configuraçăo vale $x^{15} z^{7}$.

A função de partição deste modelo fica sendo, então,

$$
\mathcal{Z}_{N}^{m}=\sum_{N_{x}, N_{z}=0}^{N} x^{N_{x}} z^{N_{z}} \Gamma_{m}\left(N_{x}, N_{z} ; N\right)
$$

na qual $\mathcal{Z}_{N}^{m}$ se refere ao modelo de monômeros interagentes, $N_{x}$ é o número de monômeros ativos, $N_{z}$ é o número de interações entre os monômeros fou o número de pares de monômeros ativos primeiros-vizinhos mas não consecutivos), $N$ é o número total de sítios da rede e $\Gamma_{m}\left(N_{x}, N_{z} ; N\right)$ é o número de modos de se ter, numa rede quadrada de $N$ sítios, um polímero $\operatorname{com} N_{x}$ monômeros tendo $N_{3}$ pares de monômeros primeiros-vizinhos não-consecutivos. Como ocorre no modelo anterior, este só pode apresentar possíveis transições de fases no limite 
termodinâmico, sendo que $x$ e $z$ devem ser mantidos fixos nesse limite. $O$ modo de estudo destes dois modelos é apresentado na seção seguinte.

\subsection{Resolução dos Modelos}

Para obter as possíveis transições de fases e, portanto, o diagrama de fases dos modelos acima, deveríamos resolver o sistema bidimensional infinito, ou seja, precisaríamos conhecer a função $\Gamma$ quando tomamos o limite termodinâmico e saber qual é a função que corresponde à soma infinita que resulta na função de partição. Isto é virtualmente impossivel, pelo menos para esses modelos de polímeros. Devemos, então, tentar seguir por um outro caminho.

Como foi visto na seção 1.2 , sistemas finitos apresentarn nas suas propriedades termodinâmicas comportamentos semelhantes ao do sistema infinito correspondente, sendo que, quanto maior for o sistema finito, mais próximo ele está de ser "infinito" e suas grandezas termodinâmicas assemelham-se mais àquelas do sistema infinito. Esse fato é conhecido como finite-size scaling. Então, para estudar o sistema infinito, podemos considerar una série de sistemas finitos e, através de um processo de extrapolação dos resultados obtidos para esses sistemas, extrair estimativas das grandezas para o sistema bidimensional infinito.

A seção 1.3 nos sugere que um meio de obter estimativas dos pontos críticos do diagrama de fases de um sistema infinito bidimensional consiste em comparar pares de tiras de largura $L$ e comprimento infinito (equação 1.19). É necessário apenas encontrar o comprimento de correlação nas referidas tiras (uma dessas tiras, para $L=4$, é apresentada na figura 2.5). É possível, também, fazer estimativas do expoente crítico $\nu$ através do uso das derivadas do comprimento de correlação calculadas nos pontos fixos obtidos no cálculo do diagrama de fases (equação 1.20). Além disso, o expoente $\eta$, utilizando as idéias de invariância conforme 
(seção 1.4), pode ser estimado através da equação 1.25, a qual novamente depende do comprimento de correlação. Cabe esclarecer que uma tira de largura $L$ e comprimento infinito é um sistema infinito unidimensional para qualquer largura $L$ finita. Só torna-se um sistema bidimensional infinito, ou seja, uma rede quadrada, quando tomamos o limite $L \rightarrow \infty$, que é o limite termodinâtuico neste caso. Então, quando nos referimos a uma tira de largura $L$ e comprimento infinito usamos o termo sistema finito porque a largura é finita. Quando queremos nos referir à rede quadrada bidimensional, na qual a largura e o comprimento são infinitos, usamos o termo sistema infinito.

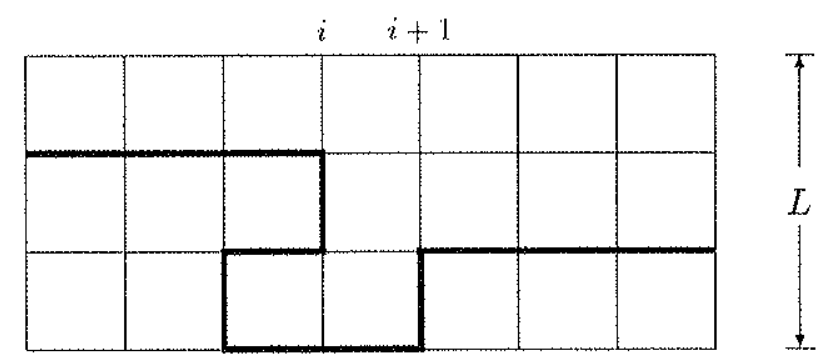

Figura 2.5: Configuração de umn polímero ntuma tira de largura $L=4$.

Do parágrafo anterior notamos que, tendo o comprimento de correlação, o resto dos cálculos é relativamente simples. Mas, como podemos obter $\xi_{L}$ ?

Da seção 1.1 vemos que o comprimento de correlação pode ser calculado em termos dos dois maiores autovalores da matriz de transferencia por meio da equação 1.13. Então, temos a seguinte seqüência de cálculos: obter os estados da matriz de transferência para duas tiras $L \mathrm{e}$ $L^{\prime}$, calcular os dois maiores autovalores, extrair o comprimento de correlação e usar a equação de renormalização fenomenológica até obter um ponto do diagrama de fases para este par de larguras. Depois disso, como já temos os estados da matriz, calculamos o comprimento de correlação para novos valores de $x$ e $y$ (ou $x$ e $z$ ) e, em seguida, varremos o diagrama de fases de forma a encontrar as fronteiras de fases. Após achar as fronteiras, podemos calcular 
os expoentes $\nu$ e $\eta$ para cada par. Finalmente, através de algum processo de extrapolação, chegamos aos resultados do sistema bidimensional infinito. Cada un desses passos é descrito com mais detalhes a seguir.

\subsubsection{Construção da Matriz de Transferência}

O primeiro passo é construir a matriz de transferencia para uma tira de largura $L$. Consideramos condições de contorno periódicas na direção transversal. Além disso, a origem situa-se sempre à esquerda e não há pontos terminais ou iniciais no interior da tira, ou seja, o polímero deve atravessar toda a tira de uma extremidade até a outra.

Para construir a matriz de transferencia devemos saber como conseguimos uma configuração $\beta$ para as ligaçóes horizontais na coluna $i+1$ partindo de uma dada configuração $\alpha$ de ligacoes horizontais incidentes muma coluna $i$ da tira $(\beta$ pode ser igual a $\alpha$ ). A figura 2.6 ilustra um exemplo.
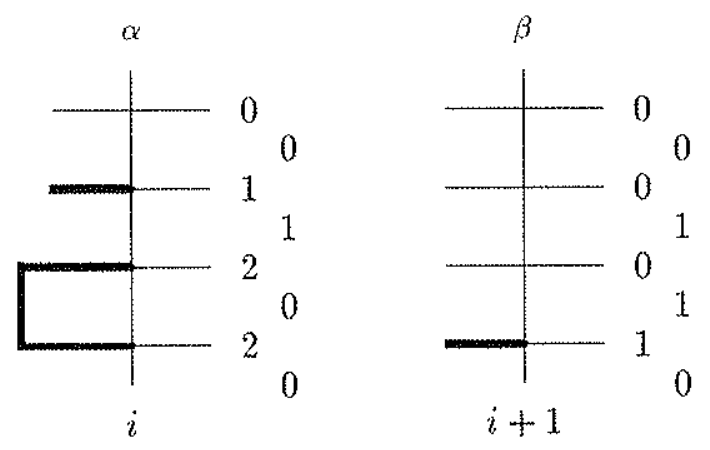

Figura 2.6: Dois exemplos de configurações para $L=4$. Os índices são explicados no texto.

Como pode ser visto na figura 2.6 , as configurações são representadas por duas sequiências verticais de índices. A primeira dessas sequiencias (da esquerda para a direita) está associada aos sítios e representa as ligações horizontais que incidem na coluna $i$ vindas da 
esquerda. Ela segue a seguinte convenção:

- Se num sítio chega uma ligação horizontal que está conectada cliretamente com a origen, ele recebe o índice 1 . Como queremos que o polímero atravesse toda a tira, sempre um dos sítios em cada coluna tem este índice. No exemplo, corresponde ao segundo sítio de cima para baixo na configuração $\alpha$ e ao quarto na $\beta$.

- Se num sítio não incide nenhuma ligação horizontal, ele recebe o índice 0. É o caso do primeiro sítio na configuração $\alpha$ e do primeiro, segundo e terceiro sítios na $\beta$.

- Se dois sítios estão conectados através de ligações, mas não diretamente com a origem, ambos recebem um índice maior do que 1 . Na configuração $\alpha$, corresponde ao terceiro e quarto sítios, que levam o índice 2 . A configuração $\beta$ não apresenta este caso.

A outra seqüência de índices está associada às ligações verticais que deven ser colocadas na coluna $i$ para se obter a coluna $i+1$. Dessa forma, temos a seguinte convenção: se a ligação está ausente, temos o índice 0. Caso contrário, temos o índice 1 . No caso de $\alpha$, temos a seguinte ordem: o primeiro sítio não se liga com o segundo (índice 0). Já este conecta-se com o terceiro (índice 1), o qual não se liga ao quarto (índice 0). O quarto, lembrando as condições periódicas de contorno, também não se conecta ao primeiro (último índice 0). No caso de $\beta$, as ligações existentes são entre o segundo e o terceiro sítios, e entre este último e o quarto sítio, tendo ambos índice 1. Os outros índices são 0. Devernos lembrar que, para obter a matriz de transferência, todas as configuraçôes possíveis devem ser consideradas. As configurações acima são apenas duas dessas possibiliclades.

Mostramos, na figura 2.7, a configuracão do elemento da matriz de transferencia associado às configurações $\alpha$ e $\beta$ acima. As interações que devemos considerar para o cálculo do elemento de matriz $\langle\alpha|T| \beta\rangle$, onde $T$ representa a matriz de transferência, são as que ocorrem dentro da região tracejada da figura 2.7. Temos assim dois resultados, dependendo do modelo 
considerado.

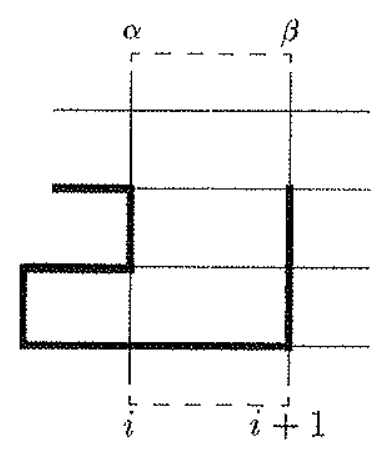

Figura 2.7: Configuração de um elemento da matriz de transferência.

Para o modelo de ligações interagentes, a situação é a apresentada na figura 2.8 .

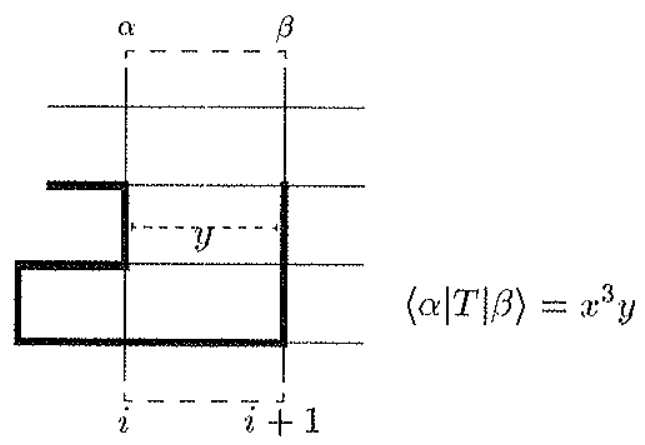

Figura 2.8: Elemento da matriz de transferência para o caso de ligaçốes interagentes.

Nesse caso existe apenas una interação entre as ligações. Ela ocorre entre as ligações que unem o segundo e o terceiro sítios das colunas $i$ e $i+1$, de cima para baixo. Isto contribui com um fator y para o elemento de matriz. No caso dos sítios, devemos considerar apenas os que estão na coluna da esquerda, pois os da direita serão contados na próxima iteração da matriz de transferência. Por esse mesmo motivo as interações entre as ligações que ocorrem antes da coluna $i$ também não são consideradas agora, pois já o foram na iteração anterior. Como existem três sítios ocupados na coluna $i$ temos uma contribuição $x^{3}$, de forma que o 
demento de matriz fica sendo

$$
\left\langle\alpha\left|T_{\ell}\right| \beta\right\rangle=x^{3} y
$$

No caso dos monômeros interagentes ocorrem mais interações, como mostra a figura 2.9 .

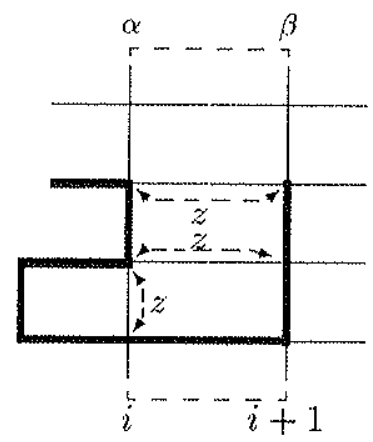

Figura 2.9: Elemento da matriz de transferência para o caso de monômeros interagentes.

Nesse caso temos três interações entre os monômeros, o que resulta num fator $z^{3}$, além dos três sítios da coluna $i$ que contribuem com $x^{3}$ como no caso anterior. Então,

$$
\left\langle\alpha\left|T_{m}\right| \beta\right\rangle=x^{3} z^{3}
$$

Após acharmos todos os elementos teremos a matriz de transferencia completa para uma largura $L$ qualquer. No apêndice A todos os estados e alguns dos elementos de matriz para $L=3$ são apresentados, para ambos os modelos. 


\subsubsection{Cálculo das Fronteiras de Fases}

Após encontrar a matríz de transferência podemos calcular seus autovalores e também o comprimento de correlação através da equação 1.13, que é

$$
\xi_{I}^{-1}=-\ln \left[\frac{\lambda_{2}(L)}{\lambda_{1}(L)}\right]
$$

Este processo é numérico devido ao tamanho das matrizes de transferencia já que, mesmo após uma bloco-diagonalização, que é um processo que explora as simetrias do modelo, o tamanho permanece relativamente grande. $\mathrm{O}$ apêndice $\mathrm{A}$ apresenta alguns dados referentes às matrizes de transferência para várias larguras $L$, além dos estados para $L=3$.

De posse do comprimento de correlaçấo para duas larguras $L$ e $L^{\prime}$ podemos usar a equação 1.19 para o ponto fixo do grupo de renormalização fenomenológico

$$
\frac{\xi_{L}\left(T_{c}^{\prime}\right)}{L}=\frac{\xi_{L^{\prime}}\left(T_{c}^{\prime}\right)}{L^{\prime}}
$$

para achar uma estimativa da atividade crítica $x_{c}$. Procedemos do seguinte modo: fixamos um valor para $y($ ou $z)$ num certo valor $y_{c}\left(\right.$ ou $\left.z_{c}\right)$ e então resolvemos a equação abaixo

$$
\frac{\xi_{L}\left(x_{c}\right)}{L}=\frac{\xi_{L^{\prime}}\left(x_{c}\right)}{L^{\prime}}
$$

Com isto, obtemos um ponto fixo $x_{c}\left(L, L^{\prime}\right)$ e, conseqüentemente, um ponto no diagrama de fases $y \times x$ (ou $z \times x$ ) para as larguras $L$ e $L^{\prime}$, pois já tinhamos fixado $y_{c}$ (ou $z_{c}$ ). Variando $y_{c}$ (ou $z_{c}$ ) extraímos todo o diagrama de fases para esse par de larguras. Podemos então realizar os mesmos cálculos para outro par $L-L^{\prime}$ e temos um conjunto de dados. Depois, resta extrapolar esses resultados para o sistema bidimensional que queríamos resolver desde o início. Esses resultados são apresentados no capítulo seguinte. 


\subsubsection{Cálculo do Expoente Crítico $\nu$}

Sendo possível obter o comprimento de correlação através da equação 1.13, o expoente crítico $\nu$ pode ser estimado mediante a equação 1.20 , que fica

$$
1+\frac{1}{\nu}=\frac{\ln \left[\frac{d \xi_{L}\left(x_{c}\right)}{d x} / \frac{d \xi_{L^{\prime}}\left(x_{c}\right)}{d x}\right]}{\ln \left(L / L^{\prime}\right)} .
$$

Também aqui $y_{c}$ (ou $z_{c}$ ) é fixado e temos uma série de estimativas para $\nu$ para os vários pares de larguras estudados. Extrapolando essas estimativas achamos o expoente $\nu$ do sistema bidimensional.

\subsubsection{Cálculo do Expoente Crítico $\eta$}

Novarnente usaudo o comprimento de correlação podemos estimar o expoente crítico $\eta$. Após um rearanjo na equação 1.25 ficamos com

$$
\eta \cong \frac{1}{\pi} \frac{L}{\xi_{L}\left(x_{c}\right)}
$$

Vale lembrar que o $x_{c}$ da equação acima é o do sistema bidimensional, ou seja, primeiro devemos extrapolar as estimativas para $x_{c}$ obtidas para os pares de larguras e depois calcular o comprimento de correlação na tira de largura $L$ no $x_{c}$ extrapolado. Isto nos fornece uma seqüência de valores para $\eta$, os quais, por sua vez, são extrapolados para o sistema bidimensional. Todos os resultados são discutidos no próximo capítulo. 


\subsubsection{Cálculo da Densidade de Sítios Ocupados e da Densidade de Interações}

O cálculo das densidades de sítios ocupados e da densidade de interações é uma ferramenta auxiliar na identificação das características físicas das fases e na determinação dos tipos de transicão que ocorrem entre duas fases do diagrama de fases. Entretanto, ela sozinha não pode determinar com precisão os pontos críticos. As densidades nas tiras podem ser definidas através de

$$
\rho_{x}=\frac{\left\langle N_{x}\right\rangle}{N}
$$

e

$$
\rho_{k}=\frac{\left\langle N_{k}\right\rangle}{N}
$$

que são as definições estatísticas usuais para qualquer densidade. Aqui, $\rho_{x}$ representa a densidade de sítios da tira de largura $L$ ocupados pelo polímero enquanto $\rho_{k}$, com $k=y, z$, é a densidade de interações, sejam elas entre ligações ou monômeros. $\left\langle N_{x}\right\rangle$ é o número médio de sítios da tira ocupados e $\left\langle N_{k}\right\rangle$ é o número médio de interações. $N$ é o número total de sítios da tira. Os valores médios de $N_{n}$ e $N_{k}$ estão relacionados à função de partição através de

$$
\begin{aligned}
\left\langle N_{x}\right\rangle_{N} & =\frac{\sum_{N_{x}, N_{k}} N_{x} x^{N_{x}} k^{N_{k}} \Gamma_{k}\left(N_{x}, N_{k} ; N\right)}{\sum_{N_{x}, N_{k}} a^{N_{x}} k^{N_{k}} \Gamma_{k}\left(N_{x}, N_{k} ; N\right)} \\
\left\langle N_{x}\right\rangle_{N} & =\frac{\sum_{N_{x}, N_{k}} N_{x} x^{N_{x}} k^{N_{k}} \Gamma_{k}\left(N_{x}, N_{k} ; N\right)}{\mathcal{Z}_{N}^{k}}
\end{aligned}
$$


e

$$
\begin{aligned}
&\left\langle N_{k}\right\rangle_{N}= \frac{\sum_{N_{x}, N_{k}} N_{k} x^{N_{x}} k^{N_{k}} \Gamma_{k}\left(N_{x}, N_{k} ; N\right)}{\sum_{N_{x}, N_{k}} x^{N_{x}} k^{N_{k}} \Gamma_{k}\left(N_{x}, N_{k} ; N\right)} \\
&\left\langle N_{k}\right\rangle_{N}=\frac{\sum_{N_{x}, N_{k}} N_{k} x^{N_{x}} k^{N_{k}} \Gamma_{k}\left(N_{x}, N_{k} ; N\right)}{\mathbb{z}_{N}^{k}} .
\end{aligned}
$$

Dessas equações, é fácil perceber que

$$
\left\langle N_{x}\right\rangle_{N}=x \frac{\partial}{\partial x} \ln z_{N}^{k}
$$

e

$$
\left\langle N_{k}\right\rangle_{N}=k \frac{\partial}{\partial k} \ln \mathcal{Z}_{N}^{k}
$$

Além disso, a função de partição pode ser obtida ern termos dos autovalores da matriz de transferência mediante a equação 1.3. No nosso caso, a tira tem largura $L, N$ sítios e comprimento $M=\frac{N}{L}$ (antes de se tomar o limite termodinâmico). Lembrando que a matriz de transferencia leva em conta $L$ sítios por coluna, a função de partição fica

$$
\begin{aligned}
& \mathcal{Z}_{N}^{k}=\sum_{i} \lambda_{i}^{M} \\
& \mathcal{Z}_{N}^{k}=\sum_{i \neq 1} \lambda_{1}^{M}\left[1+\left(\frac{\lambda_{i}}{\lambda_{1}}\right)^{M}\right]
\end{aligned}
$$

na qual $\lambda_{1}$ é o maior autovalor. Aplicando o logaritmo na expressão acima temos

$$
\ln \mathcal{Z}_{N}^{k}=M \ln \lambda_{1}+\ln \sum_{i \neq 1}\left[1+\left(\frac{\lambda_{i}}{\lambda_{1}}\right)^{M}\right]
$$

Tomando agora o limite $M \rightarrow \infty$ (e portanto, $N \rightarrow \infty$, pois $M=\frac{N}{L}$ ), temos a função de 
partição para as nossas tiras de largura $L$ e comprimento infinito

$$
\begin{aligned}
\ln \mathcal{Z}^{k} & =\lim _{N \rightarrow \infty} \frac{1}{N} \ln \mathcal{Z}_{N}^{k} \\
& =\lim _{M \rightarrow \infty} \frac{1}{M L}\left\{M \ln \lambda_{1}+\ln \sum_{i \neq 1}\left[1+\left(\frac{\lambda_{i}}{\lambda_{1}}\right)^{M}\right]\right\} \\
& =\lim _{M \rightarrow \infty} \frac{1}{L} \ln \lambda_{\perp}+\lim _{M \rightarrow \infty} \frac{1}{M L}\left\{\ln \sum_{i \neq 1}\left[1+\left(\frac{\lambda_{i}}{\lambda_{1}}\right)^{M}\right]\right\} \\
\ln \mathcal{Z}^{k} & =\frac{1}{L} \ln \lambda_{1} .
\end{aligned}
$$

O segundo termo do lado direito da equação vai a zero no limite porque a fração que envolve os autovalores é sempre menor que 1 . No limite ela tende a zero e resta $\ln 1=0$. Tendo a função de partição voltamos às equações 2.6 e 2.7 , que ficam

$$
\begin{aligned}
& \left\langle N_{x}\right\rangle=\frac{N}{L} x \frac{\partial}{\partial x} \ln \lambda_{1} \\
& \left\langle N_{x}\right\rangle=\frac{N}{L} \frac{x}{\lambda_{1}} \frac{\partial \lambda_{1}}{\partial x}
\end{aligned}
$$

e

$$
\begin{aligned}
& \left\langle N_{k}\right\rangle=\frac{N}{L} k \frac{\partial}{\partial k} \ln \lambda_{1} \\
& \left\langle N_{k}\right\rangle=\frac{N}{L} \frac{k}{\lambda_{1}} \frac{\partial \lambda_{1}}{\partial k} .
\end{aligned}
$$

As densidades nas tiras de largura $L$ ficam sendo, portanto,

$$
\begin{aligned}
& \rho_{x}=\frac{\left\langle N_{x}\right\rangle}{N} \\
& \rho_{x}=\frac{1}{L} \frac{x}{\lambda_{l}} \frac{\partial \lambda_{l}}{\partial x}
\end{aligned}
$$




$$
\begin{aligned}
& \rho_{k}=\frac{\left\langle N_{k}\right\rangle}{N} \\
& \rho_{k}=\frac{1}{L} \frac{k}{\lambda_{1}} \frac{\partial \lambda_{1}}{\partial k} .
\end{aligned}
$$

As equações acima podem ser utilizadas para o cálculo das densidades nas tiras de largura $L$ que foram estudadas. Com relação aos resultados obtidos para essas densidades, não efetuamos nenhum processo de extrapolação para o sistema bidimensional infinito.

A utilidade das densidades vem do fato de que é possível estabelecer diferenças qualitativas entre as fases. Por exemplo, para uma fase não-polimerizada as densidades devem ser próximas de zero, ao passo que, numa fase polimerizada altamente compactada, elas devem ter valores altos, próximos de 1. Isto ajuda na identificação das fases e pode colaborar na classificação das transições que ocorrem entre uma fase e outra. Devemos notar também que as densidades dependem apenas do maior autovalor da matriz de transferêneia, sendo independentes das hipóteses de renormalização fenomenológica, de finite-size scaling on de invariância conforme, de modo que os cálculos que envolvem as densidades podem ser usados para corroborar os que são obtidos através dessas técnicas.

No próximo capítulo, os resultados para os dois modelos interagentes são apresentados e discutidos. 


\section{Capítulo 3}

\section{RESULTADOS E DISCUSSÕES}

Neste capítulo, apresentamos e cliscutimos os resultados obtidos para os modelos definidos no capítulo anterior.

Primeiramente, é preciso dizer que esperávamos que os diagxamas de fases dos dois modelos interagentes, tanto o de ligações interagentes como o de monômeros interagentes, apresentassem três fases. Uma delas é a fase não-polimerizada (NP), na qual a densidade de monômeros pertencentes ao polímero é nula no limite termodinâmico. Nessa fase, o polímero não se encontra polimerizado, e isso ocorre, em geral, na região em que a atividade $x=e^{\beta \mu}$ é pequena.

A segunda fase que deve aparecer no diagrama de fases é a fase polimerizada usual (PU), na qual a densidade de sítios ocupados por monômeros varia entre zero e 1 , sendo uma função dos parâmetros $x$ e $y$, no caso de ligaçóes interagentes, ou de $x$ e $z$, no modelo de monômeros interagentes. A transição entre essa fase e a não-polimerizada deve ser de segunda ordem pelo menos para valores de $y$ ou $z$ pequenos, e um ponto dessa fronteira de fases, o qual corresponde ao caso sem interação, quando então $y=1$ (ligações interagentes) ou $z=1$ (monomeros interagentes), é bern conhecido e vale $x_{c}=0,37905227 \pm 0,00000012$ $[1,3]$. Nossos dados devem estar de acordo com esse resultado e essa é uma verificação que 
temos que fazer.

Ainda com relação à segunda fase e a fronteira entre ela e a fase não-polimerizada, podemos lembrar um trabalho de Nienhuis [4] que estabelece que os expoentes críticos de algumas transições de fase podem ser obtidos de forma exata. Nesses casos, os expoentes críticos $\nu$ e $\eta$ são dados pelas expressões

$$
\frac{1}{\nu}=4-2 t
$$

c

$$
2-\frac{\eta}{2}=1+\frac{3}{4 t}+\frac{t}{4}
$$

que dependem de um parâmetro $t$, que deve estar no intervalo $1 \leq t \leq 2$. Para o caso de polímeros lineares não-interagentes, o que corresponde a $y=1$ ou $z=1$, sabemos que $t=\frac{4}{3}$, de modo que os expoentes $\nu$ e $\eta$ valem $\nu=\frac{3}{4} \mathrm{e} \eta=\frac{5}{24}$. Assim, ao calcularmos os expoentes críticos na fronteira entre as fases não-polimerizada e polimerizada usual para $y$ ou $z$ iguais a um devemos obter esses valores para os expoentes. Isso constitui um novo teste para verificar a correção de nossos dados. Se a transição entre as fases não-polimerizada e polimerizada usual for uma transição de segunda ordem normal, os expoentes críticos devem permanecer os mesmos ao longo de toda a fronteira. Caso a transição seja de algum tipo especial, como uma transição de Kosterlitz-Thouless [18], então os expoentes podem não ser constantes em toda a fronteira. Para verificar o tipo de transição, temos que calcular os expoentes para algum outro valor de $y$ ou $z$ além de $y=z=1$.

Por fim, a terceira fase que deve existir no diagrama de fases é caracterizada pelo fato de o polímero estar numa configuração muito densa, de forma que a densidade de sítios ocupados por ele vale 1. Neste caso, todos os sítios da rede pertencem ao polímero, e ocorre uma maximização do número de interações entre as ligações ou entre os sítios. Essa fase é 
chamada fase de polimerização densa (PD), e aparece também noutros modelos $[9,14]$. A transição entre a fase não-polimerizada e a fase densa deve ser de primeira ordem, já que a densidade de sítios ocupados é descontínua, e passa de forma descontínua de um valor nulo, dentro da fase não-polimerizada, para um valor 1 , dentro da fase densa. Já a transição entre as duas fases polimerizadas precisa ser estudada em detalhes, pois pode ocorrer que numa parte da fronteira a transição seja de um tipo enquanto noutra parte a transição pode ser de um tipo diferente.

Como foi dito nos capítulos anteriores, nós estudamos tiras de largura $L$ e tamanho infinito para poder obter estimativas clas fronteiras de fases, expoentes críticos e valores de densidades para os dois modelos interagentes na rede quadrada. Para tanto, comparamos duas tiras, de larguras $L$ e $L^{\prime}$, sendo que escolhemos $L^{\prime}=L+2$. Com isso, obtivemos resultados para os pares de larguras 1-3, 2-4, 3-5, 4-6 e 5-7. Como o número de configuraçoes para as matrizes de transferência cresce muito rapidamente corn $L$ (veja a tabela A.1 do apêndice A), não foi possível ir além de $L=7$. Vejamos então os resultados obticlos, começando como modelo de ligações interagentes.

\subsection{Resultados para o Modelo de Ligações Interagentes}

Para o modelo de ligações interagentes obtivemos estimativas para o diagrama de fases para os pares de larguras 1-3, 2-4, 3-5, 4-6 e 5-7, os quais estão apresentados na figura 3.1.

Nesses diagramas, vemos que existem três regióes ou fases distintas. Para valores pequenos de $x$, aparece a fase não-polimerizada (NP). Para valores de $x$ um pouco maiores, existem duas fases polimerizadas. Quando y é pequeno, temos a fase polimerizada usual (PU). Entretanto, à medida que $y$ aumenta, para um valor fixo de $x$, a fase polimerizada usual sofre uma 


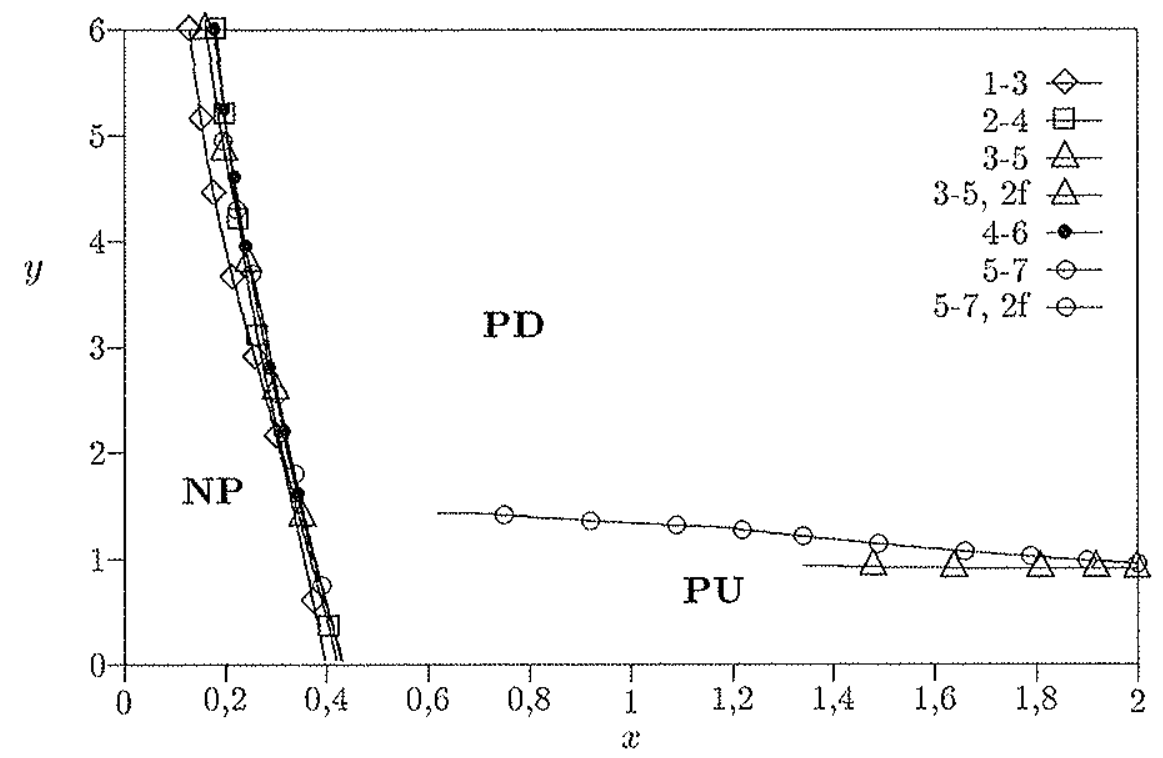

Figura 3.1: Diagramas de fases para o modelo de ligaçôes interagentes. A fronteira entre as fases polimerizadas é indicada por 2f. NP é a fase não-polimerizada, $P U$ é a fase polimerizada usual e PD é a fase polimerizada densa.

transição para a fase polimerizada densa $(\mathbf{P D})$, na qual o polímero apresenta-se colapsado. É interessante notar que somente quando usamos larguras ímpares é que obtemos estimativas para a fronteira entre as fases polimerizadas, que chamamos de segunda fronteira. A fronteira que envolve a fase não-polimerizada e as polimerizadas é a primeira fronteira. Para as larguras pares não encontramos soluções para a equação 2.3 ,

$$
\frac{\xi_{L}\left(x_{c}\right)}{L}=\frac{\xi_{L^{\prime}}\left(x_{c}\right)}{L^{\prime}}
$$

que é a expressão que fornece as estimativas para os pontos críticos.

Na figura 3.1, vemos que a fronteina entre as fases polimerizadas aproxima-se, com o aumento do tamanho das larguras, da fronteira entre a fase não-polimerizada e as fases polimerizadas. Isso é característico de finite-size scaling. No sistema infinito essas fronteiras devem se encontrar e nesse local deve ocorrer algum tipo especial de ponto crítico, cujas 
características dependem de quais são os tipos de transição de fases que ocorrem nas vizinhanças desse ponto. Para auxiliar na determinação de como se processam as transições de fases, calculamos as densidades de sítios ocupados e de interações entre as ligações e também as derivadas dessas densidades. Porém, antes de apresentarmos os resultados para as densidades vamos discutir um pouco mais sobre o procedimento operacional empregado no cálculo das fronteiras.

Como dissemos na seção 2.3.2, para achar as estimativas para as fronteiras de fases precisamos fixar um valor de $y$ (ou $z$, no caso de sítios interagentes) e procurar os pontos fixos $x_{c}$ que fazem com que a expressão 2.3 torne-se verdadeira. Mas, para usar essa equação precisamos calcular o comprimento de correlação $\xi_{L}$ para as duas larguras que estamos comparando. Para isso, necessitamos dos dois maiores autovalores da matriz de transferencia, pois o comprimento de correlação é dado pela equação 1.13 ,

$$
\xi_{L}^{-1}=-\ln \left[\frac{\lambda_{2}(L)}{\lambda_{1}(L)}\right]
$$

onde $\lambda_{2}$ é o segundo maior autovalor da matriz, e $\lambda_{1}$ é o maior autovalor. Esses dois maiores autovalores estão associados às fases, e as representam.

Na determinação dos elementos da matriz de transferência, supusemos que existe um polímero que atravessa toda a rede. Entretanto, existe uma outra possibilidade com a qual não nos preocupamos. Ela corresponde à rede vazia, ou seja, nenhum polínero atravessa as tiras de largura $L$ de um lado ao outro. Essa configuração é característica da fase não-polimerizada e precisaria ser contada nos cálculos. Porém, há uma explicação para o nosso aparente descuido. Vamos representar a configuração vazia por $|0\rangle$. Para que não exista nenhum polímero atravessando a rede, é preciso que em cada iteração cla matriz de transferência o estado obtido na coluna considerada seja novamente aquele que corresponde à configuração vazia, ou seja, 
ao estarlo $|0\rangle$. Assim, o elemento de matriz de transferência associado às configuraçóes $|0\rangle$ é

$$
\langle 0|T| 0\rangle=1
$$

Conseqüentemente, paxa que não exista um polímero terminando dentro da rede, ou então começando dentro dela, os elementos de matriz que envolvem o estado vazio e qualquer outro estado $|i\rangle$, que não seja $|0\rangle$, valem

$$
\langle 0|T| i\rangle=\langle i|T| 0\rangle=0, \quad i=1, \ldots, N
$$

onde $N$ é o número de estados em que o polímero passa pela rede. Assim, a matriz de transferência completa tem mais uma linha e uma coluna, que estão associadas ao estado $|0\rangle$. No entanto, a matriz assim formada é uma matriz bloco-diagonal, sendo que um dos blocos tem um único elemento $(\langle 0|T| 0\rangle=1)$, e o outro bloco é a matriz de transferência propriamente dita. O autovalor associado ao bloco não-polimerizado vale 1 e é independente dos valores de $x$ e $y$ (ou $z$, no modelo de monomeros interagentes), ao passo que os antovalores da matriz de transferência dos estados polimerizados precisam ser calculados numericamente.

Se os dois maiores autovalores da matriz de transferência são maiores que 1, estamos na fronteira entre as fases polimerizadas e obtemos estimativas para essa fronteira. À medicla que $a$ diminui, o segundo maior autovalor se aproxima de 1. Quando este segundo maior autovalor tornamse menor do que 1 , não podemos mais utilizá-lo já que devemos sempre considerar os dois maiores autovalores da matriz de transferencia. Nesse caso, precisamos comparar o maior autovalor da matriz e o autovalor da fase não-polimerizada (que vale 1), e achamos estimativas para a fronteira entre essa fase e as fases polimerizadas. Isso explica o fato de a segunda fronteira terminar ex algum valor de $x$, observando-se o diagrama da direita para a esquerda. Note também que, quando $L$ aumenta, o segundo maior autovalor da matriz de transferencia se aproxima de 1 mais lentamente e, por isso, a fronteira entre as 
fases polimerizadas chega mais perto da outra.

Uma questão relevante refere-se aos tipos de transição que ocorrem entre as fases. Entre as fases não-polimerizada e polimerizada densa a transição deve ser de primeira ordem já que passamos de uma fase em que a densidade de sítios ocupados por um polímero e a densidade de interações entre ligações valem, respectivamente, $\rho_{x}=0$ e $\rho_{y}=0$, para uma fase en que essas grandezas têm os valores $\rho_{x}=1$ e $\rho_{y} \approx 1$ (no sistema bidimensional infinito). Como ocorre uma transição descontínua, ela é de primeira ordem.

A transição entre a fase não-polimerizada e polimerizada usual deve ser de segunda ordern, considerando que, pelo menos num ponto dessa fronteira, o qual ocorre quando $y=1$, a transição é de segunda ordem $[1,3]$.

Com relação à fronteira entre as fases polimerizadas, a situação é mais complicada. Teoricamente, a renormalização fenomenológica só deveria funcionax apenas para transições de segunda ordem. Com base nisso, essa fronteira seria de segunda ordem. Entretanto, noutros modelos a renormalização fenomenológica também forneceu estimativas para transições de primeira ordem $[9,23]$. Além disso, a fronteira entre a fase não-polimerizada e a fase densa também é de primeira ordem, e isso não nos impediu de obter estimativas para essa fronteira para o modelo de ligações interagentes ou para o modelo de monômeros interagentes. Assim, não podenos afirmar, apenas baseados na renormalização fenomenológica, quais os tipos de transição que ocorrem entre as fases polimerizadas. Por causa disso calculamos as densidades de sítios ocupados por monômeros e de interações entre ligaçóes, além das derivadas dessas densidades, para extrair mais dados a respeito dessas transiçóes e para confirmar as características físicas das fases. Esses dados são discutidos a seguir. É importante dizer que os cálculos das densidades e derivadas das densidades dependem apenas do conhecimento da matriz de transferência. Assim, eles não dependem das hipóteses de renormalização fenomenológica ou de finite-size scaling. Portanto, os resultados obtidos são independentes 
e também servem para verificar a correção dos dados extraídos através da renormalização fenomenológica.

Da figura 3.1 vernos que, se fixarmos um certo valor de $x$ e calcularmos as densidades de sítios $\rho_{x}$ e de interaçóes entre ligaçoes $\rho_{y}$ variando o valor de $y$, estaremos varrendo o diagrama de fases no sentido vertical. Nesse caso, à medida que $y$ aumenta passaremos de uma fase para outra, dependendo do $x$ escolhido. Assim, consideramos alguns valores de $x$ relevantes e efetivamos os cálculos.

Nossa primeira escolha para $x$ foi $x=0,2$. Observando a figura 3.1 notamos que para valores pequenos de $y$ estamos dentro da fase não-polimerizada, ao passo que, com o aumento de $y$, ocorre uma transição para a fase polimerizada densa. Assim, as densidades $\rho_{x}$ e $\rho_{y}$ devem passar de valores próximos de zero para valores próximos de um de uma forma abrupta. As figuras 3.2 e 3.3 apresentam as densidades para $x=0,2$.

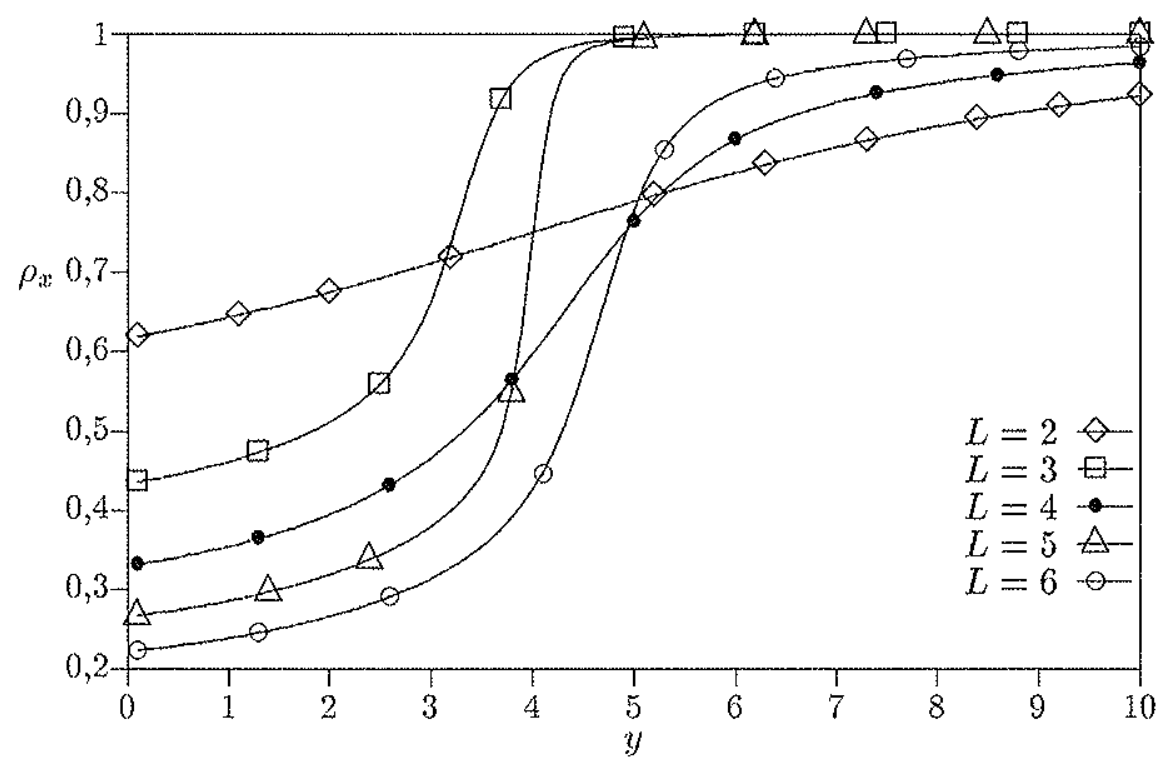

Figura 3.2: Densidade $\rho_{x}$ de sítios ocupados para $x=0,2$. 


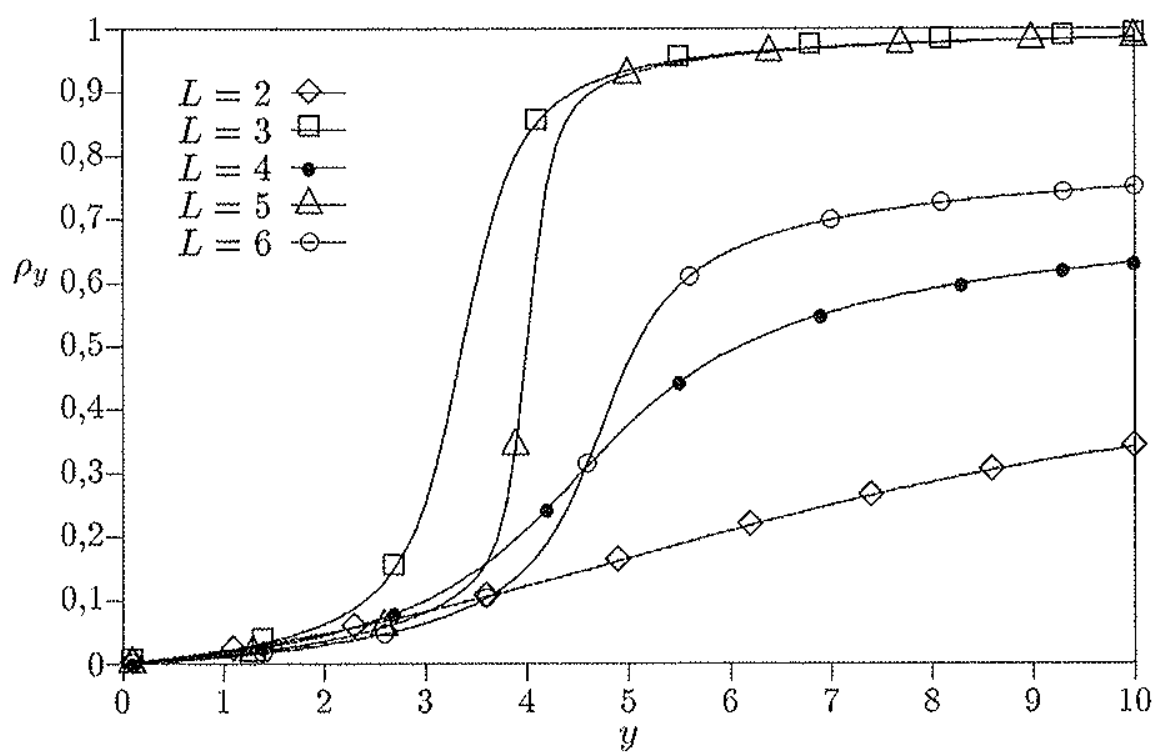

Figura 3.3: Densidade $\rho_{y}$ de interações entre as ligaçóes para $x=0,2$.

Sobre essas figuras podemos fazer alguns comentários. Primeiro, observando a forma dos gráficos vemos que há uma região, em torno de $y=4$, na qual as densidades passam de valores pequenos para valores próximos da unidade. Além disso, com o aumento do tamanho da largura $L$ essa região torna-se mais estreita e a passagem de um regime para outro fica mais abrupta. Segundo, com o aumento de $L$ os valores de $\rho_{x}$ e $\rho_{y}$ se aproximam cada vez mais de zero quando $y$ é pequeno e cadla vez mais de 1 quando $y$ é suficientemente grande. Terceiro, observando os diagramas de fases da figura 3.1 vemos que a estimativa para a transição entre as fases não-polimerizada e polimerizada densa para $x=0,2$ é realmente próxima de $y=4,5$. Outro fato interessante é que, se considerarmos apenas o conjunto formado pelas larguras pares on pelas ímpares, o comportamento exibido por um conjunto de larguras é ligeiramente diferente do apresentado pelo outro. Para as larguras ímpares, $\rho_{x}$ e $\rho_{y}$ tendem a 1 muito mais rapidamente do que para as pares, isto é, para valores de $y$ menores. Isso pode ser entendido se considerarmos que, para larguras pares, há frustração no modelo, já 
que o polímero começa na esquerda e termina na direita. Em cada coluna, necessariamente uma ligação vertical fica vazia nesse caso, ao passo que, numa largura ímpar isso não ocorre. Mas, nos dois casos o comportamento é monotônico com o aumento da largura, e assim, no limite $L \rightarrow \infty$ devemos ter um gráfico do tipo função degrau para as densidades de sítios e de interações entre ligações, sendo a localização do degrau o ponto crítico. Para valores de y menores do que o desse ponto, a fase é não-polimerizada, $\operatorname{com} \rho_{x}=\rho_{y}=0$. Para valores de $y$ maiores do que o desse ponto, a fase é polimerizada densa, sendo que $\rho_{x}=1$ (o polímero atravessa todos os sítios da rede) e $\rho_{y} \approx 1$ (como o polímero atravessa todos os sítios da rede, o número de interações entre as ligações é maximizado, e a densidade $\rho_{y}$ é muito próxima de 1). Portanto, a transição entre as fases não-polimerizada e polimerizada densa é, de fato, de primeira ordem. Podemos reforçar essa afirmativa calculando a derivada de $\rho_{z:}$ e $\rho_{y}$, com relação a $y$. Se a transição é de primeira ordem existe uma descontinuidade nas densidades, e as derivadas dessas densidades apresentam alguma singularidade. A derivada da densidade de sítios em relação a $y\left(\frac{\partial p_{x}}{\partial y}\right)$ para $x=0,2$ é mostrada na figura 3.4 abaixo.

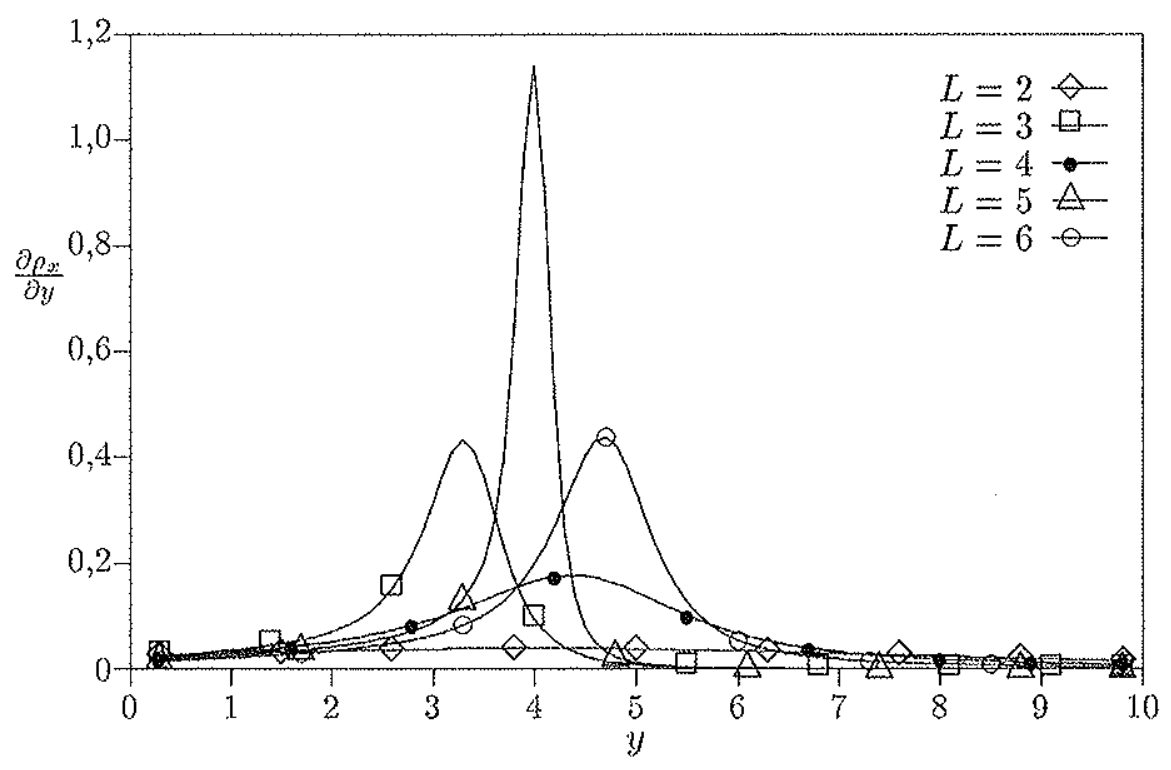

Figura 3.4: Derivada da densidade $\rho_{x}$ de sítios ocupados para $x=0,2$. 
Nessa figura, vemos que existe um pico que fica mais pronunciado à medida que a largura aumenta. Considerando apenas as larguras pares, vemos que a posição $y$ do pico fica aproximadamente a mesma, em torno de $y=4,5$, e que sua altura aumenta de forma mais lenta, mas constante, do que o pico das larguras ímpares. Para as larguras ímpares, o pico é mais pronunciado, mas ele se desloca para a direita em direção aos picos das larguras pares. Nos dois casos a localização dos picos concorda com o valor estimado para o ponto crítico obtido através dos gráficos das densidades e também mediante o diagrama de fases. A figura 3.5 apresenta o gráfico da derivada da densidade de interações entre ligaçóes em relação a $y\left(\frac{\partial \rho_{y}}{\partial y}\right)$ para $x=0,2$.

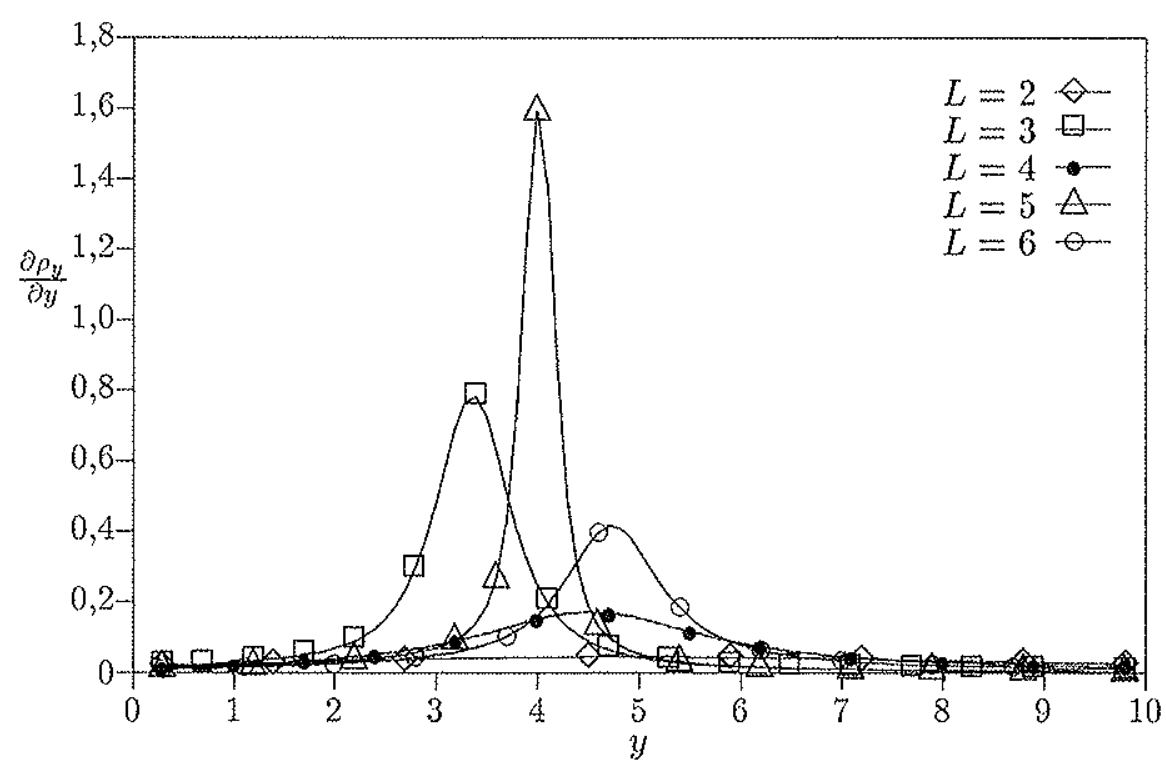

Figura 3.5: Derivada da densidade $\rho_{y}$ de interaçốes entre as ligaçốes para $x=0,2$.

Note, nessa figura, que o comportamento qualitativo é identico ao da figura 3.4 , inclusive no que se refere à posição do pico, em torno de $y=4,5$. Portanto, reunindo todos os dados, podemos afirmar: que a transição entre as fases não-polimerizada e polimerizada densa é de primeira orclem. 
Prosseguindo com o estudo das fases, vamos fixar o valor de $x$ em $x=0,4$. Observando os diagramas de fases dados pela figura 3.1 vemos que, nesse caso, estamos passando da fase polimerizada usual paxa a fase polimerizada densa, possivelmente passando ainda por uma pequena parte da fase não-polimerizada para $y \rightarrow 0$. Assim, este valor de $x$ é interessante porque podemos avaliar o que ocorre nas três fases. A densidade de sítios ocupados é apresentada na figura 3.6 .

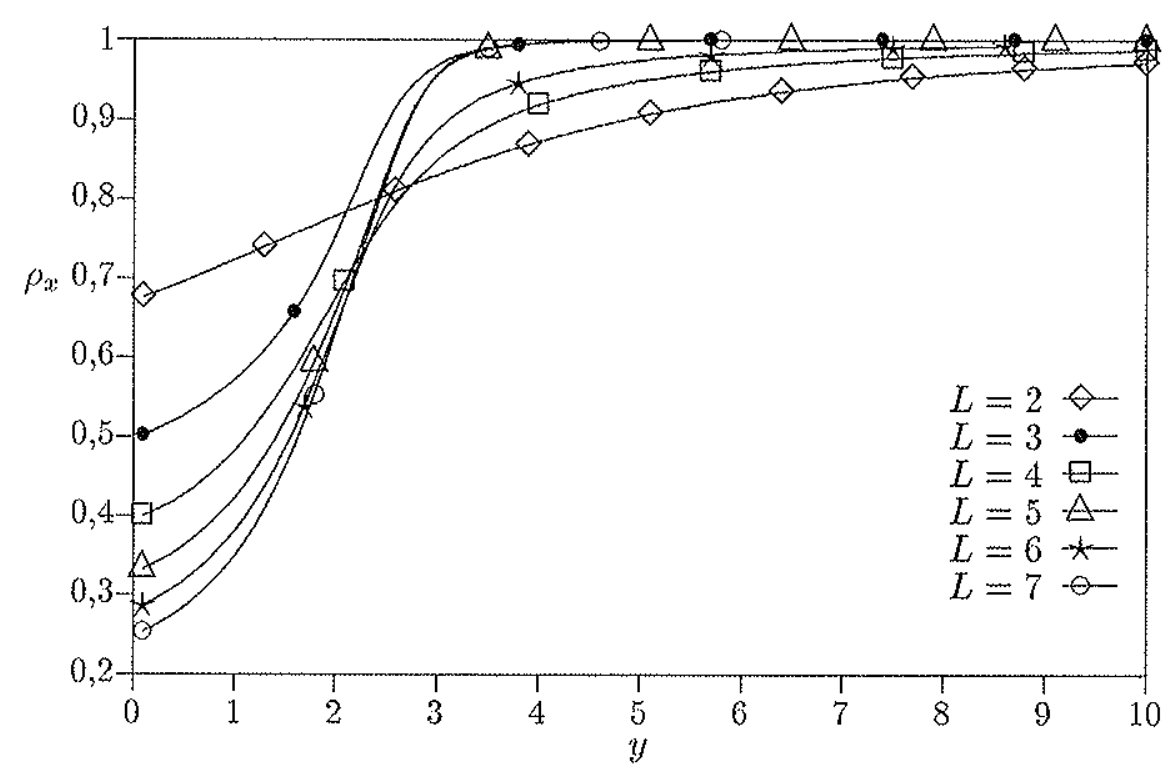

Figura 3.6: Densidade $\rho_{x}$ de sítios ocupados para $x=0,4$.

Nessa figura novamente percebemos que, com o aumento do tamanho da largura $L$, a densidade para valores pequenos de $y$ tende a um valor pequeno, próximo de zero. À medida que $y$ aumenta ocorre a mudança para os valores altos de $\rho_{x}$, e o modo pelo qual se processa essa mudança é parecido com o que ocorre quando $x=0,2$, como pode ser visto ao compararmos as figuras 3.2 e 3.6. A principal diferença quantitativa é que a transição agora acontece em torno de $y=2,0$. Observe que, se olharmos os diagramas de fases da figura 3.1 , veremos que essa transição corresponde a passarmos da fase polimerizada usual para a polimerizada densa. 
Como o ponto $x=0,4$ para valores de $y$ não muito maiores do que um é bastante próximo da fronteira de fases entre as fases não-polimerizada e polimerizada usual, a fase polimerizada usual deve ter uma densidade baixa de sítios ocupados pelo polímero, já que a transição entre as fases não-polimerizada e polimerizada usual é de segunda ordem, ou seja, a densidade não apresenta um salto, sendo uma função contínua. Sua derivada segunda é que deve apresentar alguma singularidade. Vejamos agora a densidade de interações entre ligações, mostrada na figura 3.7 .

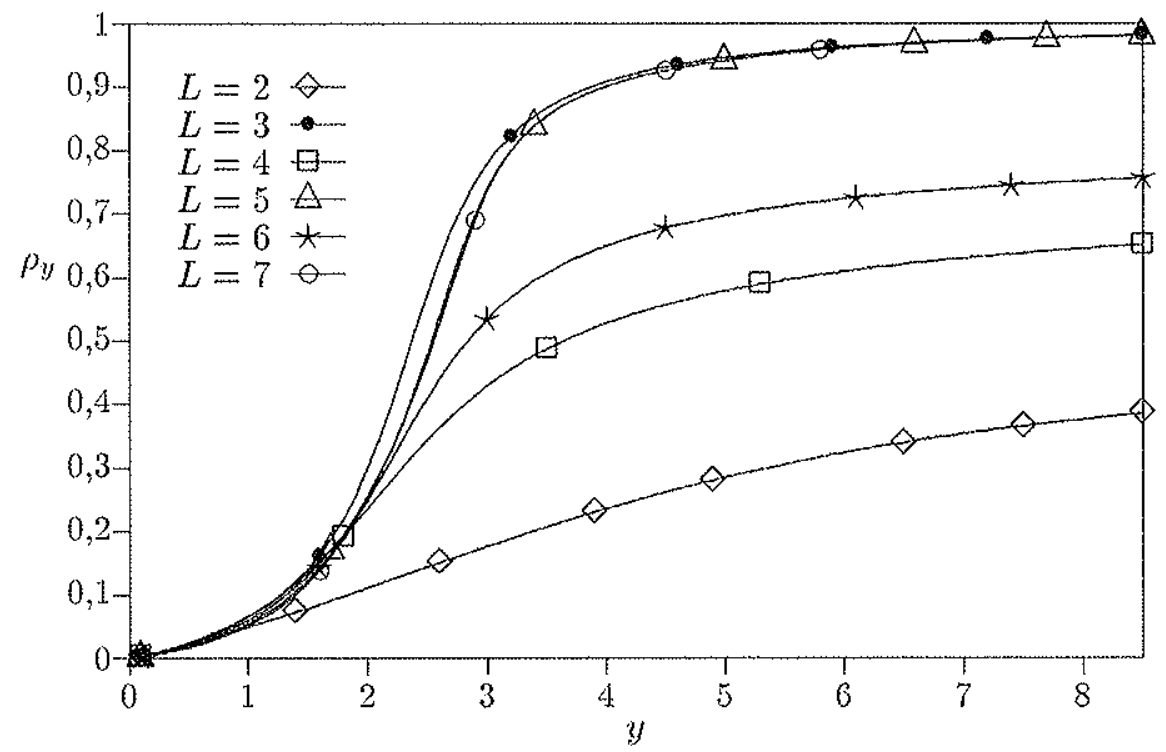

Figura 3.7: Densidade $\rho_{y}$ de interacões entre ligações para $x=0,4$.

Observando as figuras 3.3 e 3.7 , vemos que elas são qualitativamente muito semelhantes. Quantitativamente, a principal diferença ocorre na região em que ocorre a transição, já que para $x=0,2$ ela ocorre próxima a $y=4,5$, ao passo que, para $x=0,4$ ela acontece em torno de $y=2,0$. Nos dois casos, as larguras podem ser separadas em conjuntos pares e ímpares, e os comportamentos desses dois conjuntos são ligeiramente diferentes, mas ambos são monotônicos. As larguras pares tendem a $\rho_{y} \approx 1$ mais lentamente do que as ímpares, 
embora de forma continuada. As larguras ímpares atingem os valores elevados de $\rho_{y}$ quase imediatamente após a transição. Vejamos agora o que ocorre com a derivada de $\rho_{x}$, cujo gráfico é apresentado na figura 3.8 .

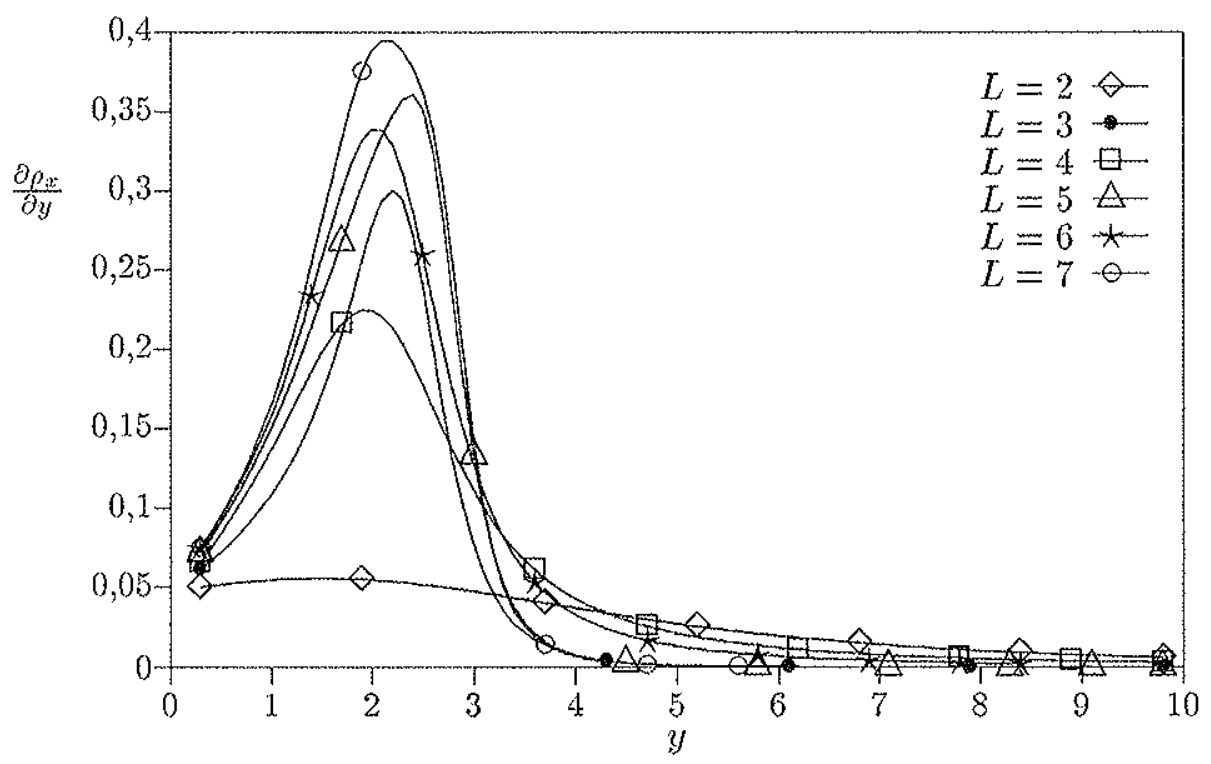

Figura 3.8: Derivada da densidade $\rho_{x}$ de sítios ocupados para $x=0,4$.

A derivada da densidade $\rho_{x}$ apresenta um comportamento semelhante ao que ocorre na figura 3.4 , na qual $x=0,2$. Também existe um pico na derivada, cuja altura aumenta com o aumento da largura. Considerando separadamente as larguras pares ou ímpares vemos que o comportamento dos gráficos é monotónico e o pico fica localizado em torno de $y=2,0$, concordando com a estimativa feita a partir das densidades. Vejamos agora a derivada da densidade de interações entre ligações $\rho_{y}$, cujo gráfico é apresentado na figura 3.9 . 


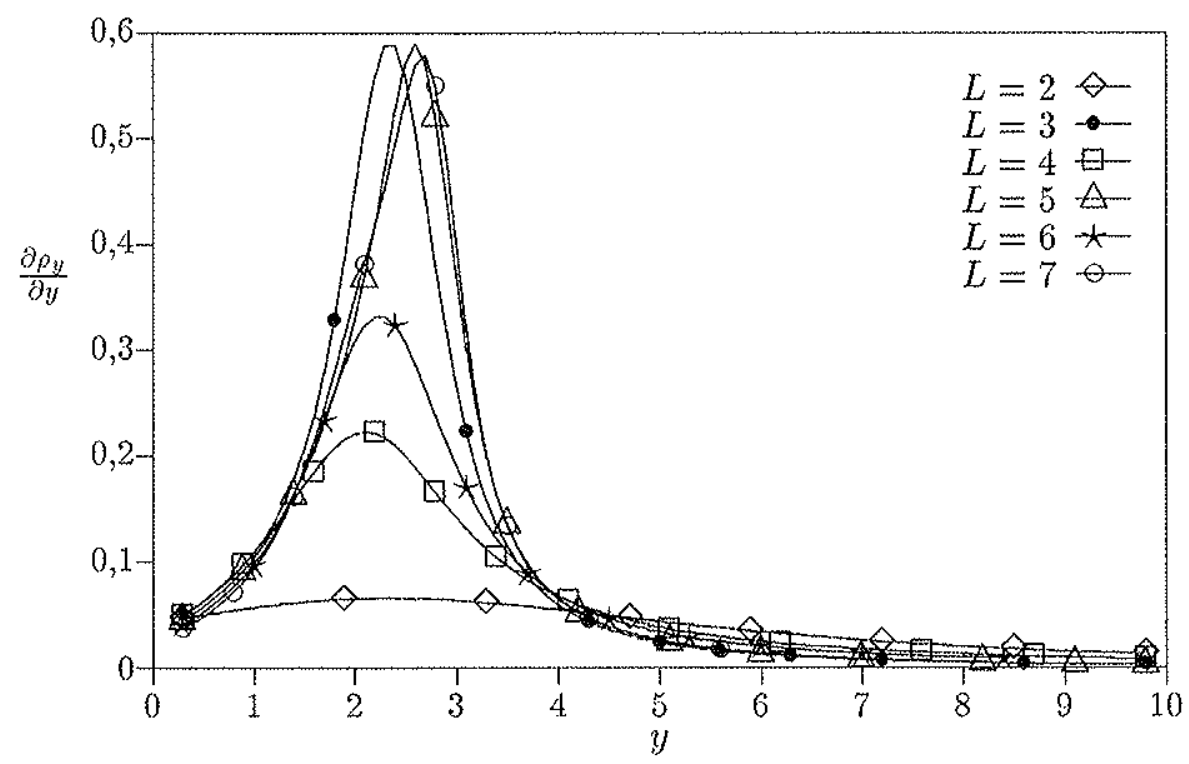

Figura 3.9: Derivada da clensidacle $\rho_{y}$ de interações entre ligações para $x=0,4$.

Observando a figura, venos que o comportamento qualitativo é o mesmo que ocorre para $x=0,2$. Assim, reunindo todos os resultados obtidos, chegamos à conclusão que, para $x=$ 0,4, a transição entre as fases polimerizada usual e polimerizada densa é de primeira ordem, e ocorre próximo ao ponto $y=2,0$.

Aqui é interessante lembrar o diagrama de fases do modelo de ligações interagentes estudado na rede de Husimi [14]. Esse diagrama de fases apresenta três fases, que são a fase não-polimerizada, a fase polimerizada usual e a fase polimerizada densa. A transição entre as fases polimerizadas é de primeira ordem até un certo valor de $x$, quando então temos um ponto tricrítico e a transição passa a ser de segunda ordem. A transição entre a fase não-polimerizada e a fase polimerizada usual é de segunda ordem, como no nosso caso, e a transição entre a fase não-polimerizada e a fase polimerizada densa é de primeira ordem, também como ocorre conosco. A transição entre a fase não-polimerizada e a fase polimerizada usual termina 
num ponto crítico terminal, que corresponde ao ponto $\theta$ desse modelo.

Como os dois modelos têm muitas características em comum até o momento, é interessante verificar se a fronteira entre as fases polimerizadas torna-se de segunda ordem para algum valor de $x$. Para verificar isso, calculamos as densidades para um valor grande de $x$, correspondente a $x=2,4$. A figura 3.10 apresenta a densidade de sítios para $x=2,4$.

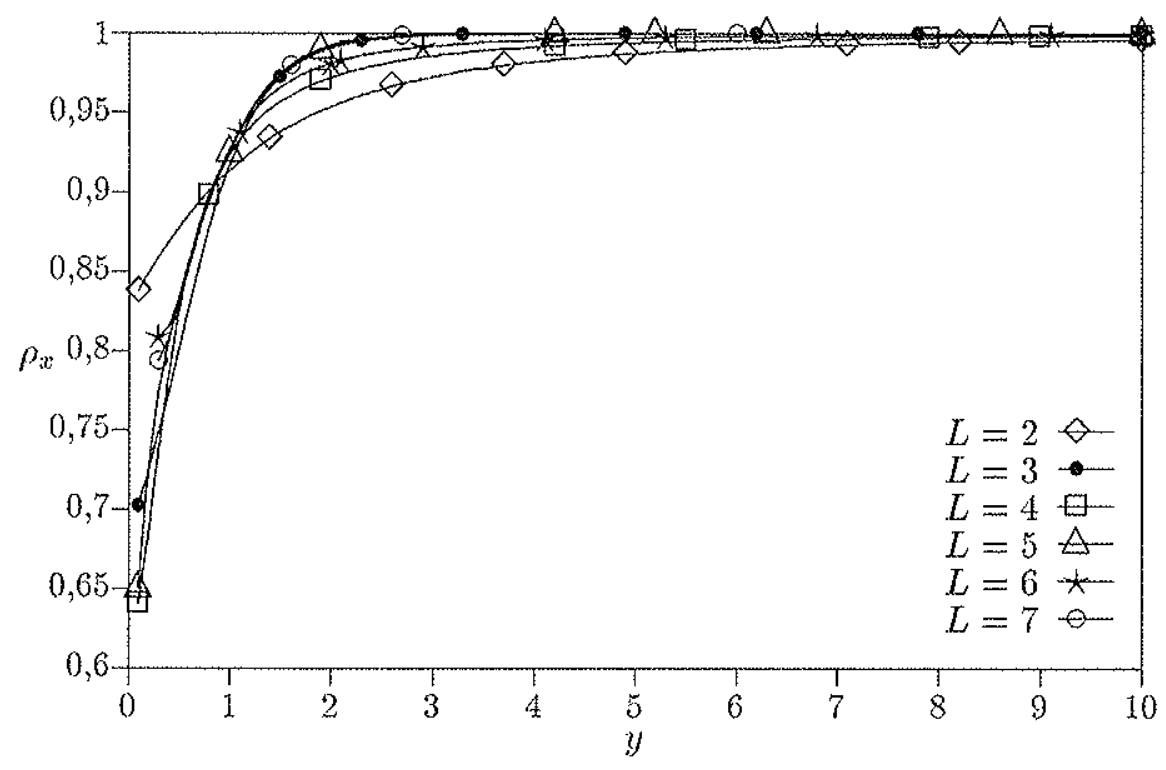

Figura 3.10: Densidade $\rho_{v}$ de sítios ocupados para $x=2,4$.

Comparando essa figura com as figuras 3.2 e 3.6 vemos que os comportamentos qualitativos são bastante diferentes. Na figura 3.10 não aparece mais a transição "abrupta" que existe nos gráficos para $x=0,2 \mathrm{e} x=0,4$. A densidade inicia já num valor alto, em torno de $\rho_{x}=0,7$, e aumenta continuamente até atingir a saturação, quando então $\rho_{x}=1$. A transição de uma fase polimerizada para a outra é suave, e deve ser de segunda ordem, para $x=2,4$. Vejamos agora o gráficos da densidade de interaçôes entre ligações, apresentado na figura 3.11. 


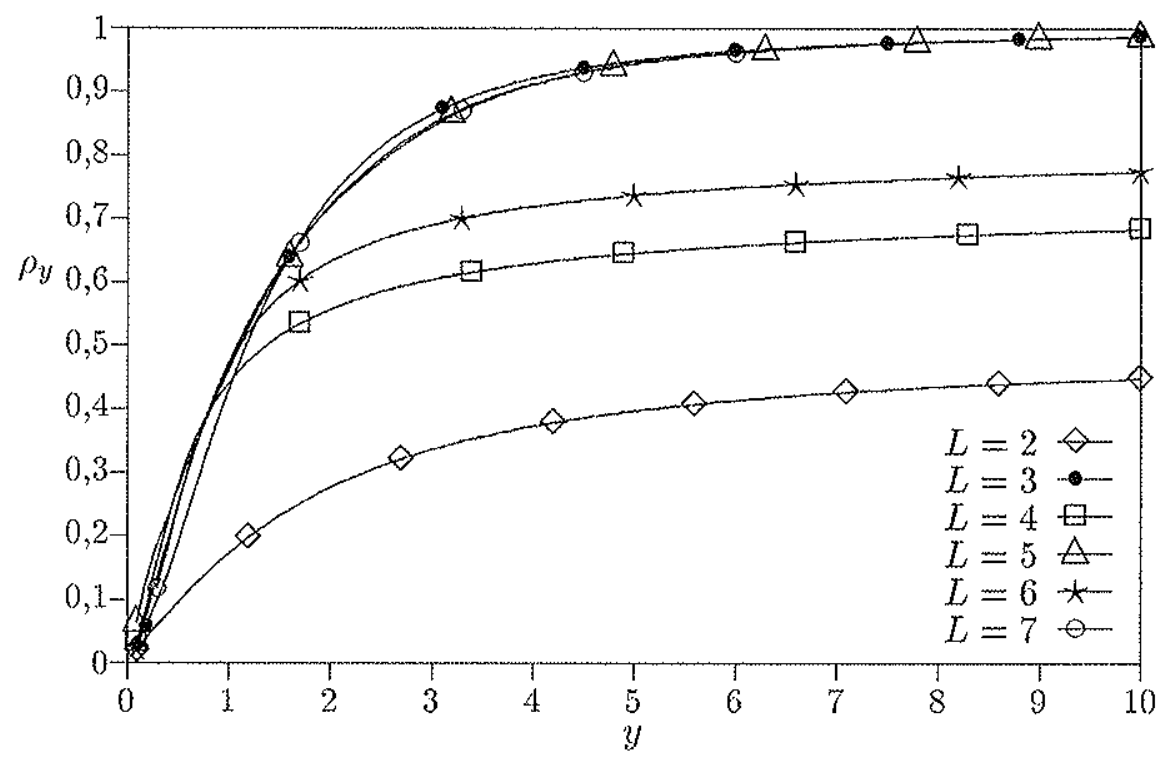

Figura 3.11: Densidade $\rho_{y}$ de interações entre ligaçóes para $x=2,4$.

É interessante notar, nessa figura, que a densidade de interações entre ligações inicia num valor bem pequeno, já que, quando $y \rightarrow 0$, a interação entre as ligações é extremamente repulsiva. Isso porque $y=e^{-\beta \epsilon}$ e, quando $\epsilon>0$, a interação é repulsiva. Assim, para termos um valor de $y$ próximo de zero, $\epsilon$ deve tender ao infinito, o que faz com que seja muito difícil uma ligação ficar próxima de outra. Assim, o número de interações entre as ligaçóes é muito pequeno, apesar de o polímero preencher razoavelmente a rede, considerando que $\rho_{x} \approx 0,6$. Quando $y$ aumenta e fica maior do que um, a interação torna-se atrativa e $\rho_{y}$ tende ao valor de saturação. Observe também que o comportamento das larguras pares é qualitativamente diferente do comportamento das ímpares, mas ambos são monotônicos.

Para reforçar a idéia de que a transição entre as fases polimerizadas para $x=2,4$ é de segunda ordem calculamos as derivadas das densidades. A figura 3.12 apresenta a derivada de $\rho_{x}$. 


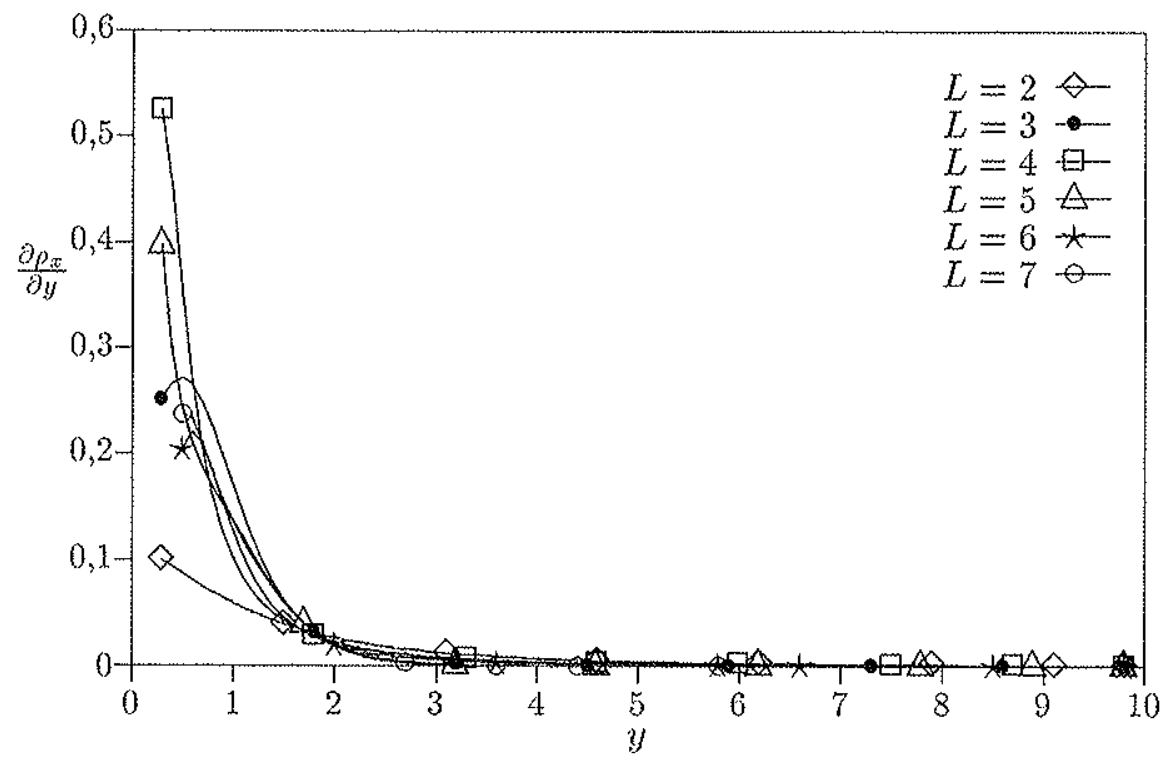

Figura 3.12: Derivada da densidade $\rho_{x}$ de sítios ocupados para $x=2,4$.

Observe que o comportamento da derivada de $\rho_{v}$ para $x=2,4$ é diferente daquele apresentado nas figuras 3.4 e 3.8. O gráfico não apresenta a formação de um pico bem definido como ocorre nas transições de primeira ordem. Quando $y$ aumenta, a dexivada tende a zero, já que a fase polimerizada densa tem uma densidade constante de sítios ocupados $\left(\rho_{x}=1\right)$. Vejamos agora o gráfico da derivada da densidade de interações entre sítios, mostrada na figura 3.13. 


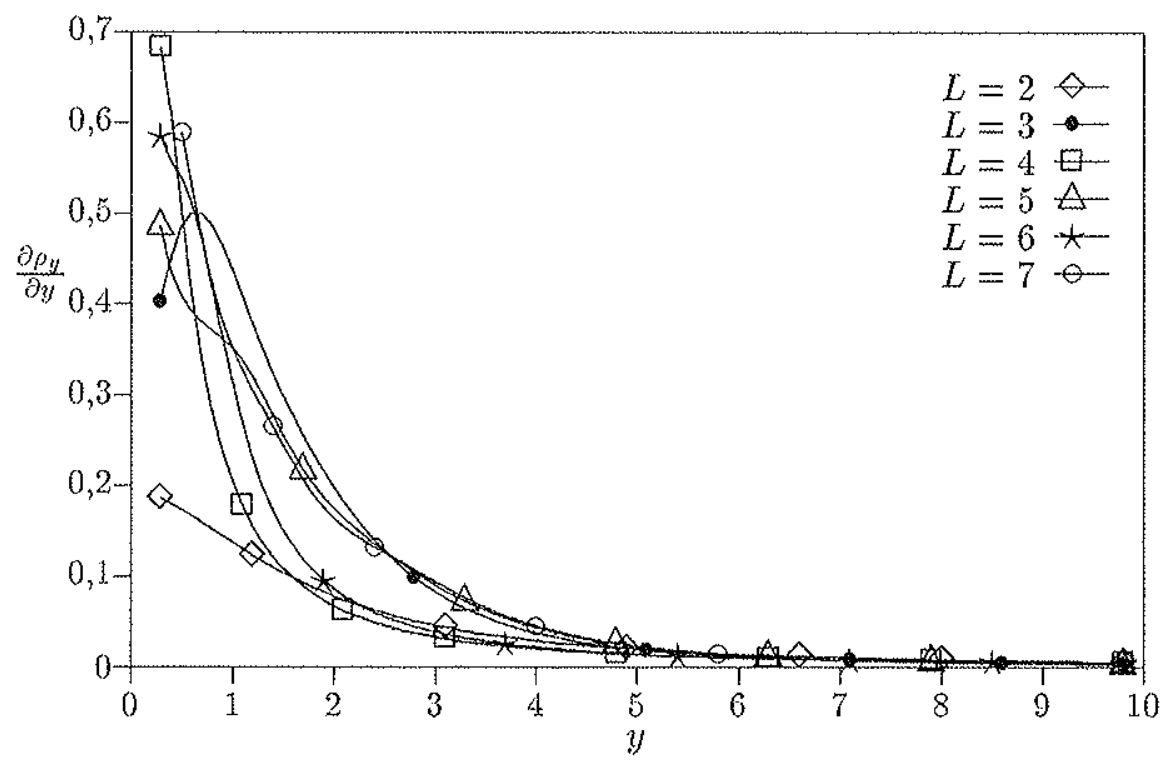

Figura 3.13: Derivada da densidade $\rho_{y}$ de interações entre ligaçoes para $x=2,4$.

Comparando essa figura com as figuras 3.5 e 3.9 , vemos que os comportamentos são diferentes. Reunindo todos os dados, concluámos que a transição entre as fases polimerizadas, para $x=2,4$, é de segunda ordem.

Como a transição entre as fases polimerizadas começa sendo de primeira ordem e alterna para uma transição de segunda ordem, em algum ponto dessa fronteira existe um ponto crítico com características especiais. Esse ponto crítico é um ponto tricrítico (PTC) é interessante poder obtê-lo de alguma forma. Além disso, a fronteira de segunda ordem que existe entre as fases não-polimerizada e polimerizada usual termina na fronteira de primeira ordem que existe entre as fases polimerizadas e que continua na fronteira entre a fase não-polimerizada e a fase polimerizada densa. Assim, no ponto onde a fronteira de segunda ordem termina, que é o ponto $\theta$, existe outro ponto crítico com características especiais. Nesse caso, o ponto é um ponto crítico terminal (PCT). 
Para determinar pontos críticos especiais, uma idéia é utilizar a renormalização fenomenológica de très larguras [8], que consiste em achar pontos $\left(x^{*}, y^{*}\right)$ que satistaçam a relação

$$
\frac{\xi_{L}\left(x^{*}, y^{*}\right)}{L}=\frac{\xi_{L^{\prime}}\left(x^{*}, y^{*}\right)}{L^{\prime}}=\frac{\xi_{L^{\prime \prime}}\left(x^{*}, y^{*}\right)}{L^{\prime \prime}}
$$

que pode ser escrita como o sistema de equaçöes

$$
\left\{\begin{array}{l}
\frac{\xi_{L}\left(x^{*}, y^{*}\right)}{L}=\frac{\xi_{L^{\prime}}\left(x^{*}, y^{*}\right)}{L^{\prime}} \\
\frac{\xi_{L}\left(x^{*}, y^{*}\right)}{L}=\frac{\xi_{L^{\prime \prime}}\left(x^{*}, y^{*}\right)}{L^{\prime \prime}} \\
\frac{\xi_{L^{\prime}}\left(x^{*}, y^{*}\right)}{L^{\prime}}=\frac{\xi_{L^{\prime \prime}}\left(x^{*}, y^{*}\right)}{L^{\prime \prime}}
\end{array} .\right.
$$

Assim, é preciso que o ponto $\left(x^{*}, y^{*}\right)$ pertença, ao mesmo tempo, às estimativas obtidas para as fronteiras de fases para os pares $L-L^{\prime}$ e $L^{\prime}-L^{\prime \prime}$, ou seja, as fronteiras precisam se cruzar nesse ponto. Observando os diagramas de fases apresentados na figura 3.1 vemos que para a segunda fronteira, que ocorre entre as fases polimerizadas, temos apenas duas estimativas, referentes aos pares 3-5 e 5-7. Essas fronteiras não se cruzam em nenhum ponto. Logo, a renormalização fenomenológica de três larguras não pode ser usada para estimar a localização do ponto tricrítico. Entretanto, considerando novamente a figura 3.1 vemos que as estimativas para as fronteiras entre a fase não-polimerizada e as fases polimerizadas se cruzarn num ponto. Esse ponto é uma estimativa para o ponto crítico terminal e aqui sim podemos usar a renormalização fenomenológica de três larguras. O resultado é que o ponto critico terminal tem as coordenadas $x_{\mathrm{PCT}}=0,244 \pm 0,002$ e $y_{\mathrm{PCT}}=3,86 \pm 0,03$. Para efeito de comparação, o modelo de ligações interagentes na rede de Husimi tem um ponto crítico terminal localizado em $x \mathrm{PCT}=0,28053$ e $y_{\mathrm{PCT}}=6,35335$. Uma possível explicação para o valor menor obtido para a rede quadrada reside na diferença entre as geometrias das duas redes. Na rede quadrada, as interações entre as ligações são mais fáceis de ocorrer do que na 
rede de Husimi, o que permite que a fase densa seja obtida com atividades $x$ e $y$ menores na rede quadrada do que na rede de Husimi.

Para estimar o ponto tricrítico não podemos usar a renormalização fenomenológica de três larguras e, portanto, precisamos proceder de outro modo. Uma idéia é calcular as derivadas das densidades para valores entre $x=0,4$, em que a fronteira é de primeira ordem, e $x=2,4$, no qual ela é de segunda ordem, e verificar para que pontos ocorre uma mudança visível de comportamento nas derivadas. Esse método não é muito preciso mas é o único disponivel, e foi o que fizemos. Escolhemos a largura $L=5$ para fazer essa varredura. Para a derivada da densidade de sítios ocupados pelo polímero, os resultados estão apresentados na figura 3.14.

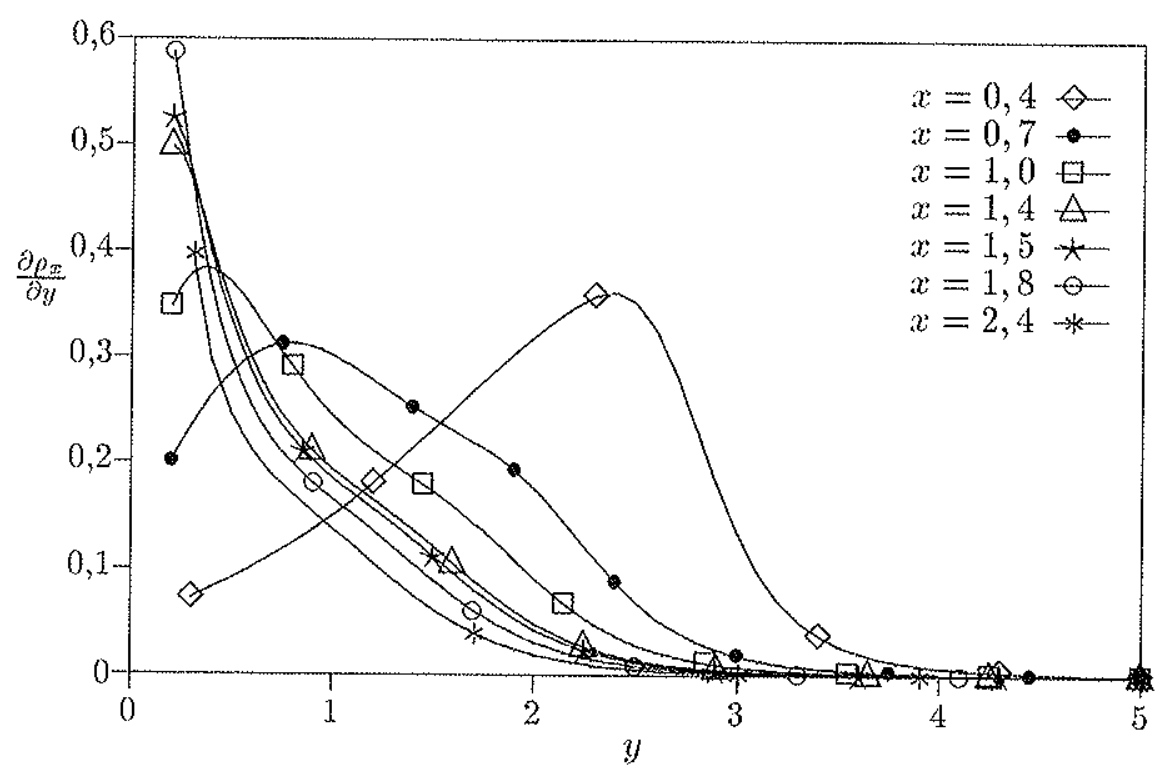

Figura 3.14: Derivada da densidade $\rho_{x}$ de sítios ocupados para alguns valores cle $x$, para estimaro ponto tricrítico.

Observando essa figura percebemos que a mudança de comportamento ocorre perto da região em que $x=1,5$. A figura 3.15 apresenta o gráfico da derivada da densidade de interaçóes 
entre as ligações.

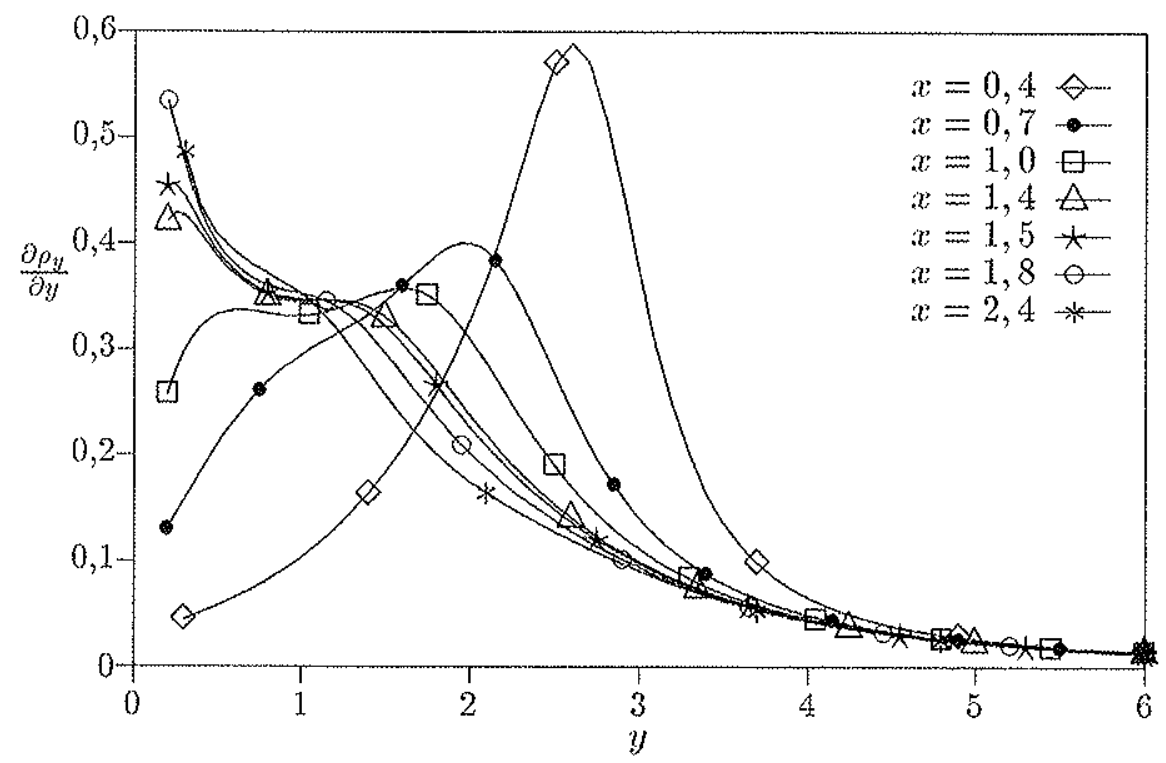

Figura 3.15: Derivada da densidade $\rho_{y}$ de interações entre ligaçôes para alguns valores de $x$, para estimar o ponto tricrítico.

Através das figuras 3.14 e 3.15 percebemos que o ponto tricrítico está próximo à região em que $x=1,5$, que é onde ocorre a mudança de comportamento nas derivadas. Assim, estimamos o ponto tricrítico como tendo as coordenadas $x_{\mathrm{PTC}}=1,5 \pm 0,1$ e $y_{\mathrm{PTC}}=1,1 \pm 0,1$. Novamente para uma comparação as coordenadas do ponto tricrítico para o modelo de ligações interagentes na rede de Husimi [14] são $x_{\mathrm{pTC}}=0,37628$ e yp $\mathrm{prC}=4,60326$.

Além de calcular as densidades e as derivadas das densidades e estimar o ponto crítico terminal e o ponto tricrítico, extrapolamos os valores obtidos para $x_{c}$ quando $y=1$. Esse é um ponto da fronteira entre as fases não-polimerizada e polimerizada usual e corresponde ao caso não-interagente, o qual tem un valor conhecido para $x_{c}\left(x_{c}=0,37905227 \pm 0,00000012\right.$ $[1,3])$. Os dados obtidos para as larguras $L$ estão na tabela 3.1 , que apresenta também o valor extrapolado usando o algoritmo VBS [19]. 
Tabela 3.1: Valores de $x_{c}$ para $y=1$, para o modelo de ligaçóes interagentes, juntamente com o valor extrapolado.

\begin{tabular}{|c|c|c|}
\hline$L$ & $L^{\prime}$ & $x_{c}$ \\
\hline 1 & 3 & 0,357100282 \\
\hline 2 & 4 & 0,369539639 \\
\hline 3 & 5 & 0,375076826 \\
\hline 4 & 6 & 0,377291276 \\
\hline 5 & 7 & 0,378185851 \\
\hline$\infty$ & & $0,37909 \pm 0,00004$ \\
\hline
\end{tabular}

Reunindo todos os dados obtidos podemos compor um esboço do diagrama de fases para o modelo de ligações interagentes na rede quadrada, o que é feito na figura 3.16 apresentada em seguida. Note que, como essa figura é apenas um esboço, ela é apresentada sem escalas.

Além de calcular o valor de $x_{c}$ para $y=1$, obtivemos também estimativas para os expoentes críticos $\nu$ e $\eta$ que caracterizam a fronteira entre as fases não-polimerizada e polimerizada usual, os quais são calculados através das expressões 2.4 e 2.5 que são, respectivamente,

$$
1+\frac{1}{\nu}=\frac{\ln \left[\frac{d \xi_{c}\left(x_{c}\right)}{d x} / \frac{d \xi_{L^{\prime}}\left(x_{c}\right)}{d x}\right]}{\ln \left(L / L^{\prime}\right)}
$$

e

$$
\eta \cong \frac{1}{\pi} \frac{L}{\xi_{L}\left(x_{c}\right)}
$$

lembrando que o expoente $\eta$ deve ser calculado, para cada largura, no valor de $x_{c}$ extrapolado para o sistema infinito $\left(x_{c}^{\infty}\right)$ e depois os valores obtidos são extrapolados para o sistema infinito. Os dados obtidos estão nas tabelas 3.2 e 3.3. Observe que os valores encontrados para $\nu$ e $\eta$ concordam bem com os valores esperados [4], que são $\nu=\frac{3}{4} e \eta=\frac{5}{24} \simeq 0,20833 \ldots$ 


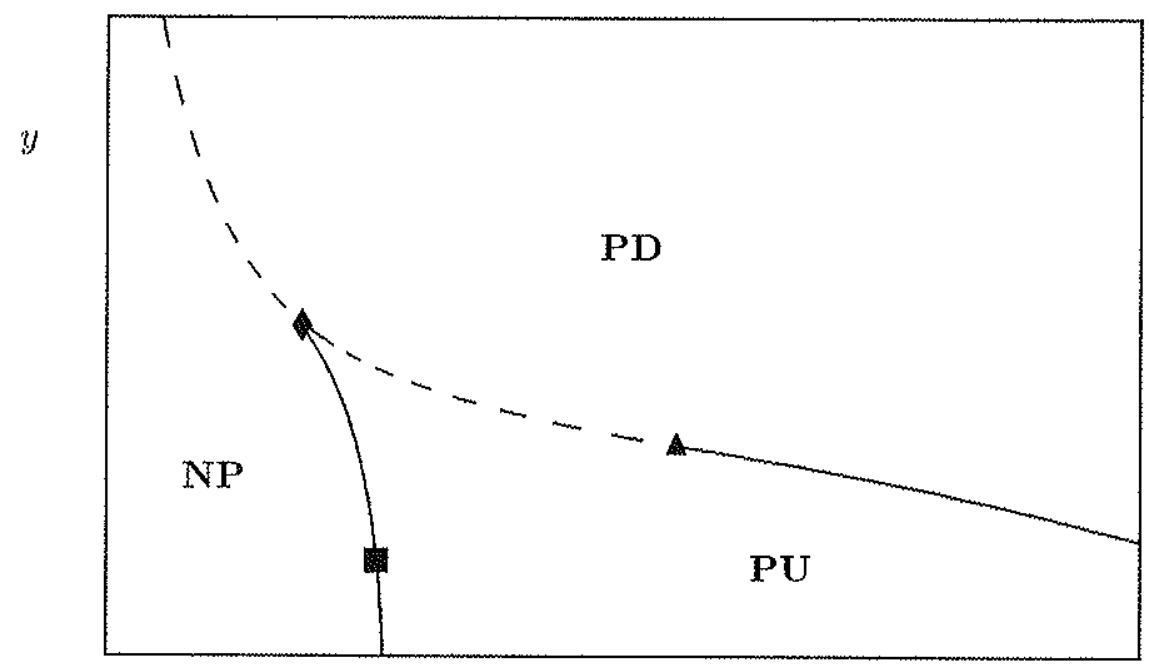

$x$

Figura 3.16: Esboço do diagrama de fases para o modelo de interaçốes entre ligaçóes para a rede quadrada. NP representa a fase não-polimerizada, PU indica a fase polimerizada usual e PD é a fase polimerizada densa. O ponto $\left(x_{c}^{\infty}=0,37909 \pm 0,00004, y_{c}=1\right)$ é inclicado por o ponto crítico terminal de coordenadas $(x \mathrm{PCT}=0,244 \pm 0,002, y \mathrm{PCT}=3,86 \pm 0,03)$ é representado por e o ponto tricrítico, situado em $\left(x_{\mathrm{p} T \mathrm{C}}=1,5 \pm 0,1, y \mathrm{prC}=1,1 \pm 0,1\right)$ é simbolizado por $\mathbf{A}$. As transiçŏes de primeira ordem săo indicadas por linhas tracejadas e as de segunda orden são as linhas contínuas.

Para verificar se a transição entre as fases não-polimerizada e polimerizada usual é uma transição de segunda ordem normal, na qual os expoentes críticos são constantes ao longo de toda a fronteira, e não uma transição en que eles são funções dos parâmetros $x$ e $y$, como acontece nas transiçöes de Kosterlitz-Thouless, nós calculamos os expoentes para outro valor de $y$, a saber, $y=1,2$. Os resultados obtidos para esse valor de $y$ são apresentados na tabela 3.4 juntamente com os valores para $y=1$. É importante notar que os expoentes críticos permanecem constantes dentro da barra de exros, o que caracteriza uma transição de segunda ordem usual. Além disso, como o expoente $\eta$ é muito sensível à avaliação de $x_{c}, 0$ exro nesse expoente deve ser maior do que o erro em $\nu$, que envolve derivadas numéricas, as quais incorporam parcialmente os erros nos cálculos. 
Tabela 3.2: Valores de $\nu$ para $y=1$, para o molelo de ligaçöes interagentes, juntamente com o valor extrapolado.

\begin{tabular}{|c|c|c|}
\hline$L$ & $L^{\prime}$ & $\nu$ \\
\hline 1 & 3 & 0,687789870 \\
\hline 2 & 4 & 0,730770808 \\
\hline 3 & 5 & 0,741863503 \\
\hline 4 & 6 & 0,746214976 \\
\hline 5 & 7 & 0,748253964 \\
\hline$\infty$ & & $0,7507 \pm 0,0008$ \\
\hline
\end{tabular}

Tabela 3.3: Valores de $\eta$ para $y=1$, para o modelo de ligaçöes interagentes, juntamente com o valor extrapolado.

\begin{tabular}{|c|c|}
\hline$L$ & $\eta$ \\
\hline 1 & 0,32777599 \\
\hline 2 & 0,28147596 \\
\hline 3 & 0,24990429 \\
\hline 4 & 0,22128292 \\
\hline 5 & 0,21588220 \\
\hline 6 & 0,21311582 \\
\hline 7 & 0,21152634 \\
\hline$\infty$ & $0,2082 \pm 0,0004$ \\
\hline
\end{tabular}


Tabela 3.4: Valores extrapolados de $x_{c}, \nu$ e $\eta$ para $y=1,0$ e $y=1,2$, para o modelo de ligacóes interagentes.

\begin{tabular}{|c|c|c|c|}
\hline$y$ & $x_{c}$ & $\nu$ & $\eta$ \\
\hline 1,0 & $0,37909 \pm 0,00004$ & $0,7507 \pm 0,0008$ & $0,2082 \pm 0,0004$ \\
\hline 1,2 & $0,36919 \pm 0,00003$ & $0,7498 \pm 0,0004$ & $0,205 \pm 0,003$ \\
\hline
\end{tabular}

É importante notar que não calculamos os expoentes críticos para a fronteira entre as fases polimerizadas por dois motivos. Primeiro, uma parte da fronteira corresponde a uma transição de primeira ordem, e não se definem expoentes críticos nesse caso. Segundo, temos apenas duas estimativas para a fronteira entre as fases polimerizadas, e não é possível realizar uma extrapolação tendo apenas dois resultados.

Acqui terminamos de apresentar os daclos obtidos para o modelo de ligações interagentes. Em seguida, inicianos a discussão sobre o modelo de sítios interagentes.

\subsection{Resultados para o Modelo de Monômeros Interagentes}

As estimativas para o diagrama de fases do modelo de monômeros interagentes estão apresentadas na figura 3.17. Como se observa na figura, para o modelo de monomeros interar gentes também temos um diagrama de fases com três fases, como ocorre no caso do modelo de ligações interagentes. Essas fases são a fase não-polimerizada, a fase polimerizada usual e a fase polimerizada densa. As características das fases e os tipos de transição entre elas foram estudadas da mesma forma que fizemos para o modelo de ligações interagentes. Inicialmente calculamos as densidades para um valor de $x$ pequeno $(x=0,2)$ e que estivesse dentro da fase não-polimerizada. A densidacle de sítios ocupados pelo polímero é mostrada na figura 3.18 . 


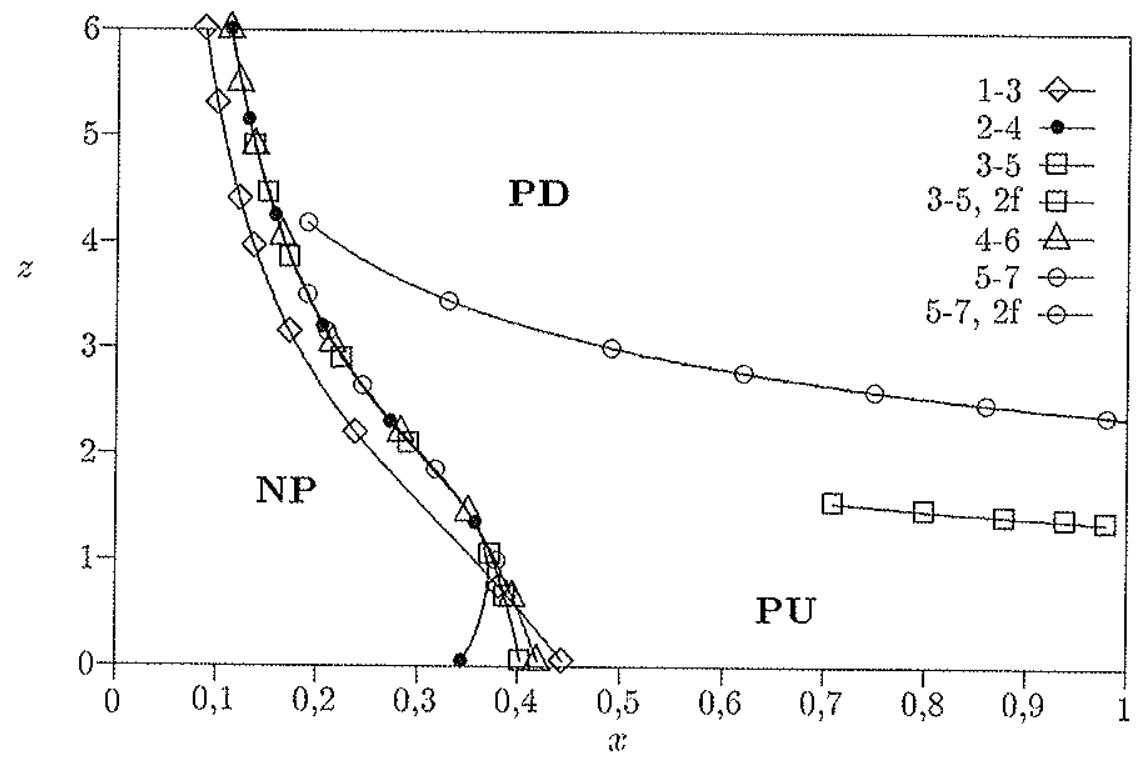

Figura 3.17: Diagramas de fases para o modelo de monômeros interagentes. A fronteira entre as fases polimerizadas é indicada por $2 f$. NP é a fase não-polimerizada, PU é a fase polimerizada usual e PD é a fase polimerizada dexisa. 


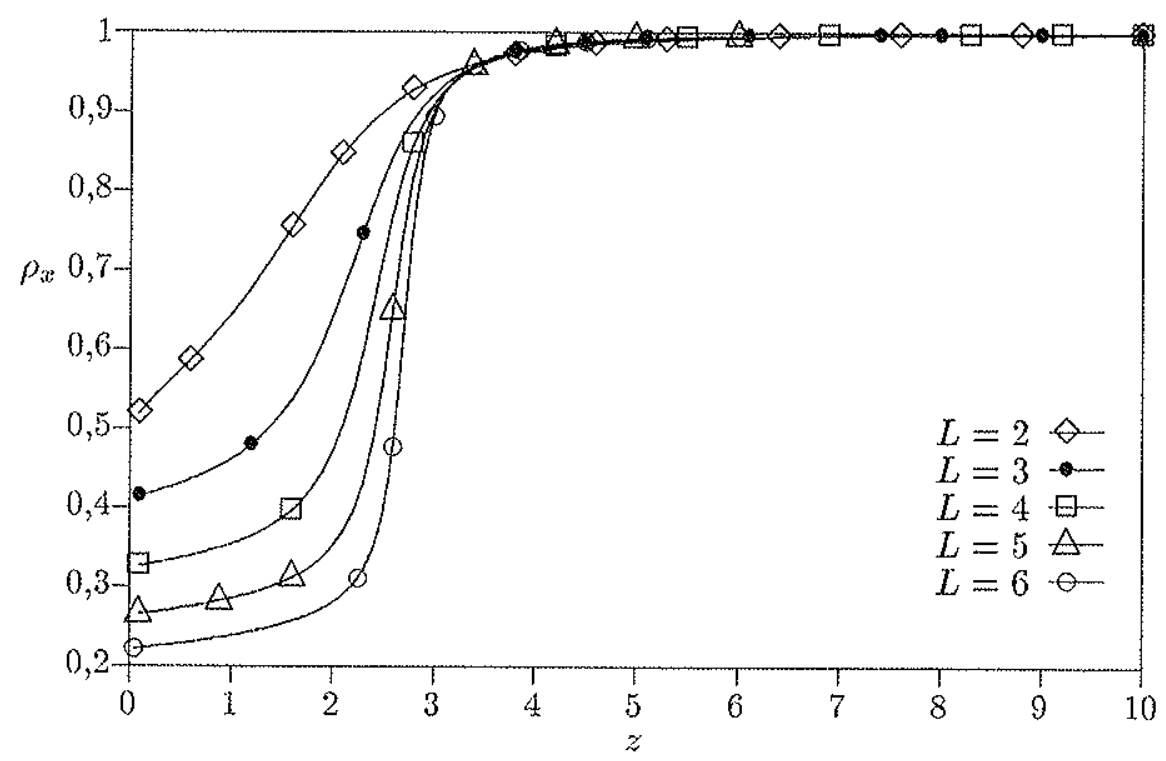

Figura 3.18: Densidade $\rho_{x}$ de sitios ocupados para $x=0,2$.

Observando essa figura vemos que ela é muito semelhante à figura 3.2, a qual mostra a densidade de sítios ocupados para $x=0,2$ para o modelo de ligações interagentes. No caso dos monômeros interagentes também ocorre a variação abrupta, que fica mais pronunciada com o aumento da largura. Comparando as figuras 3.17 e 3.18 , vemos qque a região de transição se localiza en torno de $z=3$.

Continuando com a apresentação dos dados, na figura 3.19 mostramos a densidade de interacooes entre os monômeros $\left(\rho_{z}\right)$ para $x=0,2$. 


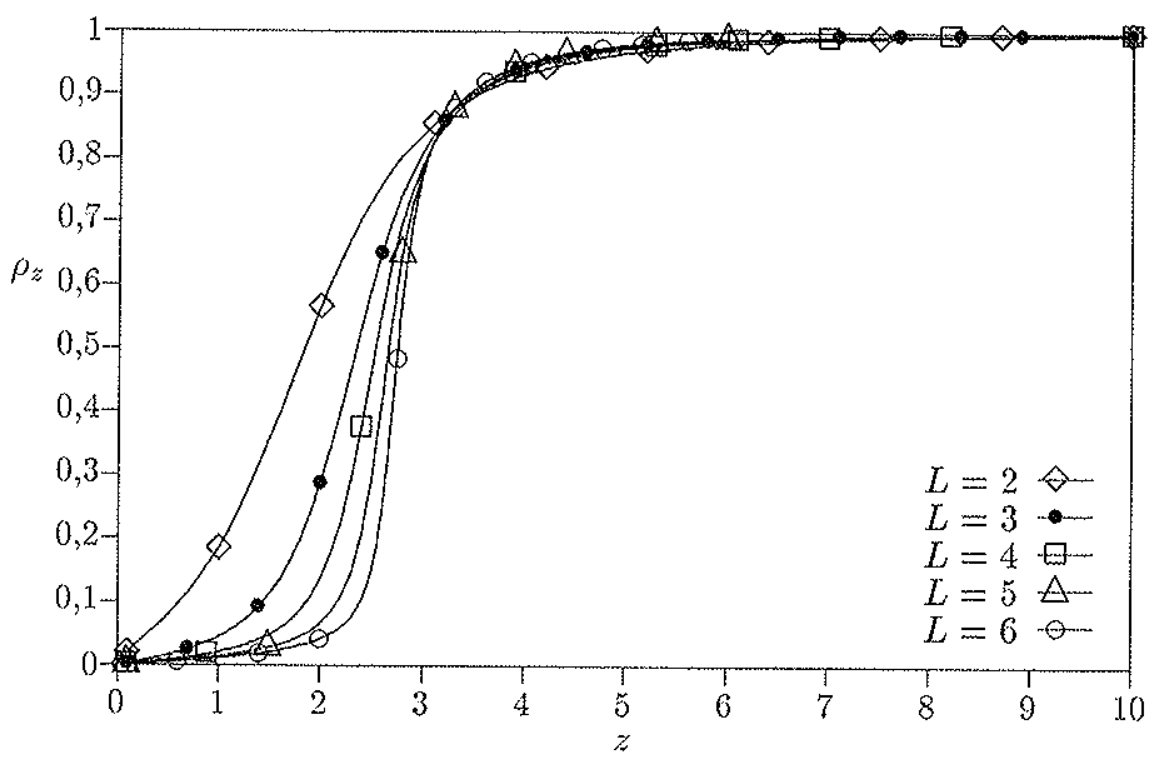

Figura 3.19: Densidade $\rho_{z}$ de interaçóes entre os monômeros para $x=0,2$.

Aqui também percebemos o comportamento abrupto em torno de $z=3$, quando a densidade de interações entre os monômeros passa de um valor nulo, dentro da fase não-polimerizada, para um valor muito próximo de 1 , dentro da fase polimerizada densa. A transição entre essas duas fases deve ser de primeira ordem. Para reforçar essa afimação, na figura 3.20 mostramos a derivada da densidade de sítios ocupados para $x=0,2$. 


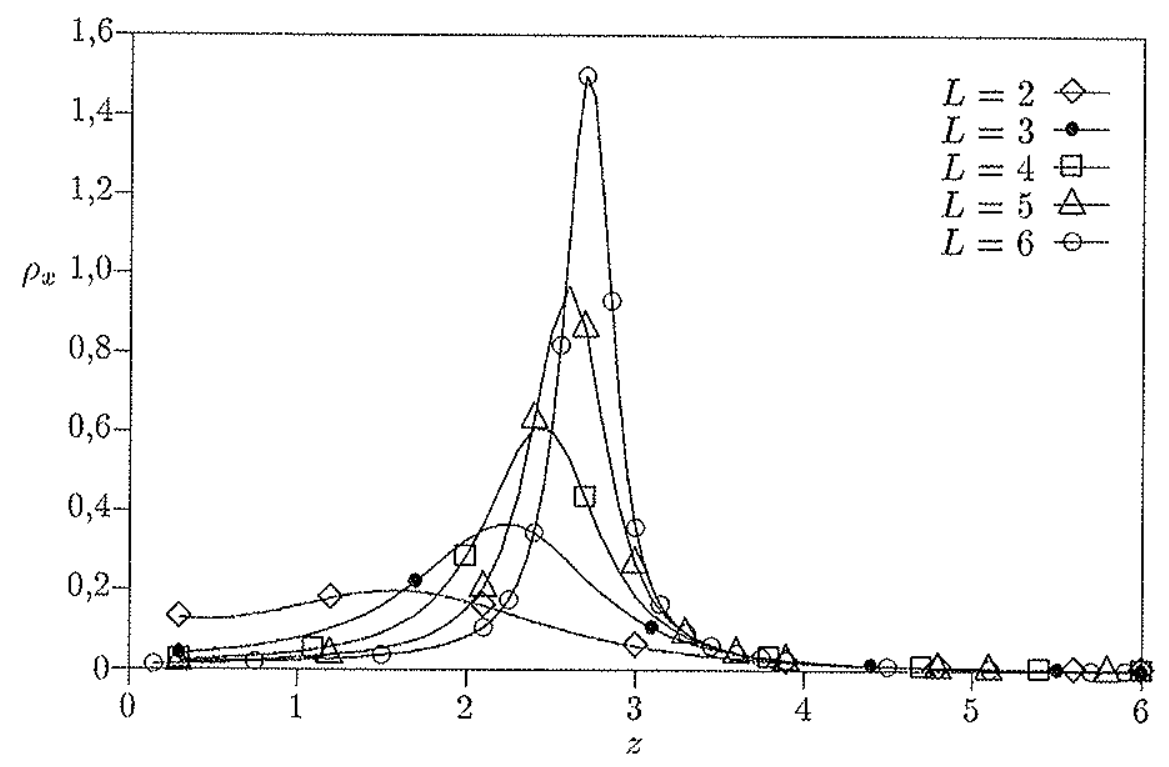

Figura 3.20: Derivada cla derasidade $\rho_{x}$ de sítios ocupados para $x=0,2$.

Como podemos ver na figura acima, com o aumento da largura o pico na derivada torna-se mais alto e pronunciado e quando $L \rightarrow \infty$ devemos ter uma divergência na derivada, o que caracteriza uma transição de primeira ordem. Além disso, o pico caminha em direção a $z=3$, concordando com as estimativas anteriores para o valor de $z$ no qual ocorre a transição correspondente a $a=0,2$.

Para complementar o estudo da fronteira entre as fases não-polimerizada e polimerizada densa, na figura 3.21 apresentamos a derivada da densidade de interações entre os monômeros para $x=0,2$. 


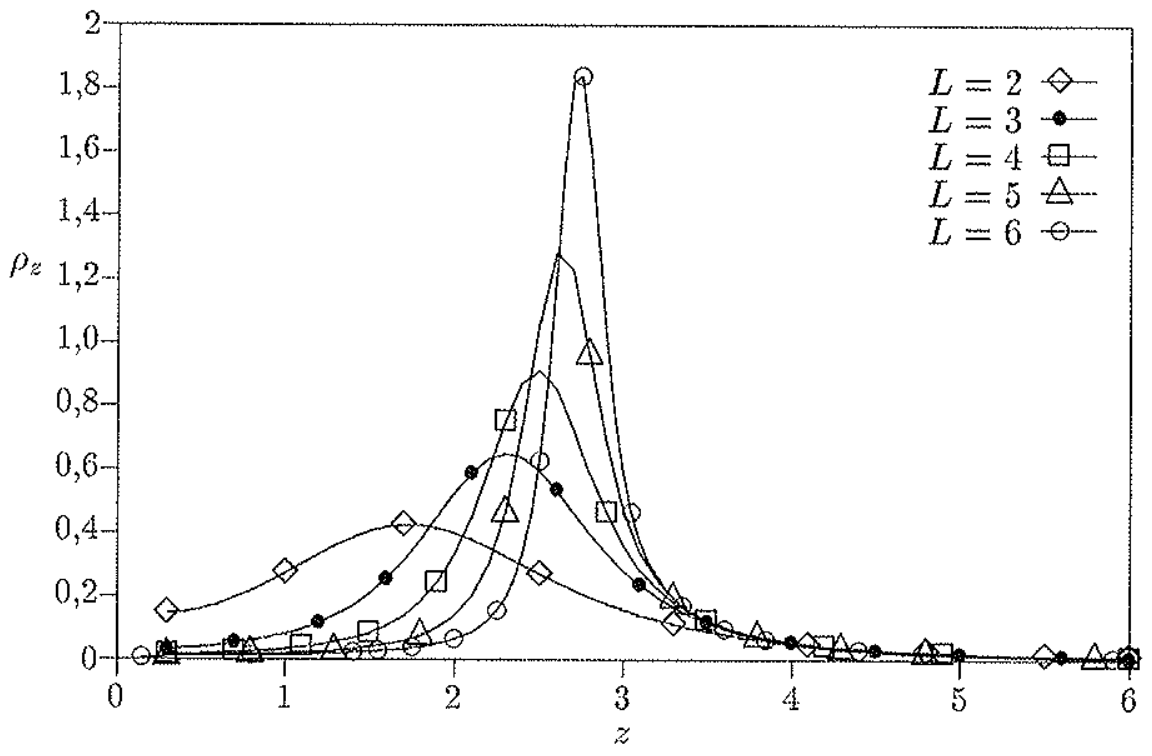

Figura 3.21: Derivada da densidade $\rho_{z}$ de interações entre os nonômeros para $x=0,2$.

Da mesma forma que no gráfico da derivada da densidade de sítios ocupados apresentado na figura 3.20 , aqui existe um pico em torno de $z=3$ que fica mais pronunciado à medida que $L$ aumenta. Reunindo todos os dados podemos afirmar que a transição entre a fase não-polimerizada e a fase polimerizada densa é de primeira ordem.

Seguindo os passos executados para o modelo de ligações interagentes vamos apresentar os dados obtidos para um valor de $x$ que está dentro da fase polimerizada usual e verificar o que ocorre com as densidades. Escolhemos novamente $x=0,4$ para facilitar a comparação entre os resultados. Iniciamos com a figura 3.22 , a qual mostra a densidade de sítios ocupados para $x=0,4$. 


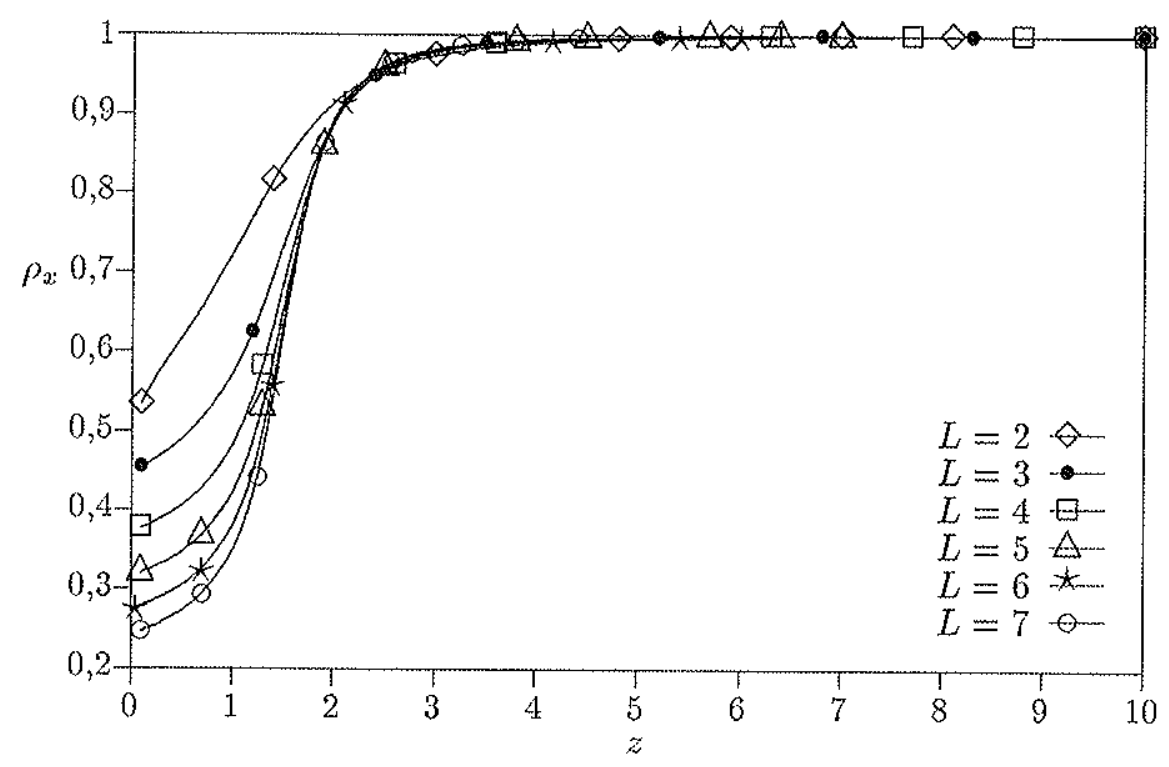

Figura 3.22: Densidade $\rho_{: x}$ de sítios ocupados para $x=0,4$.

Observando essa figura percebemos que a densidade de sítios ocupados para $x=0,4$ também apresenta a formação de uma descontinuidade, passando de valores de $\rho_{x}$ pequenos quando $z$ é pequeno para valores próximos de 1 quando $z$ passa de $z=1,8$. Esse comportamento fica mais evidente com o aumento das larguras, e a formação da descontinuidade é monotônica. É interessante comparar essa figura com a 3.6, que mostra a densidade de sítios ocupados para o modelo de ligações interagentes, para verificar que ambas têm o mesmo aspecto qualitativo. Vejamos agora a densidade de interações entre os monômeros, que pode ser vista na figura 3.23 . 


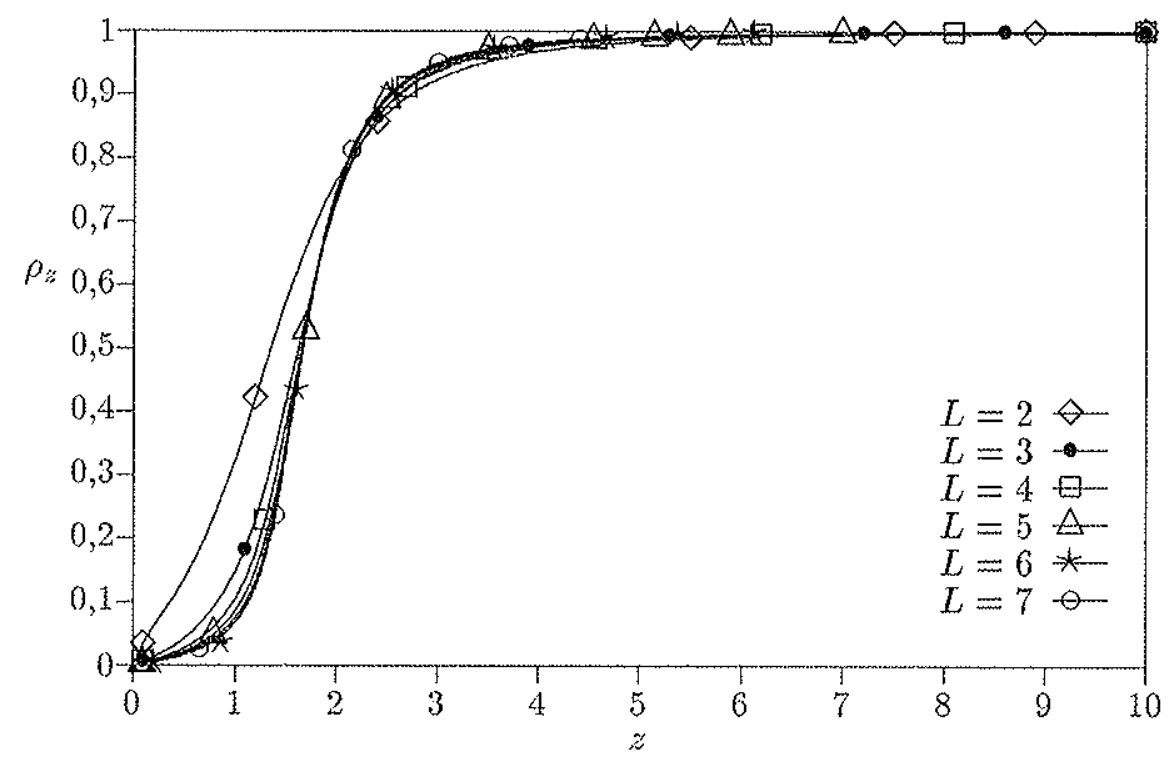

Figura 3.23: Densidade $\rho_{z}$ de interaçóes entre os monômeros paxa $x=0,4$.

A densidade de interações entre os monômeros também apresenta um comportamento característico de transições de primeira ordem. Ela é semelhante à figura 3.7, que é a sua equivalente para o modelo de ligaçóes interagentes. Note que os gráficos 3.22 e 3.23 indicam que a transição ocorre numa região próxima de $z=1,8$, a passo que as estimativas para a fronteira entre as fases polimerizadas obtidas pela renormalização fenomenológica para os pares 3-5 e, principalmente, 5-7, que são apresentadas no diagrama de fases 3.17 , sugerem um valor maior de z. Essa discrepância também ocorre no modelo de ligações interagentes, só que em menor intensidade. O fato é que as densidades não podem ser utilizadas de forma isolada para obter estimativas dos pontos críticos. Por outro lado, como temos apenas duas estimativas para a fronteira entre as fases polimerizadas, e essas estimativas são menos coincidentes no modelo de monomeros interagentes do que no de ligaçöes interagentes, elas nos informam que existe uma transição entre duas fases polimerizadas, mas os valores dos pontos críticos nessa fronteira só podem ser obtidos de forma aproximada. Observe que a convergencia da 
fronteira que envolve a fase não-polimerizada e as outras duas fases polimerizadas é muito mais rápida do que a convergência para a fronteira entre as fases polimerizadas e, por isso, os resultados obtidos para a transição entre a fase não-polimerizada e as fases polimerizadas são melhores do ponto-de-vista qualitativo e também quantitativo.

Para completar o estudo do valor $x=0,4$, vamos mostrar os gráficos das derivadas das densidades de sítios ocupados e de interações entre os monômeros. Iniciamos com a figura 3.24 , que apresenta a derivada da densidade de sítios ocupados.

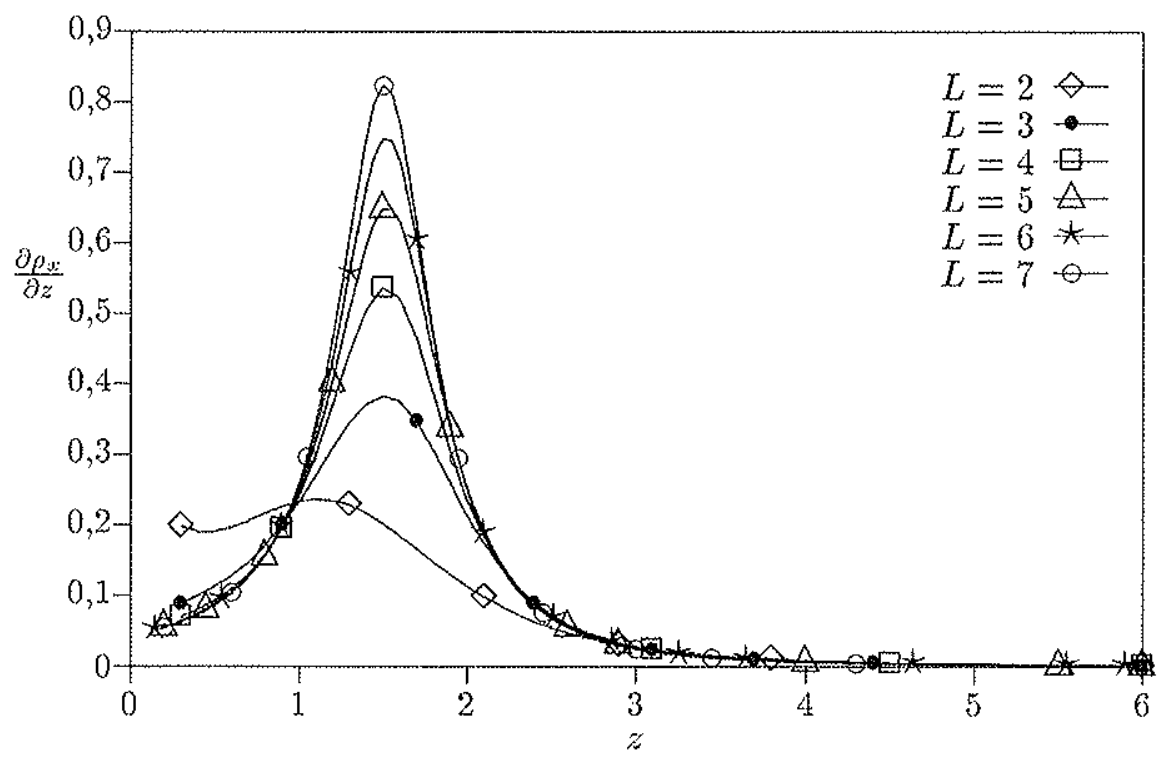

Figura 3.24: Derivada da densidade $\rho_{x}$ de sítios ocupados para $x=0,4$.

Observando essa figura vemos que com o aumento do tamanho da largura o pico na derivada tornanse mais pronunciado. É interessante ressaltar que o comportamento é monotônico considerando todas as larguras e também se as separarmos em conjuntos de larguras pares e ímpares. Note que o pico se localiza numa região em torno de $z=1,5$.

O comportamento acima também aparece na derivada da densidade de interaçóes entre os monômeros, como se vê na figura 3.25 , apresentada em seguida. 


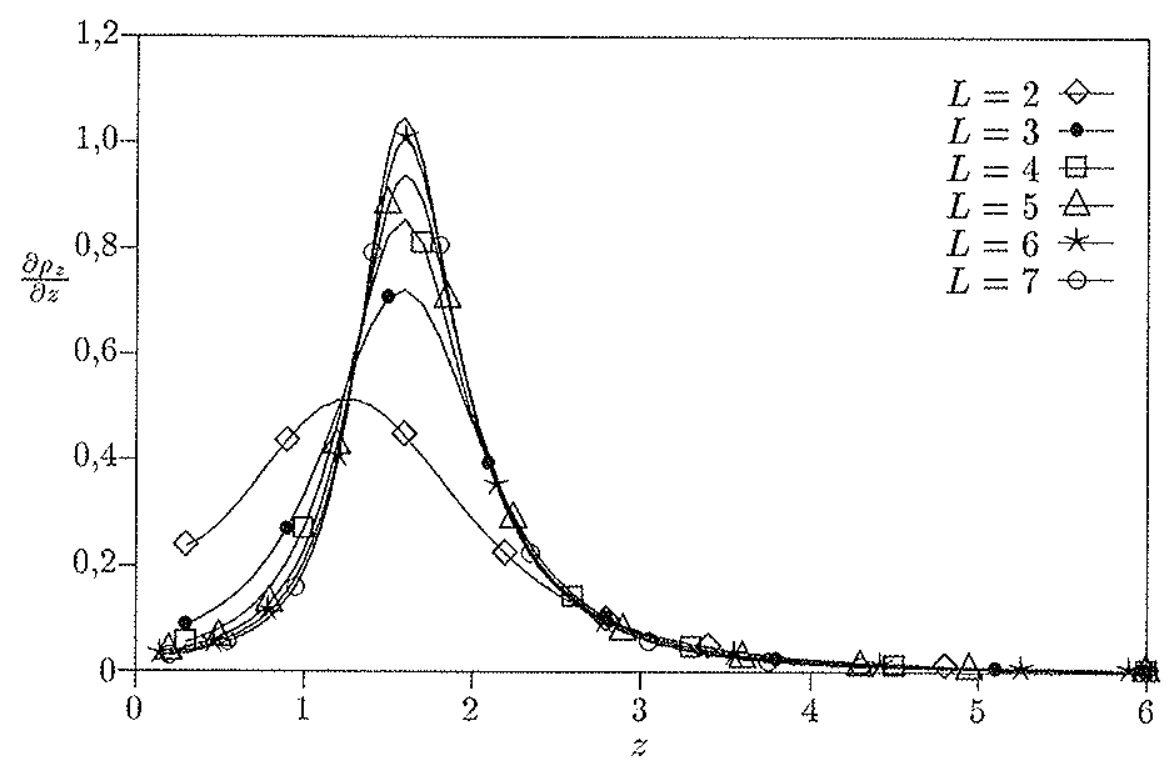

Figura 3.25: Derivada da densidlade $\rho_{z}$ de interaçóes entre os monòmeros para $x=0,4$.

Da mesma forma como acontece nas figuras 3.21 e 3.24, o comportamento do pico é monotônico e ele torna-se mais pronunciado com o aumento das larguras numa regiăo em torno de $z=1,5$. A transição para $x=0,4$ deve ser uma transição de primeira ordem.

A transição entre as fases não-polimerizada e polimerizada usual é de segunda ordem até um certo ponto em que a transição passa a ser entre as fases não-polimerizada e polimerizada densa. Nesse ponto ocorre a união entre essas duas fronteiras de fases e aquela correspondente à transição entre as fases polimerizadas. Para $x=0,4$ obtivemos como resultado que a transição entre a fase polimerizada usual e a fase polimerizada densa é de primeira ordem, e ela deve apresentar esse tipo de comportamento para $x<0,4$. Assim, no ponto de encontro das três fronteiras incidem duas linhas de primeira ordem e uma de segunda ordem. Esse ponto deve ser, então, um ponto crítico terminal, como acontece no caso do modelo de ligaçóes interagentes. Para estimar a localização desse ponto, podemos utilizar a equação 3.3 
para a renormalização fenomenológica de três larguras. O resultado por nós obticlo vale $\left(x \mathrm{PCr}=0,345 \pm 0,001, z_{\mathrm{PCT}}=1,52 \pm 0,01\right)$, que é a estimativa para o ponto crítico terminal

O nosso próximo passo é calcular as densidades para um valor maior de $x$. No caso do modelo de ligaçoes interagentes usamos o valor $x=2,4$. Entretanto, aqui optannos por $x=1,4$. O gráfico da densidade de sítios octupados aparece na figura 3.26 .

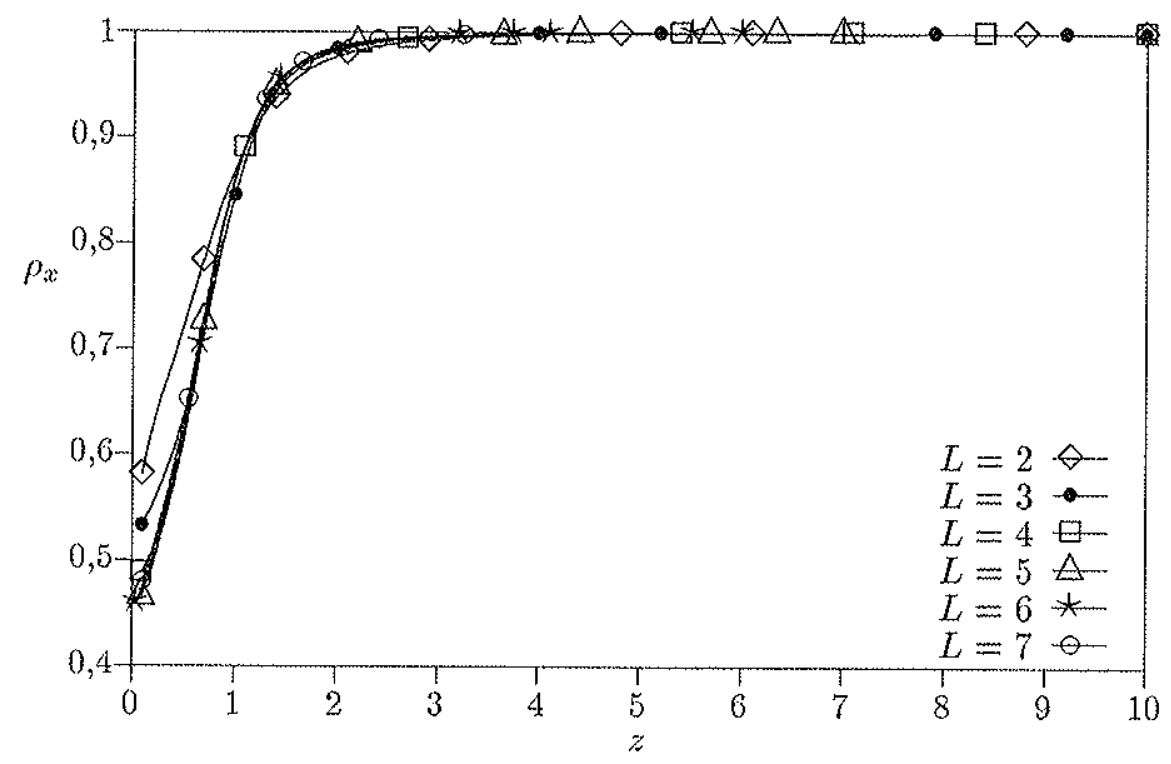

Figura 3.26: Densidade $\rho_{x}$ de sítios ocupados para $x=1,4$.

O comportamento da densidade de sítios ocupados para $t=1,4$ é semelhante ao apresentado na figura 3.10 , a qual mostra a densidade de sítios ocupados para o modelo de ligações interagentes. No caso de ligações interagentes a transição é de segunda ordem. Assim, esse gráfico indica que a transição para o modelo de monômeros interagentes para $x=1,4$ é de segunda ordem, e ocorre numa região em torno de $z=0,8$. Vejamos também o gráfico da densidade de interações entre os monotneros, apresentado na figura 3.27. 


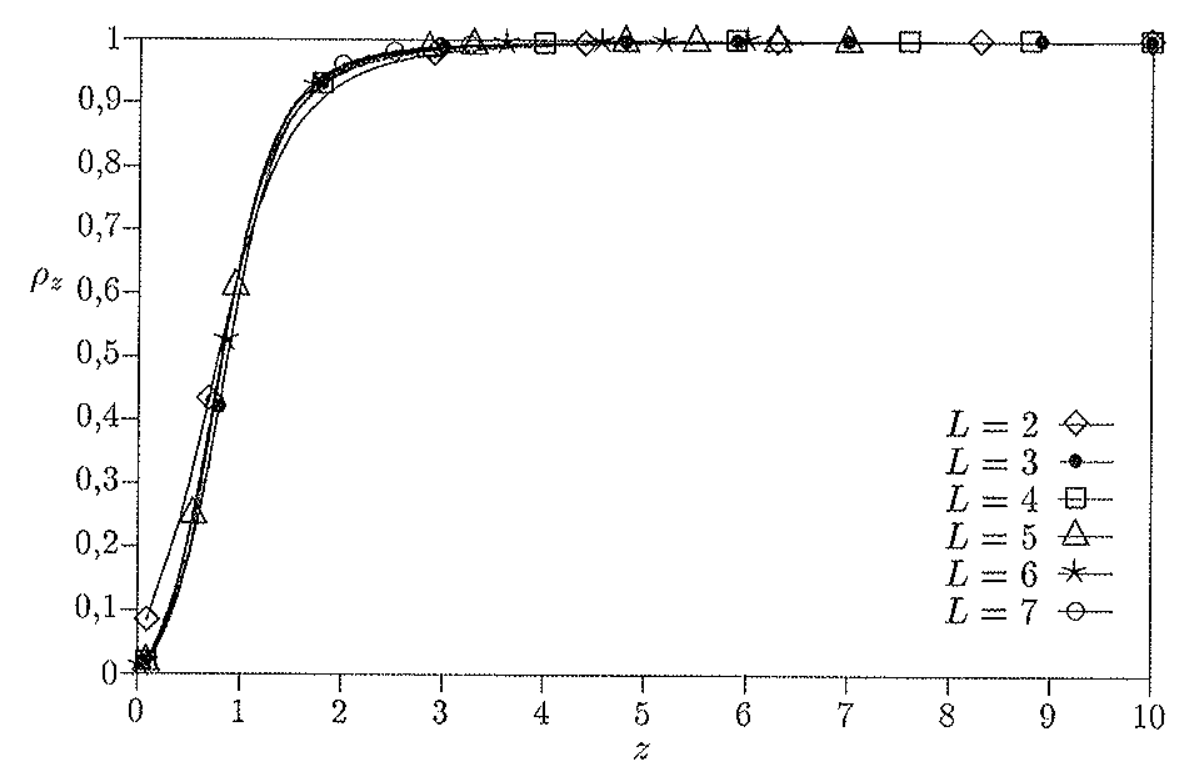

Figura 3.27: Densidade $\rho_{z}$ de interações entre os monômeros para $x=1,4$.

O gráfico para a densidade $\rho_{z}$ tem um aspecto intermediário entre os gráficos apresentados nas figuras 3.7 e 3.23 , as quais mostram, respectivamente, as densidades de interaçoes entre ligações e entre monômeros para $x=0,4$, e o gráfico 3.11 , que é a densidade de interaçóes entre ligaçôes para $x=2,4$. Assim, a densidade de interações entre monômeros não nos indica o tipo de transição, apenas a região em que ela ocorre, que coincide corn a estimativa obtida a partir do gráfico de $\rho_{x}$ e que fica próxima a $z=0,9$.

Para tentar obter um embasamento maior a respeito do tipo de transição, vamos calcular as derivadas das densidades. Iniciamos com a derivada da densidade de sítios, mostrada na figura 3.28 . 


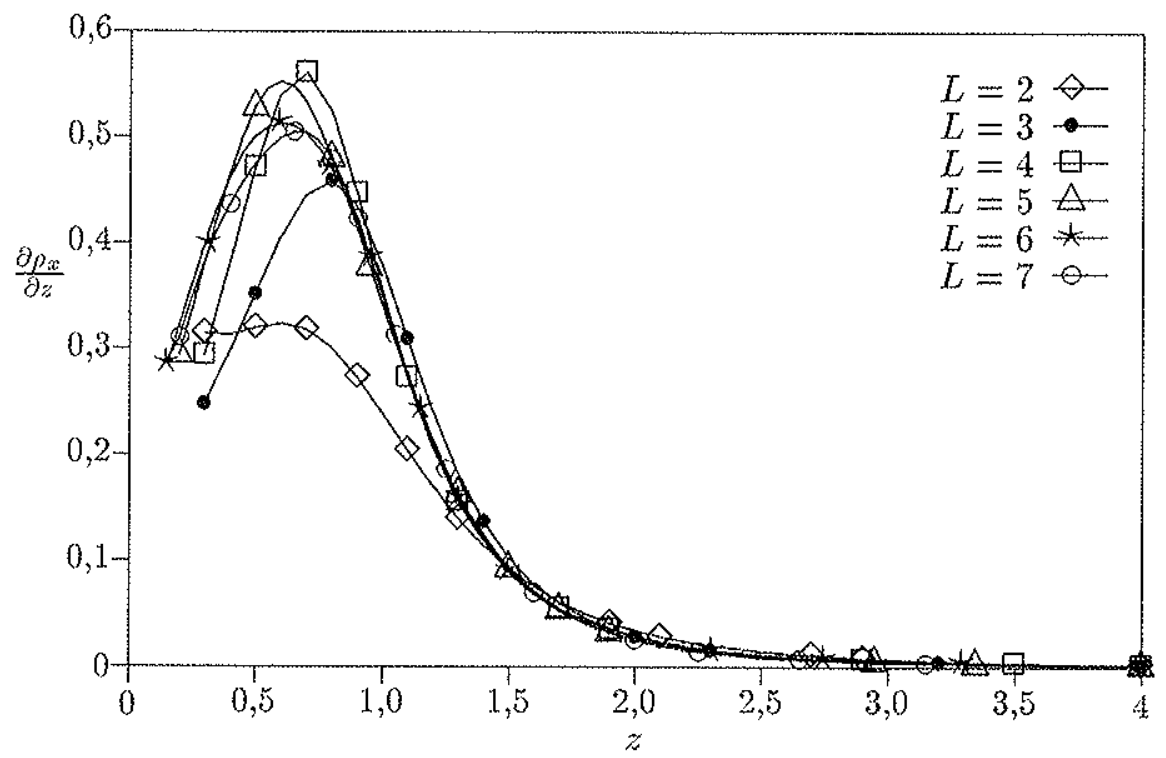

Figura 3.28: Dexivada da densidades $\rho_{x}$ de sítios ocupados para $x=1,4$.

O gráfico da derivada da densidade de sítios ocupados apresenta un pico numa região em torno de $z=0,65$. Uma análise detalhada deste pico mostra que quando passamos da largura 2 para a largura 3 e dessa para a largura 4 a altura do pico aumenta. Entretanto, quando passamos da largura 4 para a 5 a altura do pico diminui, e isso ocorre também quando passamos da largura 5 para a 6 e, por fim, para a largura 7. Mesmo se considerarmos apenas larguras pares ou ímpares, veremos que o comportamento do pico não é monotônico, e a altura do pico inicialmente cresce e depois decresce. Esse comportamento é diferente do que ocorreu até o momento em todos os gráficos analisados, tanto para o modelo de monômeros interagentes como para o modelo de ligações interagentes. Quando a altura do pico crescia monotonicamente com o aumento da largura, tinhamos uma transição de primeira ordem, porque no sistema infinito esse pico se tornaria uma descontinuidade da derivada das densidades. Nas transições de segunda ordem, a derivada não deve apresentar descontinuidades. 
Como o pico que aparece na derivada aumenta para as larguras pequenas e depois diminui para as larguras maiores, quando tomarmos o limite $L \rightarrow \infty$ ele deve desaparecer, e então a derivada das densidades deve ser uma função contínua para $x=1,4$, o que caracteriza uma transição de segunda ordem nesse ponto. Vejamos também o gráfico da densidade de interações entre os monômeros, apresentado na figura 3.29, para completar nossa discussão.

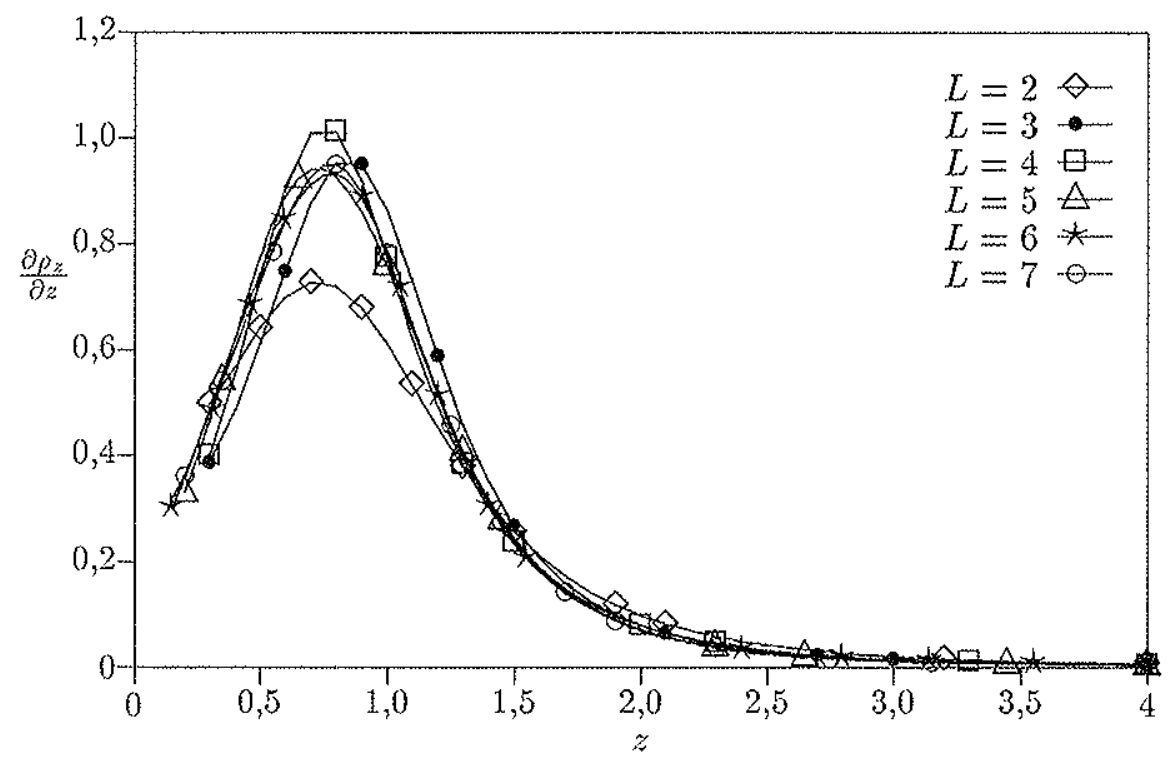

Figura 3.29: Derivada da densidade $\rho_{z}$ de interações entre os monômeros para $x=1,4$.

Nessa figura também vemos que a altura do pico, que situa-se em torno de $z=0,75$, aumenta ao passarmos de $L=2$ para $L=3$ e de $L=3$ para $L=4$, diminuindo en seguida para as larguras maiores. Aqui é interessante ressaltar que mais importante do que os valores numéricos das grandezas é o seu comportamento assintótico, por causa da hipótese de finitesize scaling. Assim, as menores larguras podem ainda não estar completamente no regime de finite-size scaling, ao contrário das larguras maiores. Se o pico diminuísse para as larguras menores e aumentasse em seguida para as larguras maiores, então nossa análise deveria priorizax essas últimas e esperaríamos uma transição de primeira ordem, não de segunda. 
Aqui é importante ressaltar que, comparando as estimativas obtidas pela renormalização fenomenológica para as fronteiras de fases entre as fases polimerizadas para as larguras 35 e 5-7 com resultados extraídos do cálculo das densidades e também das derivadas das densidades, vemos que os dados são discordantes entre si. As estimativas dos pontos críticos para as fronteiras de fases da figura 3.17 sugerem valores de z para a transição entre as fases polimerizadas em tomo de $z=2,0$ para $x=1,4$ (extrapolando-se os comportamentos das curvas para $x=1,4$ ). Esses valores são bem mais altos do que as estimativas obtidas através dos gráficos das densidades, que ficam em torno de $z=0,85$. Essas estimativas, por sua vez, são um pouco mais altas do que as que podem ser obtidas considerando-se as derivadas das densidades, que sugerem que a transição ocorre próximo a $z=0,7$.

$O$ ponto crítico terminal foi estimado en $(x \mathrm{PCT}=0,345 \pm 0,001, z \mathrm{PCT}=1,52 \pm$ 0,01). Pelo aspecto qualitativo das estimativas para as fronteiras de fases obticlas pela renormalização fenomenológica para as larguras 3-5 e 5-7 (veja a figura 3.17), na transição entre as fases polimerizadas os valores de $z$ devem diminuir à medida que $x$ aumenta, e esse comportamento também era esperado já que, quanto maior for o valor de $x$, mais monômeros estão incorporados ao polímero e mais interações entre os monômeros primeiros-vizinhos mas não-consecutivos irão ocorrer, cle modo que um valor menor de z é necessário para provocar a transição da fase polimerizada usual para a fase polimerizada densa. Portanto, para $x=1,4$ o valor de $z$ deve ser menor do que o valor dessa coordenada para o ponto crítico terminal, isto é, $z \mathrm{pCT}=1,52$. Assim, para $x=1,4$, a renormalização fenomenológica nos fornece uma estimativa quantitativa muito alta para a coordenada $z$ do ponto onde ocorre a transição entre as fases polimerizadas. Por outro lado, as estimativas extraídas das densidades e clas derivadas das densidades $(z=0,85$ e $z=0,7)$ são inconsistentes pois, se a transição para $x=1,4$ ocorrer para um $z$ tal que $z<1$, isso significa que, para algum valor de $x$ tal que $x<1,4$, a transição deve ser verificada quando $z=1$. Entretanto, $z=1$ corresponde ao modelo não-interagente, que já foi estudado por vários métodos e que possui apenas cluas fases, e a 
transição entre elas ocorre num valor de $x$ determinado por várias técnicas diferentes. Assim, ou na fronteira entre as fases polimerizadas a transição ocorre sempre para $z>1$ ou o modelo não-interagente apresenta três fases polimerizadas distintas, havendo dois pontos críticos que correspondem às transições entre essas duas fases. Um deles ocorreria num valor pequeno de $x$, que é o valor conhecido por várias técnicas $\left(x_{c}=0,37905227 \pm 0,00000012\right)$, e outro num valor maior de $x$. Essa última hipótese não é plausível pois o modelo não-interagente foi exaustivamente estudado por vários métodos diferentes e ele possui apenas uma transição entre duas fases polimerizadas distintas, de forma que a transição entre as fases polimerizadas no modelo de monomeros interagentes deve ocorrer sempre para $z>1$. Conseqüientemente, as densidades e as derivadas das densidades fornecem estimativas quantitativas para os valores de $z$ pequenas demais e não podem ser levadas em consideração. Note que, qualitativamente, os dados referentes às clensidades e às derivadas das densidades são consistentes entre si, e sugerem uma transição de segunda ordem para $x=1,4$. Do ponto-de-vista qualitativo não há discordâncias entre os resultados obtidos mediante o cálculo das densidades ou das derivadas das densidades.

Já que para $x=0,4$ a transição é de primeira ordem e para $x=1,4$ ela é de segunda ordem, entre esses dois valores de $x$ existe um ponto tricrítico. Observando as figuras 3.24 até 3.29 , vemos que passamos de uma situação em que o pico cresce de forma monotonica, para $x=0,4$, sendo que a sua altura para a largura $L$ é menor do que para a largura $L+1$, para uma situação em que os picos, a partir de $L=4$, diminuem com o aumento da largura. Isso significa que, para algum valor de $x$, todos os picos têm aproximadamente a mesma altura, e esse valor de $x$ é a nossa estimativa para o ponto tricrítico. As curvas das derivadas das densidades nas figuras 3.28 e 3.29 são bastante próximas umas clas outras, o que indica que o ponto tricrítico não deve estar muito longe de $x=1$, 4. Para tentar obtê-lo, calculamos as derivadas das densidades para alguns valores de $x$. Note que aqui novamente a renormalização fenomenológica de três larguras não pode sex utilizada pois, observando a 
figura 3.17 , verificamos que existem apenas duas estimativas para a fronteira entre as fases polimerizadas e elas não se cruzam, não existindo solução para a equação 3.3 nessa região. Assim, a estimativa do ponto tricrítico pode ser feita apenas de modo gráfico, como no caso do modelo de ligações interagentes. Porém, infelizmente o cálculo das derivadas das densidades não foi conclusivo a esse respeito. Não é possível, a partir dos gráficos das derivadas das densidades, fazer qualquer tipo de afirmação sobre a localização do ponto tricrítico. Para comprovar isso, apresentamos em seguida os resultados para alguns clos valores de $x$ para. os quais calctulamos as derivadas das densidades de sítios ocupados e de interaçóes entre. monômeros.

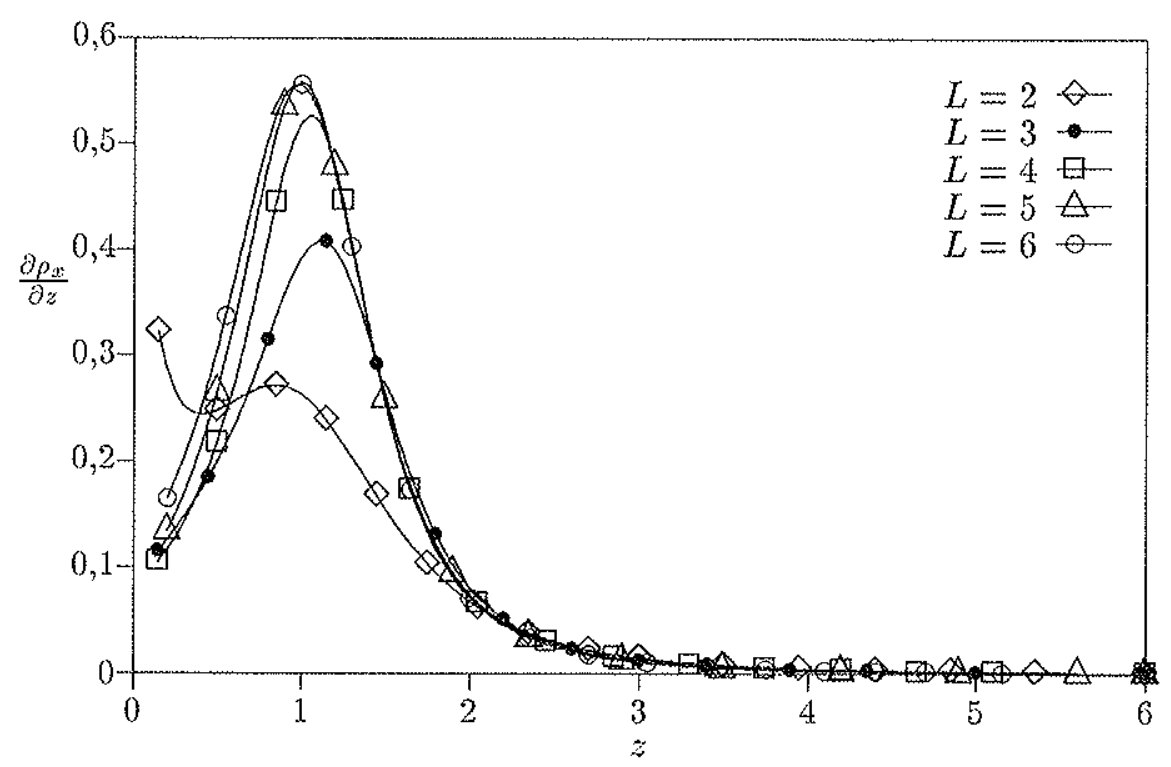

Figura 3.30: Derivada da densidade $\rho_{x}$ de sítios ocupados para $x=0,7$. 


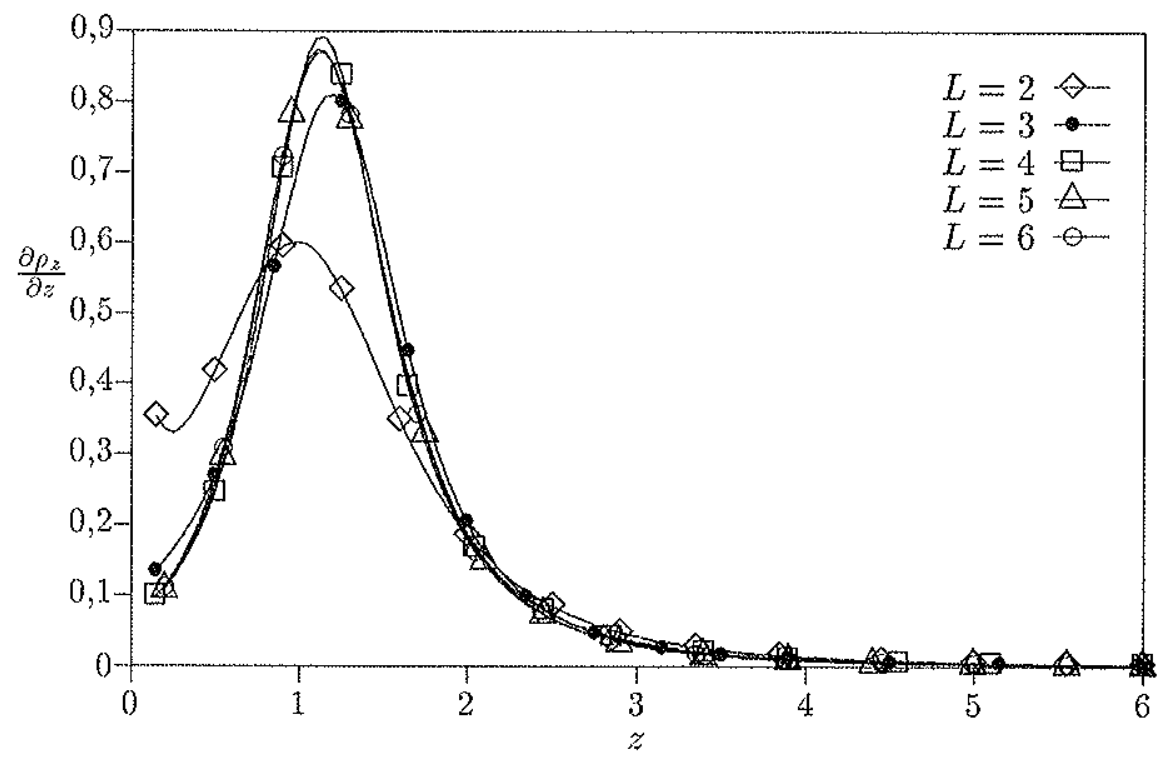

Figura 3.31: Derivada da densidade $p_{z}$ de interaçôes entre os monômeros para $x=0,7$. 


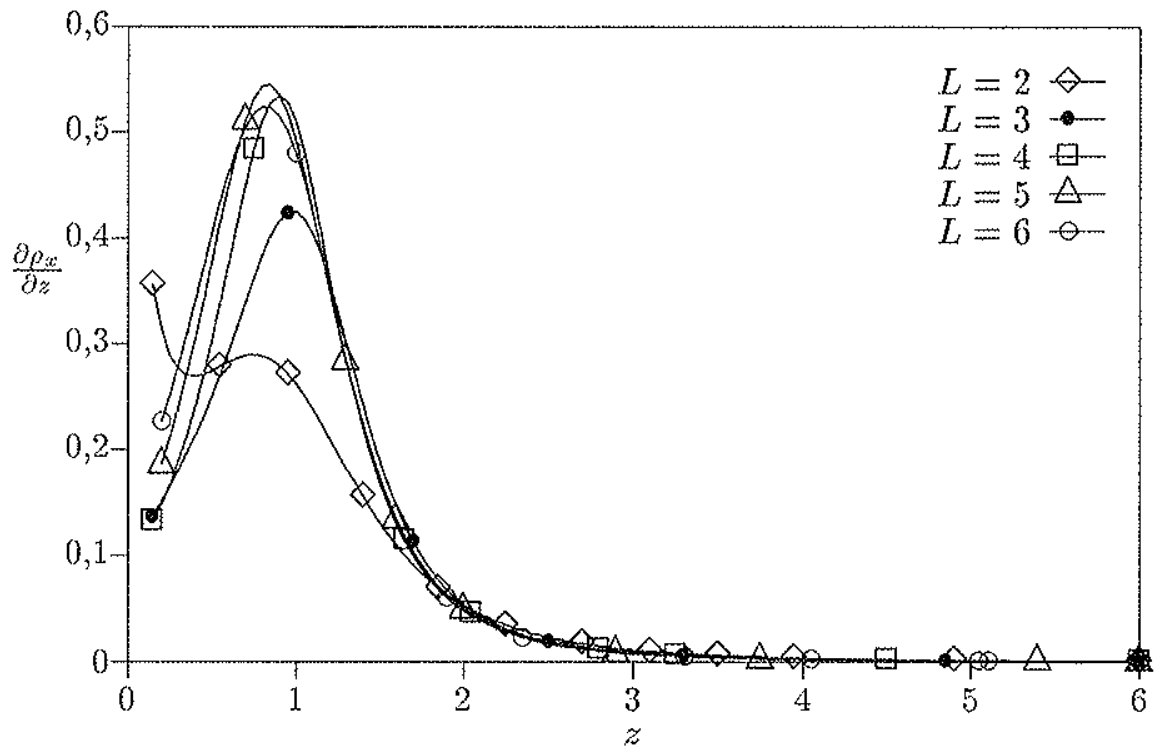

Figura 3.32: Derivada da densidade $\rho_{x}$ de sítios ocupados para $x=0,9$. 


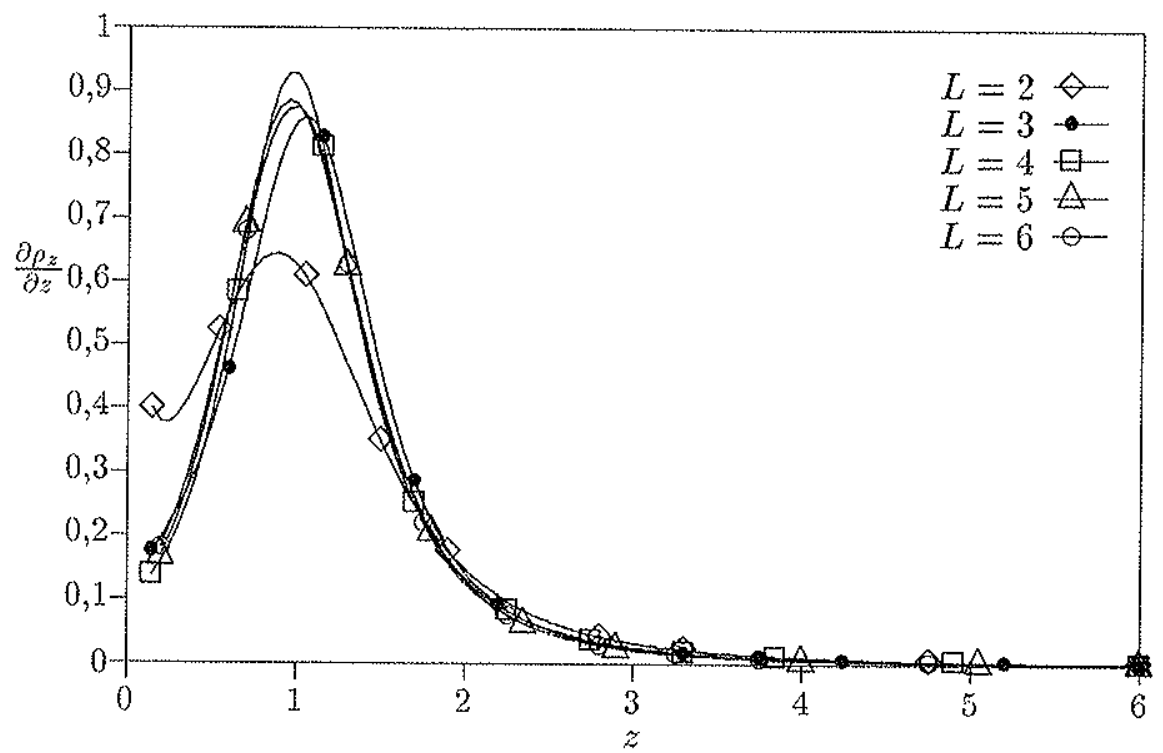

Figura 3.33: Derivada da densidade $\rho_{z}$ de interaçôes entre os monôneros para $x=0,9$. 


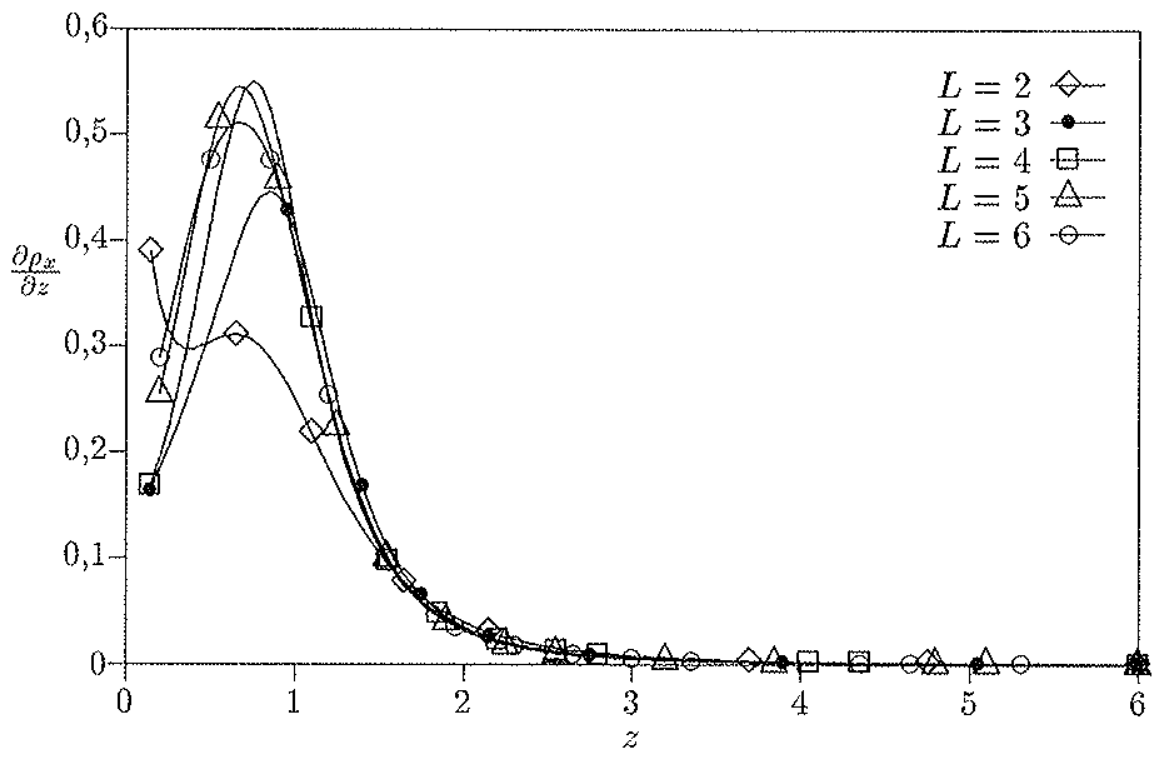

Figura 3.34: Derivada da clensidade $\rho_{x}$ de sítios octupados para $x=1,2$. 


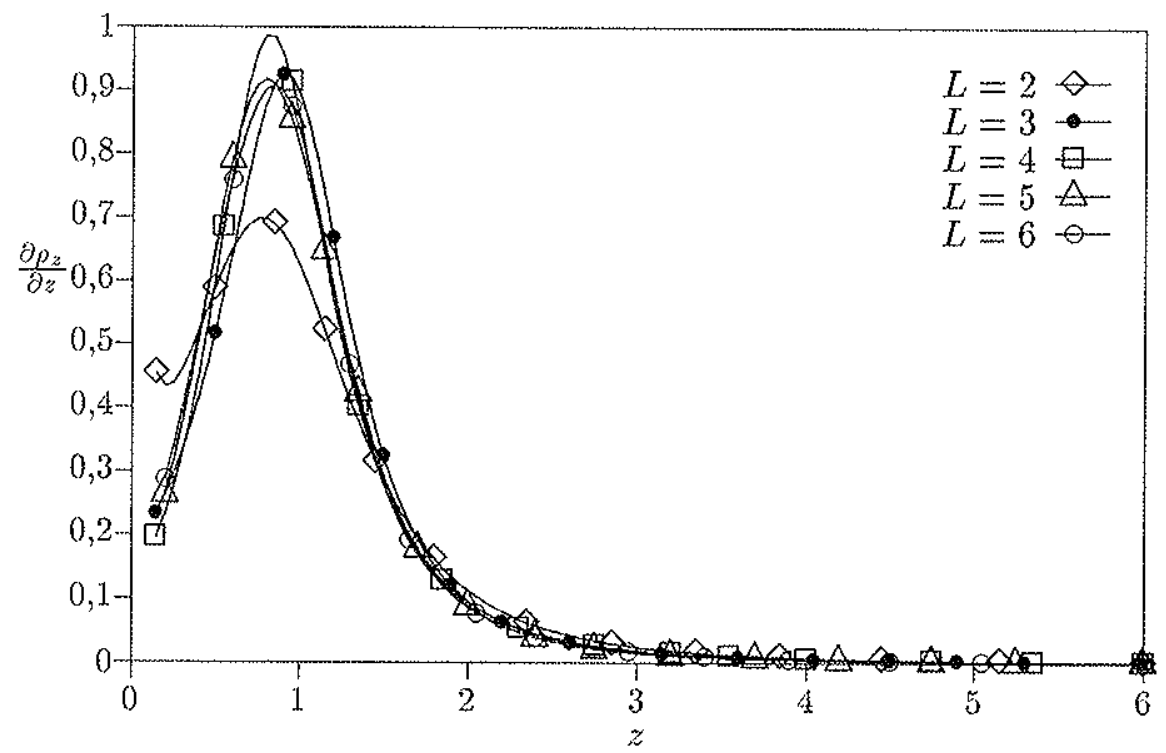

Figura 3.35: Derivada da densidade $\rho_{z}$ de interaçóes entre os monomeros para $x=1,2$.

Como se observa nas figuras 3.30 até 3.35 , os gráficos para os três valores de $x(x=0,7$, $x=0,9$ e $x=1,2)$ são muito parecidos entre si. Não seria prudente afirmar que o ponto tricrítico tem uma determinada coordenada. O que se pode dizer é que o ponto tricrítico deve estar situado entre $x=0,4$ e $x=1,4$. No caso da rede de Husimi, o ponto tricrítico para o modelo de monômeros interagentes está localizado em (xpre $=0,32774$, zpro $=1,84193)$. Aqui é interessante lembrar o cliagrama de fases do modelo de monômeros interagentes estudado na rede de Husimi [14]. Considerando apenas a rede de Husimi, o diagrana de fases 
para o modelo de monômeros interagentes é qualitativamente diferente do diagrama para o modelo de ligaçóes interagentes. No caso de ligações interagentes, o diagrama de fase da rede de Husimi mostra que a transição de segunda ordem entre a fase não-polimerizada e a fase polimerizada usual termina num ponto crítico terminal, sendo que, entre as fases po. limerizadas a transição é de primeira ordem para valores pequenos de $x$ e passa para uma transição de segunda ordem para valores de $x$ maiores. Existe, portanto, um ponto tricrítico nessa fronteira. Esse comportamento qualitativo é verificado também no nosso modelo de ligações interagentes na rede quadrada, mas ocorrem diferenças quantitativas com relação às localizações dos pontos multicríticos, o que não é nada surpreendente, já que são modelos estudados em redes diferentes, uma real (rede quadrada) e outra matemática (rede de Husimi). Note que a rede de Husimi de coordenação $q=4$ é uma aproximação para uma rede quadrada melhor do que a rede de Bethe, mas ainda é um cálculo de campo médio.

O modelo de monômeros interagentes na rede de Husimi tem um diagrama de fases qualitativamente diferente. A transição entre as fases não-polimerizada e polimerizada usual termina num ponto tricrítico localizado en $\left(x_{\mathrm{PTC}}=0,32774, z \mathrm{p}_{\mathrm{TC}}=1,84193\right)$. A partir desse ponto, a transição torna-se de primeira ordem e ela contimua na fronteira entre as fases não-polimerizada e polimerizada densa. A transição entre as fases polimerizadas é toda de segunda ordem e termina num ponto crítico terminal ao unir-se com a fronteira que envolve a fase não-polimerizada e as fases polimerizadas. A localização desse ponto crítico terminal é $(x \mathrm{PCT}=0,24987, z \mathrm{PCT}=2,82996)$. A explicação para as diferenças qualitativas entre os dois modelos na rede de Husimi baseia-se no fato de que as interações entre monomeros ocorrem com maior freqüência do que entre ligações já que, para que ocorra uma interação entre duas ligaçóes, necessariamente existe pelo menos uma interação entre alguns dos nonômeros que formam essas ligações. Por outro lado, é possível existix uma interação entre monômeros sem que ocorram interações entre ligaçôes, como ocorre quando o polímero se encontra consigo mesmo de modo que dois monômeros sejam primeiros-vizinhos mas sem que haja duas ligações 
primeiras-vizinhas. Uma configuração exn que isso ocorre corresponde ao polímero formar um "L" numa certa região e outro "L" noutra, de modo que os vértices dos "L" sejam primeirosvizinhos mas sem que os lados dos "L", que seriam as ligaçoes, sejam. Com isso, os monotmeros dos vértices interagem entre si, mas não haveria uma interação entre ligações. Assim, fixado um valor de $x$, para valores iguais de $y$ e $z$ as interações entre os monômeros são mais eficientes do que as interações entre as ligações para produzir configurações de densidades maiores, ou seja, no modelo de monômeros interagentes o polímero atinge a fase densa para valores menores de $z$ do que para o modelo de ligaçóes interagentes. A mesma situação ocorre no caso dos nossos modelos definidos na rede quadrada, o que pode ser verificado comparando os diagramas de fases e também os valores dos pontos multicríticos. Portanto, considerando um mesmo valor de $x$, a fronteira entre as fases polimerizadas no modelo de monômeros interagentes aparece numa região em que os valores de $z$ são menores do que os valores de $y$ da fronteira entre as fases polimerizadas no modelo de ligações interagentes, e isso ocorre tanto na rede de Husimi como na rede quadrada. Por causa da própria maneira como a rede de Husimi é definda e construída não é possível para as ligaçóes em um quadrado elementar da rede interagir com as ligações em outro quadrado elementar. Dessa forma, uma interação entre duas ligaçôes é bem mais difícil de ocorrer do que uma interação entre monômeros. Isso faz com que a fronteira entre as fases polimerizadas ocorra para valores de interação entre os monômeros bem menores do que entre as ligaçôes, e essa diferença entre os valores de $y$ e $z$ para as duas fronteiras é de tal ordem que muda qualitativamente o diagrama de fases na rede de Husimi.

Considerando agora os modelos definidos na rede quadrada vemos que a questão referente à maior eficiència das interações entre os monômeros do que entre as ligaçóes na produção da fase densa permanece. Contudo, a rede quadrada permite que quadrados adjacentes interajam por meio de ligaçóes, o que é proibido pela rede de Husimi. Assim, a existencia de uma interação entre ligações é menos comum de ocorrer do que entre monômeros, mas ainda 
é um fato bem mais freqüiente na rede quadrada do que na rede de Husimi. Conseqüentemente, os valores da coordenada $z$ dos pontos críticos que pertencem à fronteira entre as fases polimerizadas no modelo de monômeros interagentes são menores do que os valores da coordenada $y$ para os pontos que pertencem à fronteira entre as fases polimerizadas no modelo de ligações interagentes, mas não tanto que leve a uma mudança qualitativa do diagrama. Ela é apenas quantitativa. Além disso, o detalhe de a interação ser entre ligações ou monômeros não deveria ser suficiente para fazer com que os diagramas de fases para os dois modelos na rede quadrada fossem qualitativamente diferentes.

Para o modelo de monômeros interagentes também calculamos a atividade $x_{c}$ para $z=1$ e para $z=1,2$, além dos expoentes críticos $\nu$ e $\eta$. Os dados obtidos estão na tabela 3.5 abaixo.

Tabela 3.5: Resultados para $x_{c}, \nu$ e $\eta$ para o modelo de monômeros interagentes, para $z_{c}=1 \mathrm{e}$ $z_{i}=1,2$. Os expoentes para a rede cutadrada para $y=1$ são $\nu=\frac{3}{4}$ e $\eta=\frac{5}{24}=0,2083333 \ldots$

\begin{tabular}{|c|c|c|c|}
\hline$z_{c}$ & $x_{c}$ & $\nu$ & $\eta$ \\
\hline 1,0 & $0,37902 \pm 0,00003$ & $0,7507 \pm 0,0007$ & $0,2089 \pm 0,0009$ \\
\hline 1,2 & $0,366848 \pm 0,000003$ & $0,7500 \pm 0,0004$ & $0,205 \pm 0,008$ \\
\hline
\end{tabular}

Como se observa na tabela, os expoentes também permanecem constantes dentro da barra de erros e a transição entre a fase não-polimerizada e a fase polimerizada usual é uma transição de segunda ordem normal. Da mesma forma como fizemos para o modelo de ligaçōes interagentes na rede quadrada, na figura 3.36 apresentamos um esboço do diagrama de fam ses para o modelo de monômeros interagentes. Note que os diagramas são qualitativamente similares, mas os valores numéricos dos pontos multicríticos são diferentes. 


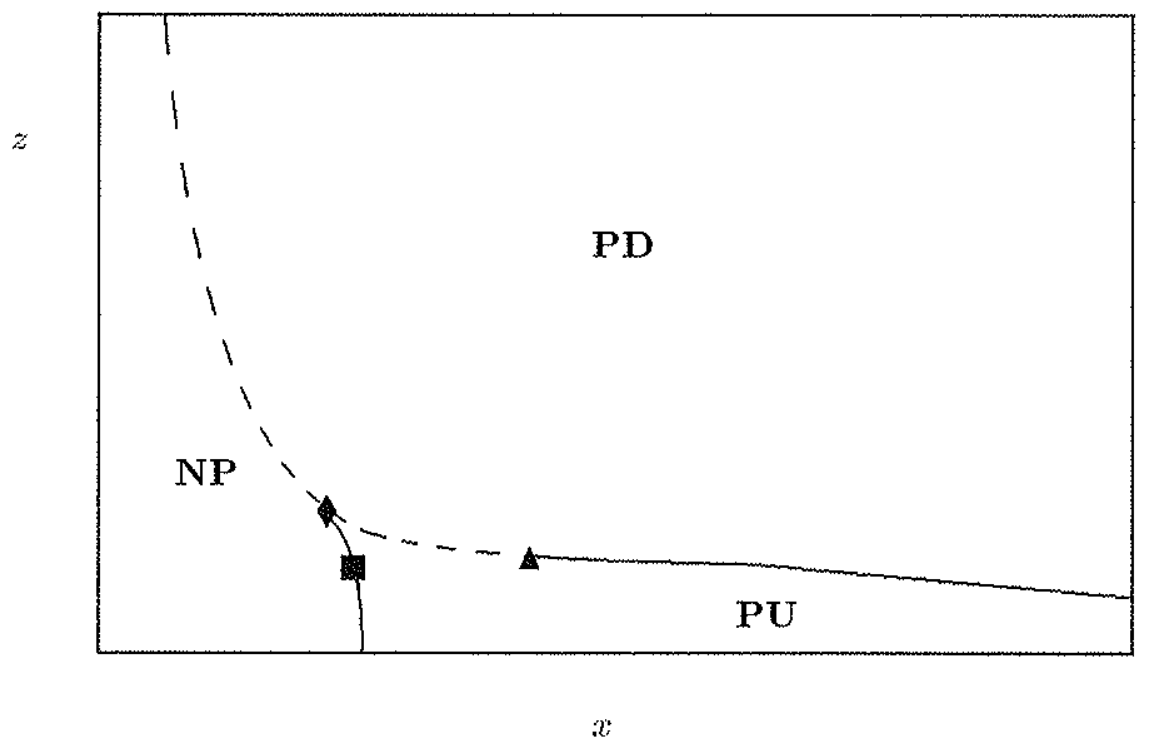

Figura 3.36: Esboço do diagrama de fases para o modelo de interações entre monômeros para a rede quadrada. NP representa a fase não-polimerizada, $\mathbf{P U}$ indica a fase polimerizada usual e $\mathbf{P D}$ é a fase polimerizada densa. O ponto $\left(x_{c}^{\infty}=0,37902 \pm 0,00003, z_{c}=1\right)$ é indicado por $\mathbf{m}$, o ponto crítico terminal de coordenadas $(x \mathrm{PCT}=0,345 \pm 0,001, z \mathrm{PC} T=1,52 \pm 0,01)$ é representado por $\$$. Como não temos a localização exata do ponto tricrítico, apenas indicamos a sua existência por um A. As transições de primeira ordem são indicadas por linhas tracejadas e as de segunda ordem são as linhas contínulas.

Como último comentário, devemos dizer que nossos resultados sấo consistentes com um ponto $\theta$ (o ponto no qual termina a transição de segunda ordem entre a fase não-polimerizada e polimerizada usual) que seja um ponto crítico terminal em ambos os modelos. O próximo capítulo apresenta as conclusões e reúne todos os dados obtidos. 


\section{Capítulo 4}

\section{CONCLUSÕES}

\subsection{Modelo de Ligações Interagentes}

Concluindo o estudo por nós realizado, sobre o modelo de ligaçóes interagentes na rede quadrada podemos dizer que:

1. O modelo de ligações interagentes na rede quadrada apresenta um diagrama de fases com três fases distintas. Essas fases são a fase nãomolimerizada, a fase polimerizada usual e a fase polimerizada densa. Nesse modelo, $x$ é a atividade de um monômero que pertence ao polímero e $y=e^{-\beta \varepsilon_{\ell}}$ é o peso estatístico associado a uma interação entre ligações. Aqui, $\epsilon_{\ell}$ é a energia de interação (veja a figura 3.1).

2. A fase nãopolimerizada é caracterizada por não ter a formação de um polímero que atravesse toda a rede. Nessa fase, a densidade de sítios ocupados por um polímero é nula $\left(\rho_{x}=0\right)$ no limite termodinâmico. Da mesma forma, como não há um polímero não há interações entre as ligações e a densidade de interações entre as ligações também é nula $\left(\rho_{y}=0\right)$.

3. A fase polimerizada usual corresponde à fase em que o polímero se encontra polimeri- 
zado, com uma densidade que depende dos valores de $x$ e $y$, ou seja, $\rho_{x}=\rho_{x}(x, y)$ e $\rho_{y}=\rho_{y}(x, y)$. Na região próxima a fronteira entre a fase não-polimerizada e esta fase as densidades devem ter valores pequenos que văo aumentando quando $x$ e a aumentam.

4. A fase polimerizada densa é caracterizada por ser uma fase em que o polímero torna-se bastante compactado de forma que o número de interaçôes entre as ligaçôes é maximizado. Nessa fase o polímero percorre todos os sítios da rede, o que faz com que a densidade de sítios ocupados atinja seu valor máximo $\left(\rho_{x}=1\right)$. Como o número de interações entre as ligações é maximizado, a densidade de interações entre as ligações também atinge valores muito altos, próximos de 1 , isto é, $\rho_{y} \approx 1$.

5. Ao passarmos da fase não-polimerizada para a fase polimerizada densa as densidades passam de $\rho_{x}=\rho_{y}=0$ para $\rho_{x}=1$ e $\rho_{y} \approx 1$. Essa transição é descontínua e corresponde a uma transição de primeira ordem. Ao calcularmos as densidades e as derivadas das densidades para $x=0,2$ (figuras $3.2,3.3,3.4$ e 3.5 ) vimos que, ao passarmos da fase não-polimerizada para a fase polimerizada clensa, as derivadas das densidades apresentaun um pico que aumenta com o tamanho da largura das tiras e que se torta uma descontinuidade no sistema infinito, comprovando, assim, a transição de primeira ordem caracterizada por una singularidade na primeira derivada da densidade.

6. Ao passarmos da fase não-polimerizada para a fase polimerizada usual as densidades não sofrem nenhuma alteraçăo brusca. Essa transição é de segunda ordem e um ponto dessa fronteira já tinha sido obtido por outras técnicas [1,3]. Esse ponto corresponde a $y=1$, ou seja, ao modelo simples de polímeros em que não há interação entre as ligações. Nesse caso, o valor de $x$ já conhecido é $x_{c}=0,37905227 \pm 0,00000012$.

7. O valor de $x_{c}$ para $y=1$ obtido através de extrapolaçóes [19] foi $x_{c}=0,37909 \pm 0,00004$, que está de acordo com o valor anteriormente citado. 
8. A transição da fase polimerizada usual para a fase polimerizada densa é de primeira ordem para valores pequenos de $x$, como comprovamos ao fazermos os gráficos das densidades (figuras 3.6 e 3.7 ) e das derivadas das densidades (figuras 3.8 e 3.9 ) para $x=0,4$. Esses gráficos são muito semelhantes aos gráficos equivalentes para $x=0,2$, onde ocorre a passagem da fase não-polimerizada para a fase polimerizada densa e existe uma transição de primeira ordem. Para valores maiores de $x$ a transição torna-se de segunda ordem, como pode ser visto nas figuras 3.10 e 3.11 , as quais apresentam as densidades de sítios ocupados e de interações entre as ligações, respectivamente, para $x=2,4$. As derivadas das densidades são mostradas nas figuras 3.12 e 3.13. Nessas figuras podemos ver que não existe mais o pico característico das transições de primeira ordem. A derivada é bastante "suave", o que caracteriza uma transição de segunda ordem. Portanto, existe uma mudança no tipo de transição na fronteira entre as fases polimerizadas, passando de primeira ordem para segunda ordem em algum ponto. Esse ponto é um ponto tricrítico.

9. A localização do ponto tricrítico não pode ser feita através do método de renormalização fenomenológica de três larguras, já que temos apenas duas estimativas para a fronteira entre as fases polimerizadas, associadas aos pares 3-5 e 5-7, e essas estimativas não se cruzam em nenhum ponto. Assim, para estimar as coordenadas desse ponto calculamos as densidades e derivadas das densidades para vários valores de $x$ para verificar quando havia uma alteração no comportamento dessas funções, passando de características típicas de transição de primeira ordem para características de segunda ordem. Esses cálculos podem ser vistos nas figuras 3.14 e 3.15, nas quais a mudança de um comportamento para outro é facilmente percebida. Com isso, obtivemos para as coordenadas do ponto tricrítico as seguintes estimativas: $x_{\mathrm{PTC}}=1,5 \pm 0,1$ e $y_{\mathrm{PTC}}=$ 1,1 $\pm 0,1$. Para uma comparação, o modelo de ligações interagentes na rede de Husimi tem um ponto tricrítico localizado em $\left(x_{\mathrm{PTC}}=0,37628, y_{\mathrm{PTC}}=4,60326\right)$.

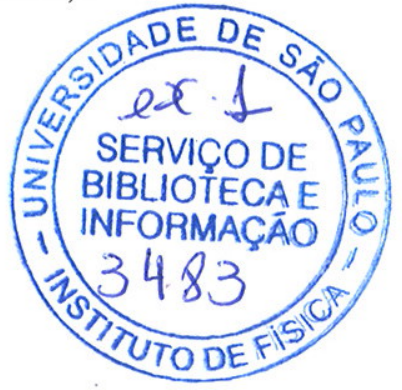


10. A fronteira de segunda ordem entre a fase não-polimerizada e a fase polimerizada usual termina na fronteira de primeira ordem entre a fase não-polimerizada e a fase polimerizada densa, como pode ser visto na figura 3.16, a qual apresenta um esboço do diagrama de fases do modelo. Nesse ponto existe um ponto crítico terminal, cujas coordenadas foram estimadas através da renormalização fenomenológica de três larguras em $\left(x_{\mathrm{PCT}}=0,244 \pm 0,002, y \mathrm{PCT}=3,86 \pm 0,03\right)$. Também para uma comparação, o modelo de ligaçoes interagentes na rede Husimi tem um ponto crítico terminal localizado em $\left(x_{\mathrm{PCT}}=0,28053, y_{\mathrm{PCT}}=6,35335\right)$. Uma explicação para o motivo de os pontos multicríticos ocorrerem para valores menores de y no modelo na rede quadrada reside no fato de que nessa rede as interações entre ligações podem ocorrer com mais facilidade do que na rede de Husimi. Assim, como há um número maior de interasoóes na rede quadrada do que na rede de Husimi, a intensidade da interação na rede quadrada pode ser menor mas produz o mesmo efeito.

11. O ponto $\theta$ é o ponto em que termina a transição entre a fase não-polimerizada e polimerizada usual. É onde ocorre pela primeira vez a transição de colapso, em que o polímero passa da fase polimerizada usual para a fase densa. No modelo de interaçóes entre ligações nossos cálculos indicam que esse ponto corresponde ao ponto crítico terminal discutido acima. Portanto, o ponto $\theta$ nesse modelo é um ponto crítico terminal.

12. Calculamos os expoentes críticos para a fronteira de segunda ordem entre a fase não-polimerizada e a fase polimerizada usual. Para $y=1$ os expoentes são $\nu=0,7507 \pm 0,0008$ e $\eta=0,2082 \pm 0,0004$. Para $y=1,2$ o valor de $x_{c}$ correspondente é $x_{c}=0,36919 \pm$ 0,00003 , o expoente $\nu$ vale $\nu=0,7498 \pm 0,0004$ e o expoente $\eta$ vale $\eta=0,205 \pm 0,003$ Pelos resultados acima podemos concluir que os expoentes críticos ficam constantes ao longo da fronteira, o que caracteriza uma transif̧ão de segunda ordem usual, e não uma transição especial como uma transição de Kosterlitz-Thouless, na qual os expoentes 
variam. Os valores esperados para os expoentes são $\nu=\frac{3}{4} \mathrm{e} \eta=\frac{5}{24}[4]$, de modo que os valores obtidos concordam muito bem com os esperados.

13. O diagrama de fases do modelo de ligaçóes interagentes na rede quadrada é qualitativamente semelhante ao diagrama do mesmo modelo na rede de Husimi [14], apesar de existirem diferenças quantitativas já mencionadas, que estão associadas às características geométricas das duas redes.

\subsection{Modelo de Monômeros Interagentes}

Com relação ao modelo de monômeros interagentes na rede quadrada podemos conduir que:

1. O diagrama de fases do modelo de monômeros interagentes também apresenta três fases, como ocorre com o modelo de ligações interagentes (veja a figura 3.17). As três fases têm características físicas semelhantes às desse modelo. Na fase não-polimerizada, o polímero não é formado e as densidades de sítios ocupados e de interaçóes entre os monômeros são ambas nulas no limite termodinâmico. Vale lembrar que no modelo de monômeros interagentes a atividade de um monômero é também dada por $x$, ao passo que $z=e^{-\beta \epsilon_{m}}$ é o fator de Boltzmann associado com as interaçóes entre os monômeros, onde $\epsilon_{m}$ é a energia de interação entre os monômeros.

2. Na fase polimerizada usual a densidade de sítios ocupados e de interaçóes entre os monomeros depende de $t$ e $\%$, enquanto na fase polimerizada densa as densidades atingem seus valores máximos, isto é, $\rho_{x}=1$ e $\rho_{z}=1$.

3. A transição da fase não-polimerizada para a fase polimerizada densa é de primeira 
ordem, como pode ser visto nas figuras 3.18 até 3.21 , as quais apresentam as densidades $\rho_{x}$ e $\rho_{z}$ e as derivadas dessas densidades, todas para $x=0,2$. Note que nas clerivadas temos o pico característico associado com as transições de primeira ordem.

4. A transição entre a fase não-polimerizada e a fase polimerizada usual é de segunda ordem. Quando $z=1$, o modelo de monômeros interagentes recai no modelo usual de polímeros não-interagentes e o valor de $x_{c}$ correspondente obticlo por nós vale $x_{c}=0,37902 \pm 0,00003$, que está de acordo com o valor esperado $x_{c}=0,37905227 \pm$ $0,00000012[1,3]$.

5. No estudo da transição entre as fases polimerizadas usual e densa procedemos do mesmo modo que no caso do modelo de ligações interagentes. Iniciamos os cálculos com um valor pequeno de $x$, no caso, $x=0,4$. As densidades e suas derivadas podem ser vistas nas figuras 3.22 até 3.25 . Observe que as derivadas novamente apresentam um pico cuja altura aumenta monotonicamente com o aumento do tamanho da largura das tiras, caracterizando assim uma transição de primeira ordem para $x=0,4$.

6. Prosseguindo com os cálculos, escolhemos agora $x=1,4$. Nesse caso, a densidade de sítios ocupados apresentada na figura 3.26 sugere que a transição é de segunda ordem. A densidade de interaçóes entre os monômeros, figura 3.27 , não é conclusiva a esse respeito, pois apresenta características intermediárias entre as figuras 3.19 e 3.11 , por exemplo, que representam transições de primeira e de segunda ordem, respectivamente. Passando para o estudo das derivaclas das densidades, apresentadas nas figuras 3.28 e 3.29, vemos que nelas aparece um pico, sugerindo uma transição de primeira ordem. No entanto, uma análise mais detalhada desses gráficos revela que a altura do pico aumenta de $L=2$ para $L=3$, e também de $L=3$ para $L=4$, mas diminui de $L=4$ para $L=5$, de $L=5$ para $L=6$ e de $L=6$ para $L=7$. Portanto, como precisamos analisar a tendência de comportamento com o aumento da largura, concluímos que 
no sistema infinito, quando $L \rightarrow \infty$ e tivermos uma rede quadrada, as derivadas das densidades não apresentarão esse pico e serão funções analíticas, caracterizando uma transição de segunda ordem. Assim, para $x=1,4$, a transição é de segunda ordem. Cabe ressaltar que ocorrem discrepancias entre os valores estimados para a localização da transição entre as fases polimerizadas através da renormalização fenomenológica, através das densidades de sítios ocupados e de interaçoes entre monômeros e através das derivadas dessas densidades. A renormalização fenomenológica fornece estimativas para a transição em valores muito altos de $z$, ao passo que as densidades e derivadas das densidades nos dão valores de $z$ menores do que 1 , o que é inconsistente. Assim, do ponto-de-vista quantitativo não podemos afirmar a localização exata dos pontos críticos. Entretanto, considerando apenas os aspectos qualitativos vemos que os dados obtidos para as densidades e as derivadas das densidades são consistentes entre si e, no caso de $x=1,4$, indicam que a transição é uma transição de segunda ordem.

7. Como a transição entre as fases polimerizadas muda de prirneira para segunda ordem, nessa fronteira também existe um ponto tricrítico, o qual, em princípio, pocleria ser estimado usando a renormalização fenomenológica de três larguras. Porém, como acontece no caso de ligaçoes interagentes, temos apenas duas estimativas para essa fronteira (veja a figura 3.17). Logo, precisamos estimar o ponto tricrítico através do cálculo de densidades e suas derivadas, como fizemos para o modelo anterior. Note que para $x=1,4$ os gráficos das derivadas para as diversas larguras não estão muito separados espacialmente, e esperávamos que o ponto tricrítico ficasse localizado próximo a $x=1,4$. Entretanto, os resultados obtidos para as derivadas das densidades para alguns valores de $x$ entre $x=0,4$ e $x=1,4$ não forneceram dados conclusivos a respeito da localização do ponto tricrítico, como pode ser visto nas figuras 3.30 até 3.35 . Assim, não seria prudente fazer qualquer afirmativa sobre a localização exata do ponto tricrítico. O que podemos dizer é que a transição para $x=0,4$ é de primeira ordem e para $x=1,4$ da 
é de segunda ordem, de modo que ocorre, em algum ponto entre esses dois valores de $x$, uma mudança de comportamento para a transição. Esse ponto cla fronteina entre as fases polimerizadas é um ponto tricrítico, mas não podemos precisar sua localização. No caso da rede de Husimi, o ponto tricrítico para o modelo de monômeros interagentes situa se em $\left(x_{\mathrm{PTC}}=0,32774, z_{\mathrm{PTC}}=1,84193\right)$. É importante ressaltar que o ponto tricrítico para o modelo de monômeros interagentes na rede de Husimi localiza-se na fronteira entre a fase não-polimerizada e polimerizada usual, e não na fronteira entre as fases polimerizadas, como acontece na rede quadrada.

8. A transição de segunda ordem entre a fase nãomplimerizada e a fase polimerizada usual termina ao encontrar a fronteira de primeira ordem entze as fases não-polimerizada e polimerizada densa. Nesse ponto existe um ponto crítico terminal que pode ser estimado através da renormalização fenomenológica de três larguras. Sua localização é $\left(x_{\mathrm{PCT}}=0,345 \pm 0,001, z_{\mathrm{PCO}}=1,52 \pm 0,01\right)$. Para uma comparação, o diagrama de fases na rede de Husimi tem um ponto crítico terminal de coordenadas $(x \mathrm{PCT}=0,24987, z \mathrm{PCT}=2,82996)$, e ele representa o ponto onde termina a fronteira entre as fases polimerizadas, que nessa rede é toda de segunda ordem. Note que existem diferenças quantitativas e qualitativas entre os diagramas de fase para os modelos interagentes na rede de Husimi, ao passo que na rede quadrada as diferenças são apenas quantitativas, como pode ser visto se compararmos as figuras 3.16 e 3.36 , que mostram os esbogos dos diagramas de fases dos modelos de ligaçóes e de monômeros interagentes na rede quadrada, respectivamente.

9. Nossos dados sugerem que o ponto $\theta$, no modelo de monômeros interagentes, também é um ponto crítico terminal.

10. Os expoentes críticos para a fronteira de segunda ordem entre a fase não-polimerizada e polimerizada usual também foram calculados. Os valores obtidos para $z=1$, que 
corresponde ao modelo não-interagente, são $\nu=0,7507 \pm 0,0007$ e $\eta=0,2089 \pm 0,0009$. Para $z=1,2$ os valores encontrados foram $x_{c}=0,366848 \pm 0,000003, \nu=0,7500 \pm$ 0,0004 e $\eta=0,205 \pm 0,008$. Vale lembrar que os valores esperados para os expoentes são $\nu=\frac{3}{4}$ e $\eta=\frac{5}{24}$.

11. O diagrama de fases do modelo de monòmeros interagentes é qualitativamente semeThante ao diagrama do modelo de ligações interagentes na rede quadrada, apresentando apenas diferenças quantitativas. Porém, ele é qualitativamente diferente se comparado com o modelo de monomeros interagentes na rede de Husimi. Os motivos que levam a essa discrepância são discutidos a seguir.

\subsection{Considerações Gerais a Respeito dos Dois Modelos}

Observando os vários resultados obtidos, que incluem gráficos, dados para os pontos multicríticos e valores de expoentes críticos, percebemos que há várias semelhanças e algumas diferenças entre os dois modelos interagentes na rede quadraden, e entre os modelos na rede quadrada e na rede de Husimi. Vamos comentar essas características comparando os dois modelos.

Tanto na rede de Husimi como na rede quadrada os pontos da fronteira entre as fases polimerizadas têm valores de coordenadas $y$ ou $z$ menores no modelo de monomeros interagentes do que no modelo de ligaçóes interagentes. Isso tem uma explicação simples, baseada no fato de que, se uma parte do polímero se apresenta numa configuração em que existem duas ligações primeiras-vizinhas, essa configuração tem, no mínimo, dois monômeros primeiros-vizinhos não-consecutivos. Por outro lado, se existem dois monômeros primeirosvizinhos numa configuração, não necessariamente existem ligações primeiras-vizinhas, como 
ocorre, por exemplo, quando duas partes do polímero que formam uma configuração em forma de "L" se aproximam de modo que os vértices dos "L" sejam primeiros-vizinhos mas sem que os lados dos "L", que seriam as ligações, sejam. Assim, considerando um mesmo valor para a energia de interação entre as ligações e entre os monômeros, no caso dos monômeros a densidade de interações será maior do que no de ligaçôes e o polímero se apresentará mais denso no modelo de monômeros do que no de ligaçöes interagentes para um mesmo valor de energia de interação. Conseqüentemente, no caso clos monômeros interagentes a transição para a fase densa ocorre para valores menores de $z$ do que no caso das ligaçöes interagentes, e esse fato independe de o modelo ser na rede quadrada on na rede de Husimi. Assim, para uma mesma rede, é esperado que a transição entre as fases polimerizadas para o modelo de monomeros interagentes ocorra para valores de $z$ menores, e a transição entre essas fases para o modelo de ligacones interagentes deve ocorrer para valores de $y$, que corresponde ao $z$, maiores. Isso é facilmente verificado nos nossos diagramas de fases e valores dos pontos multicríticos, e explica as diferenças quantitativas, que já eram esperadas, entre os modelos na rede quadrada.

Na rede de Husimi existem, além das diferenças quantitativas, que deveriam ocorrer, diferenças qualitativas entre os diagramas de fases dos cois modelos interagentes, o que já não ocorre no caso da rede quadrada. Nesse caso, a explicação vem das diferenças geométricas entre as duas redes. Na rede quadrada, é muito mais fácil existir uma interação entre ligações do que na rede de Husimi, por causa do modo como as duas redes são definidas e construídas. Assim, na rede de Husimi existe uma grande diferença entre considerar que as interações são entre monômeros ou ligações. O que ocorre na rede de Husimi é que, no modelo de monômeros interagentes, a transição entre as fases polimerizadas ocorre para valores de $z$ consideravelmente menores do que essa mesma transição para o modelo de ligações interagentes, e isso faz corn que o diagrama de fases mude qualitativamente, ocorrendo uma alteração na localização dos pontos multicríticos. Na rede quadrada a fronteira também situa-se em valores de 
$z$ menores. Mas, como a geometria da rede é diferente, ocorre apenas uma alteração quantitativa nos valores dos pontos multicríticos. De fato, não parece razoável que o detalhe de ser a interação entre as ligações ou entre os monomeros altere qualitativamente o diagrama de fases do modelo na rede quadrada, que é uma rede real, ao contrário da rede de Husimi que, não sendo uma rede real e sim uma aproximação para uma rede real, é mais susceptivel a esses detalhes.

Nos dois modelos na rede quadrada o ponto $\theta$, que é o ponto onde termina a transição entre a fase não-polimerizada e polimerizada usual, é um ponto crítico terminal, já que a fronteira de segunda ordem entre essas fases termina na fronteira de primeira ordem entre a fase não-polimerizada e polimerizada densa, e esta fronteira continua sendo de primeira ordem na transição entre as fases polimerizadas até um ponto tricrítico, quando então ela muda para uma fronteira de segunda ordem. Esse diagrama nos parece bastante razoável, já que na região bem próxima à fronteira de segunda ordem entre a fase não-polimerizada e polimerizada usual, dentro da fase polimerizada e em torno do ponto crítico terminal, as densidades devem ter valores pequenos e, ao aumentarmos o valor da interação entre os monômeros ou ligaçóes, passaremos da fase polimerizada usual para a fase polimerizada densa, que tem densidades iguais a um. Essa transição deve ser descontínua, e o ponto de encontro entre as três fronteiras deve ser mesmo ser um ponto crítico com características de um ponto crítico terminal.

Como última consideração, deve ser dito que nos dois modelos os valores obtidos para os expoentes críticos concordam muito bem com os valores esperados e permanecem constantes ao longo de toda a fronteira de segunda ordem entre a fase nãomplimerizada e a fase polimerizada usual. 


\subsection{Considerações Finais sobre as Técnicas Empregadas}

É importante fazer algumas considerações a respeito das técnicas e métodos utilizados nos cálculos.

1. A técnica da matriz de transferência provou mais uma vez ser extremamente eficiente no estudo de sistemas em que pode ser definida uma matriz de transferencia. Várias propriedades termodinâmicas podem ser obticlas através dos autovalores da matriz.

2. A renormalização fenomenológica forneceu estimativas tanto para as transições de segunda ordem quanto para as transiçoes de primeira ordem. Teoricamente, a renormalização fenomenológica só deveria funcionar para as transições de segunda ordem, mas esse não foi o primeiro caso em que isso ocorreu $[9,23]$.

3. O cálculo das densidades e derivadas das densidades provou ser muito útil na identificação das características físicas das fases e também dos tipos de transição entre elas, apesar de não poder ser usada de forma isolada para estimar a localização exata dos pontos onde ocorrem as transições de fase. Deve ser ressaltado que as densidades são calculadas de forma independente, baseadas apenas na matriz de transferência, e não têm correlação com as suposições feitas para a renormalização fenomenológica. Entretanto, como qualquer grandeza termodinâmica, estão sujeitas ao finite-size scaling, e essa propriedade foi utilizada na estimativa dos pontos tricríticos.

4. As propriedades de invariancia conforme fornecem muitas informações sobre os sistemas e, no nosso caso específico, o expoente crítico $\eta$ foi obtido através de consideraçóes que envolvem invariancia conforme. 


\section{Apêndice A}

\section{ESTADOS DA MATRIZ DE}

\section{TRANFERÊNCIA PARA $L=3$}

Neste apêndice apresentamos alguns dados relacionados com a thatriz de transferência e também os estados da matriz para $L=3$. Assim, é interessante relenbrarmos como a matriz de transferência é construída.

Para obter a matriz de transferência para uma tira de largura $L$ precisamos saber as configurações que o polímero pode apresentar numa dada coluna $i$ da tira. Para representar essas configurações usamos dois conjuntos de índices numéricos, como foi descrito na seção 2.3.1 (veja também a figura 2.6). No primeiro conjunto os índices podem assumir os valores 1 , se no sítio da coluna $i$ considerado chega uma ligação horizontal diretamente ligada à origem (que está situada à esquerda), o que sempre ocorre com um dos sítios da tira, já que queremos que o polímero atravesse toda ela; 0 , se o sítio não está conectado por ligaçoes horizontais a nenhum outro; $e$, se dois sítios estão conectados entre si mas não diretamente com a origem, ambos recebem um par de índices maiores do que 1. Para o segundo conjunto de índices, temos os valores 0 , se entre dois sítios consecutivos da coluna $i$ da tira não existe uma ligação vertical, e 1, se ela existe (veja a figura 2.6). Considerando todas as possibilidades que 
ocorrem para uma dada largura $L$ temos os estados da matriz de transferência. A partir dos estados da matriz de transferência, que são iguais nos dois modelos interagentes estudados, podemos calcular os elementos da matriz, que diferem de um modelo para o outro.

O número de estados da matriz de transferência cresce muito rapidamente com o aumento da largura, como pode ser visto na tabela A.1, a qual apresenta o número de estados $N_{S}$ da matriz para as larguras estudadas.

Tabela A.1: Número de estados da matriz de transferência antes $\left(N_{S}\right)$ e após $\left(N_{S B D}\right)$ o processo de bloco-diagonalização, em função da largura $L$.

\begin{tabular}{|c|c|c|c|c|c|c|c|}
\hline$L$ & 1 & 2 & 3 & 4 & 5 & 6 & 7 \\
\hline$N_{S}$ & 1 & 6 & 27 & 124 & 570 & 2652 & 12439 \\
\hline$N_{S B D}$ & 1 & 3 & 9 & 31 & 114 & 442 & 1777 \\
\hline
\end{tabular}

Para reduzir o tamanho da matriz de transferencia, utilizamos a simetria de rotação $C_{L}$ que existe nas configuraçoes dos estados, de forma que pudemos efetuar um processo de bloco-diagonalização da matriz. Com esse processo, passamos de uma matriz $N_{S} \times N_{S}$ para $L$ matrizes $N_{S B D} \times N_{S B D}$, cujos valores também estão na tabela A.1. Mesmo assim, a quantidade de memória necessária para alocar matrizes desse tamanho permitiu que nós estudássemos apenas as larguras até $L=7$, mesmo utilizando os supercomputadores CRAY disponíveis no Centro Nacional de Supercomputação - CESUP (UFRGS) e no Núcleo de Atendimento à Computação de Alto Desempenho - NACAD/COPPE (UFRJ).

Em seguida apresentamos, na figura A.1, os estados-base cla matriz de transferencia para $L=3$. Esses estados são aqueles que são rodados para fornecer os demais. Como já foi dito, os estados são igutais para os dois modelos, mas os elementos da matriz não. 


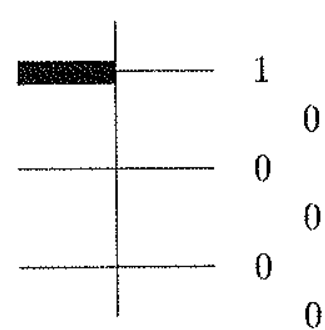

$|1\rangle$

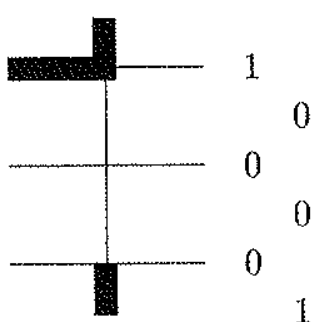

$|10\rangle$

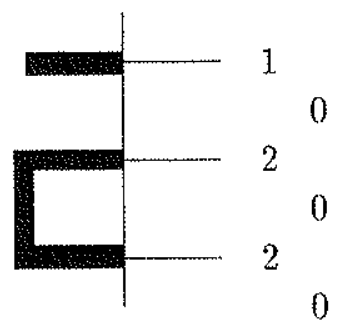

$|19\rangle$

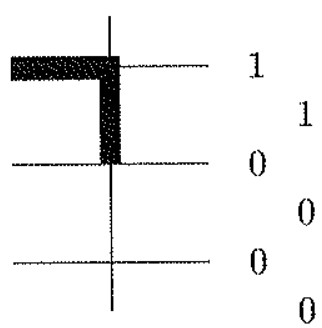

$|4\rangle$

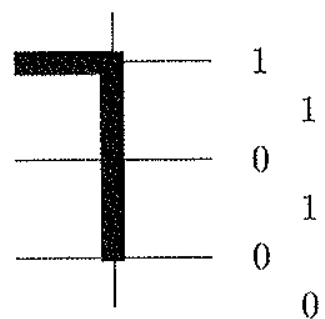

$|13\rangle$

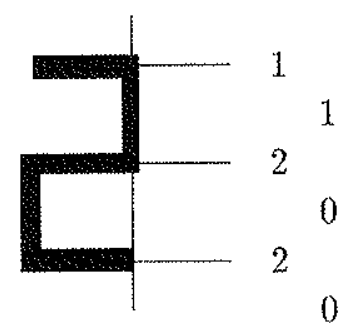

$|22\rangle$

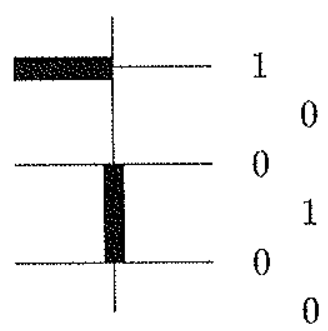

$|7\rangle$

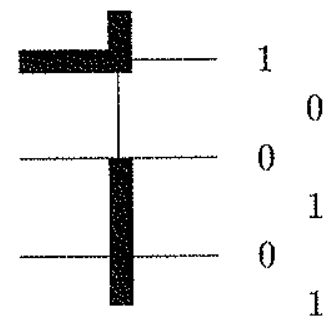

$|16\rangle$

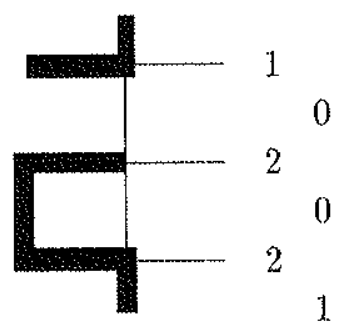

$|25\rangle$

Figura A.1: Estados-base da matriz de tranferência para $L=3$.

Conhecendo os estados-base, os outros são obtidos através da simetria de rotação $C_{3}$, de forma que carla estado gera dois outros por rotação. Após determinar todos os estados, podemos obter a matriz de transferência para a largura $L=3$ para os dois modelos interagentes estudados. O processo envolve três programas escritos em linguagem FORTRAN, que executan os seguintes passos:

- O primeiro programa acha os estados da matriz de transferencia, que são os mesmos para ligações interagentes ou monômeros interagentes. Esse programa é rodado uma 
vez para cada largura, é bastante rápiclo.

- O segundo programa obtém os elementos da matriz de transferencia, que diferem de um modelo para o outro. Assim, ele é executado uma vez para o modelo de ligacõoes interagentes e outra para o de monômeros interagentes, para cada largura $L$. Ele é rápido para $L$ pequeno, mas fica mais lento à medida que a largura aumenta.

- Por fim, o terceiro programa calcula a matriz de transferencia para obter seus autovalores e assim achar a localização de um ponto crítico. Esse programa precisa ser executado para cada ponto do diagrama de fases, para cada par de larguras. Esse programa é rápido para os primeiros pares de larguras, mas para os maiores ele tornar-se extremamente lento e as matrizes ocupam uma quantidade muito grande de memória.

Além dos três programas discutidlos acima, existem mais quatro auxiliares, que são:

- Un programa que realiza as extrapolações dos dados.

- Um programa que calcula os expoentes críticos $\nu$ e $\eta$. Esse programa precisa dos valores das estimativas dos pontos críticos e, para o cálculo de $\nu$, é preciso fazer uma derivada numérica dos comprimentos de correlação, o que necessita, por sua vez, dos autovalores da matriz de transferencia, que deve ser novamente diagonalizada.

- Um programa para o cálculo das densidades, que envolvem derivadas numéricas dos autovalores da matriz de transferência.

- Um programa que realiza a derivada numérica das densidades.

Voltando à questão dos elementos da matriz de transferência, apresentamos nas figuras A.2 e A.3 alguns elementos de matriz para os modelos de ligaçóes interagentes e monômeros interagentes, respectivamente. Note cute as configuraçöes são as mesmas mas alguns dos valores dos elementos são diferentes por causa das diferenças que existem entre os 
dois modelos. Sempre que existe uma interação entre ligaçôes existe pelo menos uma entre monômeros. No entanto, pode ocorrer uma interação entre monômeros sem existir uma entre ligações, como acontece nos elementos $\left\langle 13\left|T_{m}\right| 3\right\rangle$ ou $\left\langle 16\left|T_{m}\right| 11\right\rangle$, por exemplo. 


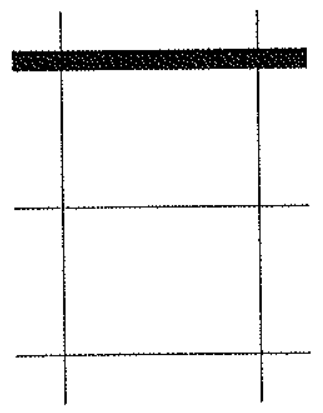

$\left\langle 1\left|T_{\ell}\right| 1\right\rangle=x$

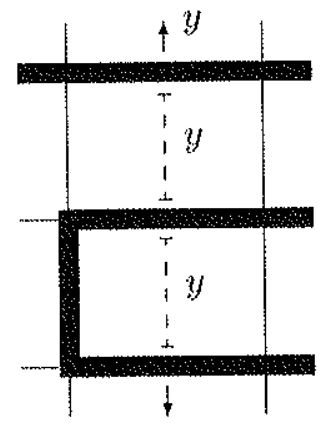

$\left\langle 7\left|T_{\ell}\right| 19\right\rangle=x^{3} y^{3}$

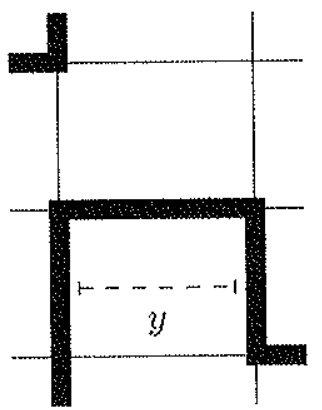

$\left\langle 16\left|T_{\ell}\right| 5\right\rangle=x^{3} y$

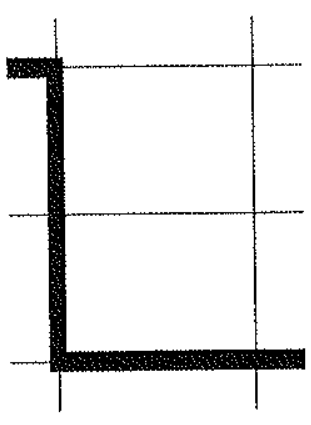

$\left\langle 13\left|T_{\ell}\right| 3\right\rangle=x^{3}$

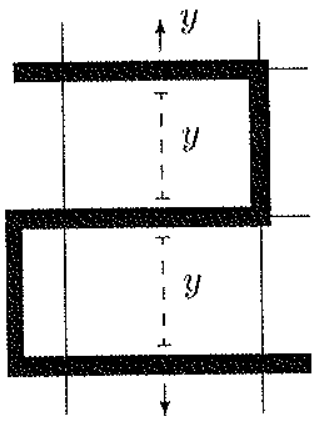

$\left\langle 19\left|T_{\ell}\right| 22\right\rangle=x^{3} y^{3}$

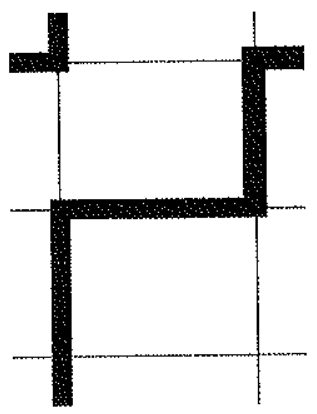

$\left\langle 16\left|T_{e}\right| 11\right\rangle=x^{3}$

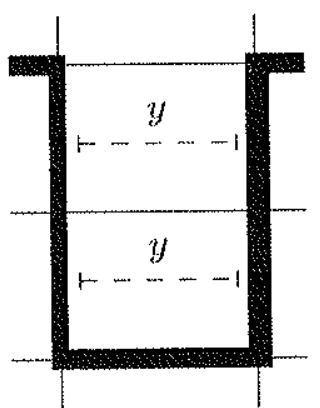

$\left\langle 13\left|T_{\ell}\right| 18\right\rangle=x^{3} y^{2}$

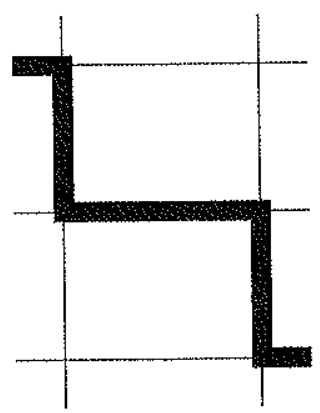

$\left\langle 4\left|T_{\ell}\right| 5\right\rangle=x^{2}$

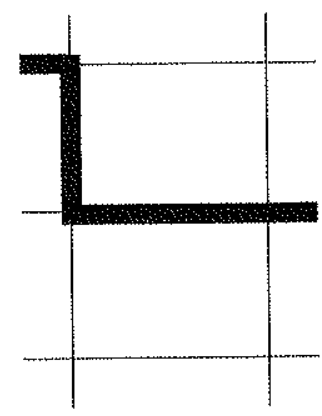

$\left\langle 4\left|T_{\ell}\right| 2\right\rangle=x^{2}$

Figura A.2: Alguns elementos da matriz de transferência para $L=3$ para o modelo cle ligações interagentes. 


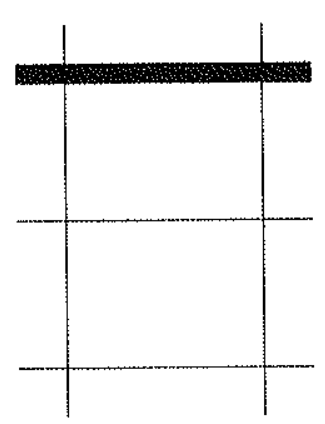

$\left\langle 1\left|T_{m}\right| 1\right\rangle=x$

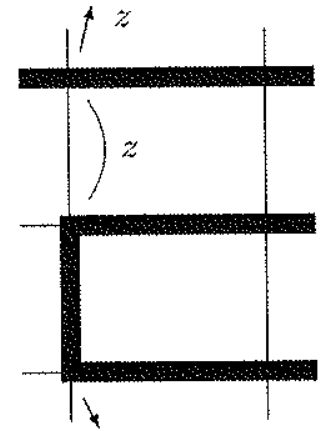

$\left\langle 7\left|T_{m}\right| 19\right\rangle=x^{3} z^{2}$

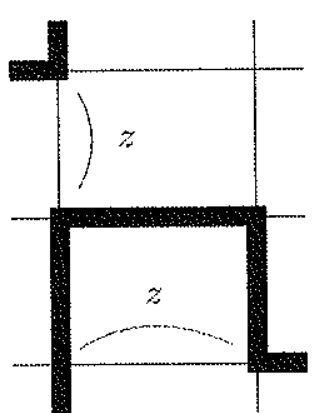

$$
\left\langle 16\left|T_{m}\right| 5\right\rangle=x^{3} z^{2}
$$

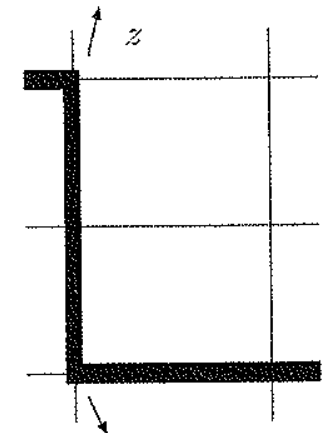

$\left\langle 13\left|T_{m}\right| 3\right\rangle=x^{3} z$

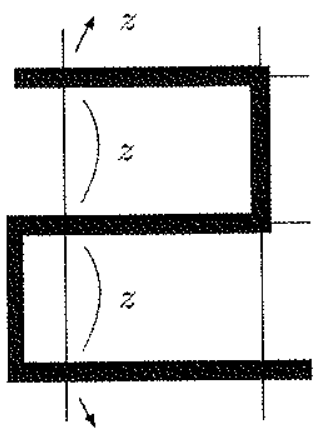

$\left\langle 19\left|T_{m}\right| 22\right\rangle=x^{3} z^{3}$

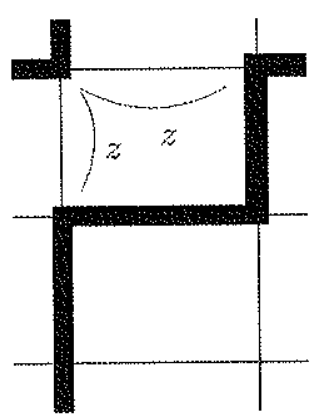

$\left\langle 16\left|T_{m}\right| 11\right\rangle=x^{3} z^{2}$

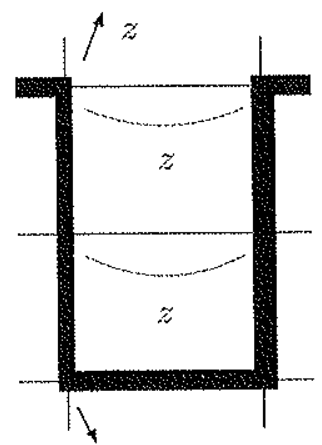

$\left\langle 13\left|T_{m}\right| 18\right\rangle=x^{3} z^{3}$

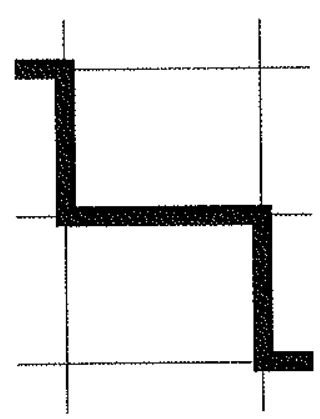

$\left\langle 4\left|T_{m}\right| 5\right\rangle=x^{2}$

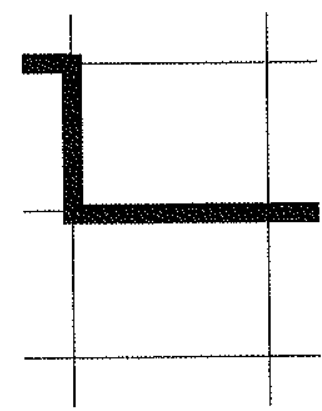

$\left\langle 4\left|T_{m}\right| 2\right\rangle=x^{2}$

Figura A.3: Alguns elementos da matriz de transferencia para $L=3$ para o modelo de monomeros interagentes. 


\section{Referências Bibliográficas}

[1] A. R. Conway e A. J. Guttmann. Phys. Rev. Lett., 77:5284, 1996.

[2] A. J. Guttmann e J. Wang. J. Phys. A, 24:3107-3109, 1991.

[3] B. Derrida. J. Phys. A, 14:L5 L9, 1981.

[4] B. Nienhuis. Phys. Rev. Lett., 49(15):1062-1065, 1982.

[5] J. C. Wheeler, S. J. Kennedy, e P. Pfenty. Phys. Rev. Lett., 45(22):1748 1752, 1980.

[6] J. C. Wheeler e P. Pfeuty. Phys. Rev. A, 24(2):1050-1062, 1981.

[7] J. F. Stilck e J. C. Wheeler. Physica A, 190:24 48, 1992.

[8] B. Derrida e H. J. Herrman. J. Physique, 44:1365 1376, 1983.

[9] K. D. Machado e J. F. Stilck. J. Phys. A, 30:1445, 1997.

[10] B. Derrida e H. Saleur. J. Phys. A, 18(L1075), 1985.

[11] H. Saleur. J. Stat. Phys., 45:419, 1986.

[12] P. G de Gennes. J. Physique, 36(L55), 1975.

[13] P. G de Gennes. J. Physique, 39(L299), 1978.

[14] J. F. Stilck, K. D. Machado, e P. Serra. Phys. Rev. Lett., 76:2734, 1996. 
[15] J. M. Yeomans. Statistical Mechanics of Phase Transitions. Oxford University Press, Walton Street, Oxford, 1992.

[16] Rodney J. Baxter. Exactly Solved Models in Statistical Mechanics. Academic Press Inc, 24-28 Oval Road, London, 1984.

[17] B. Derrida e L. De Seze. J. Physique, 43:475, 1982.

[18] M. N. Barber. Finite-Size Scaling, vol. 8 de Phase Transitions and Critical Phenomena, cap. 2, pág. 146. C. Domb e J. L. Lebowitz, Academic Press Inc., London, 1983.

[19] M. E. Fisher e A. E. Ferdinand. Phys. Rev. Lett., 19:169, 1967.

[20] M. P. Nightingale. Physica A, 83:561, 1976.

[21] J. L. Cardy. J. Phys. A, 17:L385-L387, 1984.

[22] John L. Cardy. vol. 11 de Phase Transitions and Critical Phenomena, cap. 2, pág. 55. C. Domb e J. L. Lebowitz, Academic Press Inc., London, 1987.

[23] F. C. Alcaraz, J. R. Drugowich, R. Köberle, e J. F. Stilck. Phys. Rev. B, 32(11):7469 $7475,1985$. 